\title{
IMPACT OF PLUG IN ELECTRIC VEHICLE BATTERY CHARGING ON A DISTRIBUTION SYSTEM
}

By

Sharmila Kumari Bunga

\begin{abstract}
Approved:
\end{abstract}
Ahmed H. Eltom

Professor of Electrical Engineering (Thesis Advisor)

Nurhidajat Sisworahardjo

Assistant Professor of Electrical Engineering (Committee member)

William H. Sutton

Dean, the College of Engineering and Computer Sciences
Abdul R. Ofoli

Assistant Professor of Electrical Engineering (Committee member)

A. Jerald Ainsworth

Dean, the Graduate School 


\section{IMPACT OF PLUG IN ELECTRIC VEHICLE BATTERY CHARGING ON A DISTRIBUTION SYSTEM}

By

Sharmila Kumari Bunga

A Thesis Submitted to the Faculty of the University of

Tennessee at Chattanooga in Partial Fulfillment of the Requirements of the Degree of Master's of Science in Engineering

The University of Tennessee at Chattanooga Chattanooga, Tennessee

May 2013 


\begin{abstract}
Plug-in Electric Vehicles (PEV) battery chargers are mostly connected to the low-voltage grid for charging, hence their increased penetration coupled with uncoordinated charging could impact the distribution system in terms of voltage unbalance and transformer overloading. Although PEV battery charging is increasing, impact on the distribution system is not fully understood.

This study focuses on voltage unbalance caused by uneven distribution of PEV penetration among the phases. Using real data provided by utility, a distribution system has been modeled and tested using MATLAB-SIMULINK. PEV penetration level at $10-80 \%$ is studied, voltage unbalance is calculated and transformer overloading is analyzed. In the simulations conducted without PEV penetration, the real data at intellirupters of the system were close to simulated system voltages and currents. As PEV adoption is expected to increase, the impact on the distribution system will increase. Coordinated or smart charging of PEVs will be essential for consumers and utilities.
\end{abstract}




\section{DEDICATION}

I dedicate this work to my parents and in-laws, for their love, encouragement, and support. 


\section{ACKNOWLEDGEMENTS}

The first person I would like to express my heartfelt gratitude is Dr. Ahmed Eltom whose support and supervision has been unlimited throughout this thesis and my masters. I am indebted to the opportunity he has provided me with. He molded me in the right direction and taught me to be positive always.

I would like to thank the other members of my thesis committee, namely, Dr. Abdul Ofoli and Dr. Nurhidajat Sisworahardjo for their invaluable aid and direction in this thesis.

I would also like to thank Dr. Stephen D. Craven for his guidance and supervision provided throughout the intricacies of the master's program and thesis process.

I would also like to thank Bob Hay of EPB (Electric Power Board) for guiding me throughout the thesis and helping me by providing necessary data \& valuable advice.

I reserve my special thanks to my husband Raj; I couldn't have accomplished all this without his encouragement, love, and most importantly his constructive criticism. I deeply appreciate and acknowledge all the love and support I received from my family and their belief in me.

I would like to thank my fellow graduate students, for their friendships and support. The last two years have been quite an experience and you have all made it a memorable time of my life. Also, I am very grateful to my close family friends Sujatha and Yugandhar for their encouragement and for being a constant source of support both morally and emotionally which always made me feel at home. 


\section{TABLE OF CONTENTS}

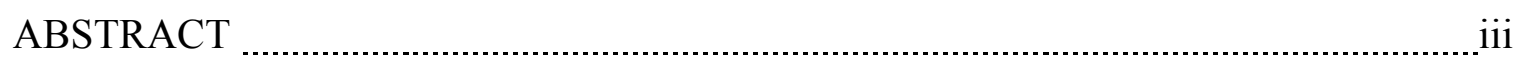

DEDICATION _..__ _ _ iv

ACKNOWLEDGEMENTS ………

LIST OF TABLES

LIST OF FIGURES

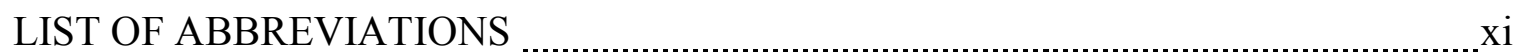

\section{CHAPTER}

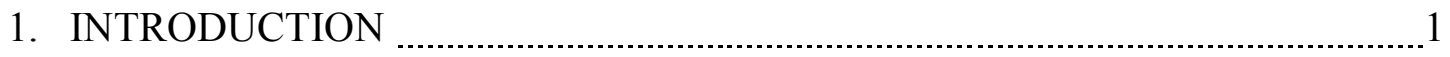

1.1 Background .

1.2 PEVs Market and Government Policy _....................................................

1.3 Statement of the Problem _........................................................

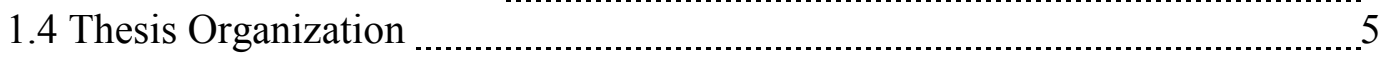

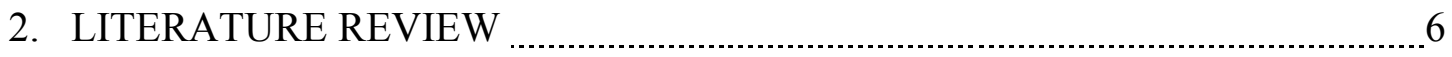

2.1 Types of Plug-in Electric Vehicles

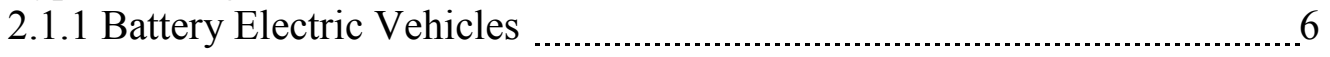

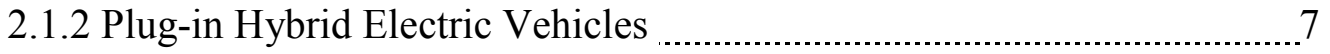

2.1.3 Extended-Range Electric Vehicles ……............................................ 7

2.2 PEV Charging Characteristics _......................................................... 8

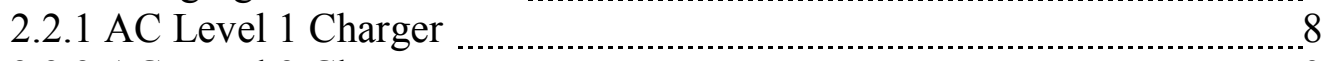

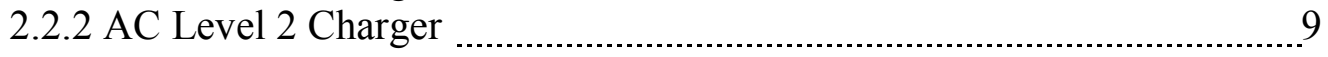

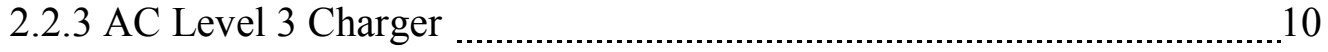

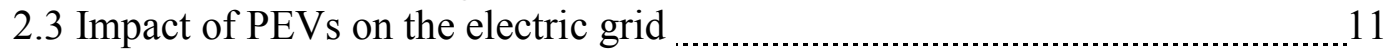

2.3.1 Impact on Generation $\ldots$

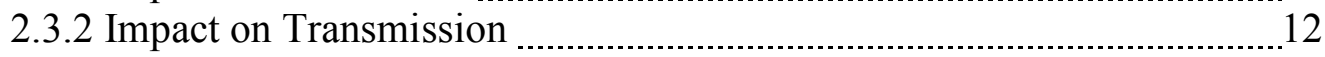

2.3.3 Impact on Distribution ……………

2.4 Implications of voltage unbalance 
3. MODELING OF A DISTRIBUTION SYSTEM

USING MATLAB - SIMULINK

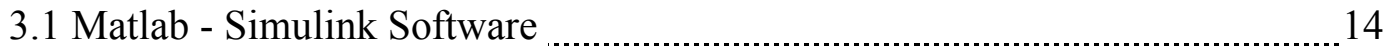

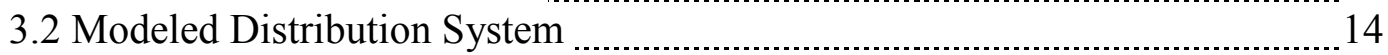

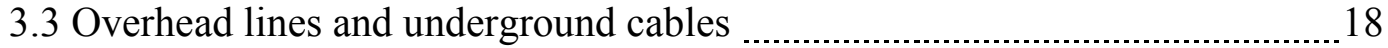

3.4 Service Transformers

3.5 Distribution system load

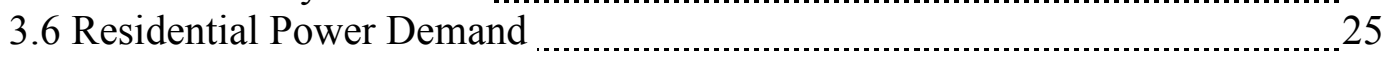

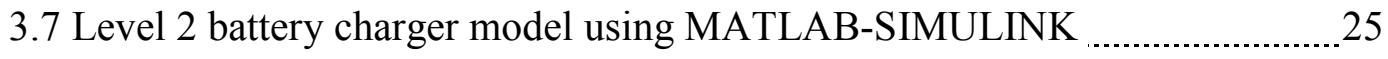

4. DISTRIBUTION SYSTEM LOAD DATA ANALYSIS _....................................... 27

4.1 Introduction

4.2 Reactive Power Calculations

4.3 Active to Reactive Power Ratio at Peak and Off-Peak _............................... 30

5. CASE STUDY AND SIMULATION RESULTS _.................................. 35

5.1 Simulink model testing without PEV penetration _..........................................36

5.1.1 Voltages and currents at peak demand ……......................................... 36

5.1.2 Voltages and currents at off-peak demand ……................................. 39

5.2 Simulink model testing with PEV penetration …_..............................................

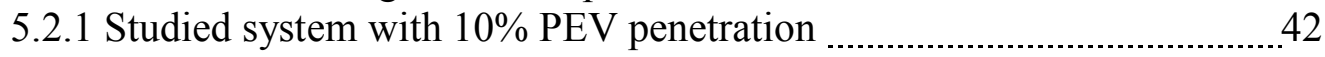

5.2.2 Studied system with 30\% PEV penetration …........................................ 45

5.2.3 Studied system with 50\% PEV penetration _.................................. 47

5.2.4 Studied system with 60\% PEV penetration ……............................. 49

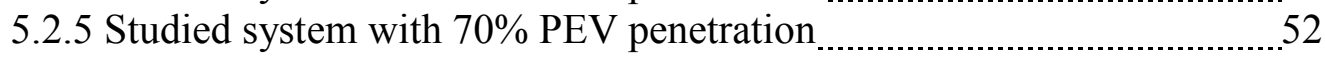

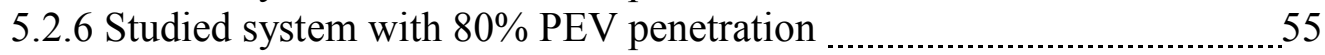

5.3 Impact of PEV Penetration on Simulated System ……............................ 57

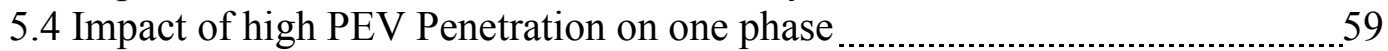

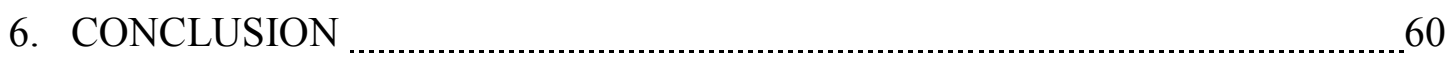

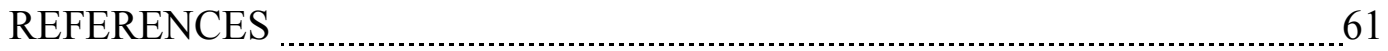

APPENDIX

A. DISTRIBUTION SYSTEM FOR VOLTAGE STUDY ………................ 65

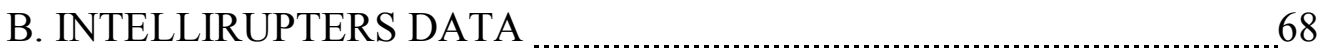

VITA 


\section{LIST OF TABLES}

2.1 PEV charging characteristics for various levels

3.1 Impedances of Overhead Lines 20

3.2 Resistances, Inductances and Capacitances of OH lines and UG cables 20

3.3 Service transformer Impedances by rating 22

3.4 Nominal current ratings of single-phase transformers 23

4.1 Peak and Off-Peak Active and Reactive Powers for CB1 and CB2 30

4.2 Active to Reactive Power Ratio of the system 30

4.3 Real and Reactive power demands for all service transformers 32

5.1 Measured and actual phase voltages and currents at CB1 at peak demand 37

5.2 Measured and actual phase voltages and currents at CB2 at peak demand 38

5.3 Measured and actual phase voltages and currents at CB1 at off-peak demand 40

5.4 Measured and actual phase voltages and currents at CB2 at off-peak demand 41

5.5 Phase voltages at peak and off-peak demand for $10 \%$ penetration of PEVs 44

5.6 Phase voltages at peak and off-peak demand for 30\% penetration of PEVs 46

5.7 Phase voltages at peak and off-peak demand for 50\% penetration of PEVs 48

5.8 Phase voltages at peak and off-peak demand for $60 \%$ penetration of PEVs 50

5.9 Rated and Measured Currents for Phase-B Transformers in the simulated system ....52

5.10 Phase voltages at peak and off-peak demand for 70\% penetration of PEVs 54

5.11 Phase voltages at peak and off-peak demand for $80 \%$ penetration of PEVs 56 


\section{LIST OF FIGURES}

1.1 Projected New Vehicle Market Share Categories .................................................... 3

2.1 Level 2 charging station

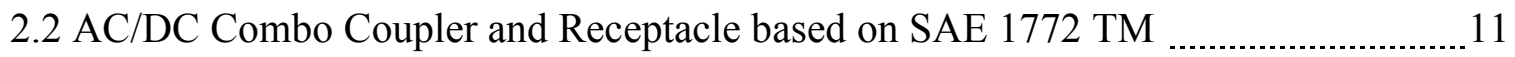

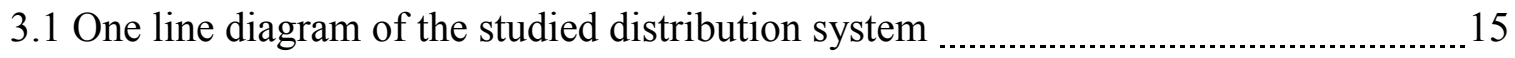

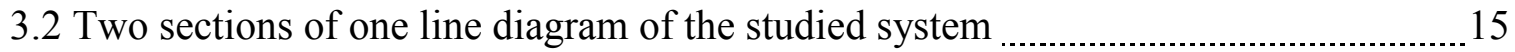

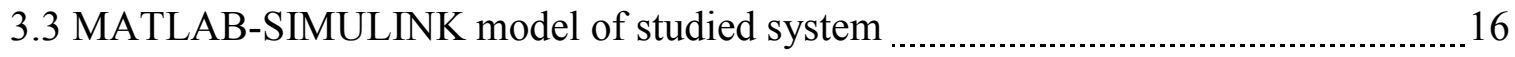

3.4 Simplified one line diagram of distribution system layout ..................................... 17

3.5 Simulink distribution system layout of subsystem section $1 \ldots 17$

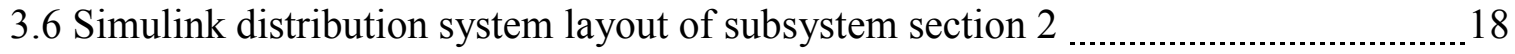

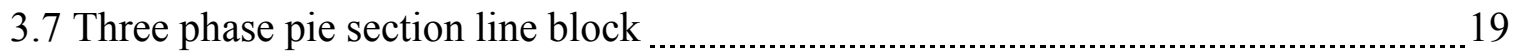

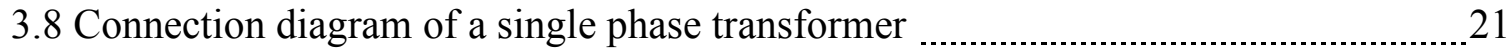

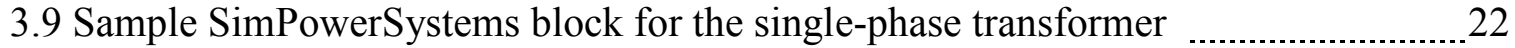

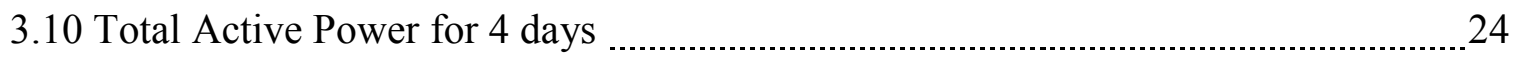

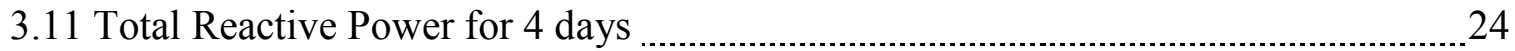

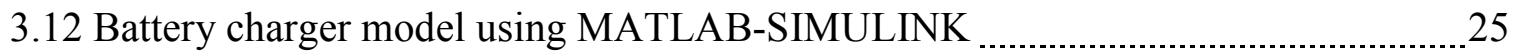

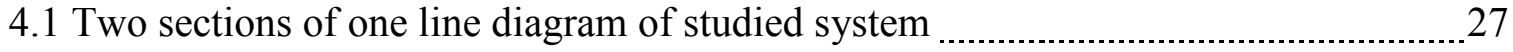

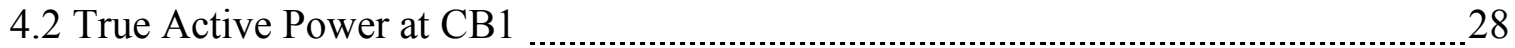

4.3 True Reactive Power at CB1

4.4 Total real power of each service transformer at peak and off-peak demand ............... 33 
4.5 Total reactive power of each service transformer at peak and off-peak demand 34

5.1 Simplified diagram of the modeled distribution system $\ldots \ldots \ldots \ldots$

5.2 Measured three-phase voltages at CB1 of the system at peak demand ......................... 36

5.3 Measured three-phase currents at CB1 of the system at peak demand ......................... 37

5.4 Measured three-phase voltages at CB2 of the system at peak demand ........................ 38

5.5 Measured three-phase currents at CB2 of the system at peak demand ........................ 38

5.6 Measured three-phase voltages at CB1 of the system at off-peak demand ................. 39

5.7 Measured three-phase currents at CB1 of the system at off- peak demand .................. 39

5.8 Measured three-phase voltages at CB2 of the system at off- peak demand ................. 40

5.9 Measured three-phase currents at CB2 of the system at off- peak demand ................ 41

5.10 Distribution system model with $10 \%$ of PEV Penetration ...................................... 43

5.11 Distribution system model with $30 \%$ of PEV Penetration _................................... 45

5.12 Distribution system model with $50 \%$ of PEV Penetration …............................... 47

5.13 Distribution system model with $60 \%$ of PEV Penetration ................................... 50

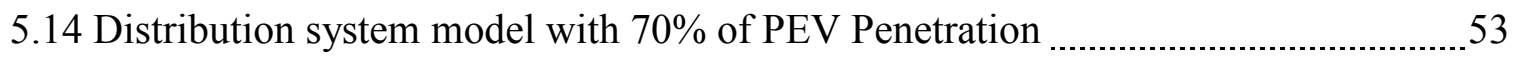

5.15 Distribution system model with $80 \%$ of PEV Penetration ..................................... 55

5.16 Maximum Voltage Deviation with level of PEV Penetration .................................58

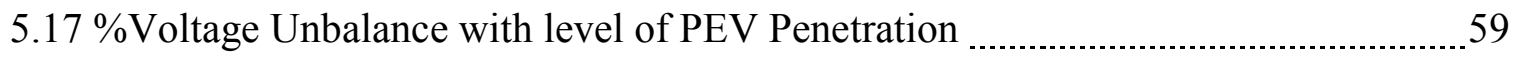




\section{LIST OF ABBREVIATIONS}

AC, Alternating Current

AER, All Electric Range

AL, Aluminum

ALXLP, Aluminum Cross Linked Polyethylene

BEV, Battery Powered Electric Vehicle

CB, Circuit Breaker

$\mathrm{CV}$, Conventional Vehicle

DC, Direct Current

EREV, Extended Range Electric Vehicle

EV, Electric Vehicle

HEV, Hybrid Electric Vehicle

IEEE, Institute of Electrical and Electronics Engineers

KV, Kilo volts

KVA, Kilo Volt-Ampere

KVAR, Kilo volt-ampere reactive

KW, Kilo watt

KWH, Kilo watt hour

LVUR, Line Voltage Unbalance Rate

MVAR, Mega volt-ampere reactive 
MW, Mega watt

NEMA, National Electrical Manufacturer Association

$\mathrm{OH}$, Overhead

PEV, Plug-in Electric Vehicle

PHEV, Plug-in Hybrid Electric Vehicle

PVUR, Phase Voltage Unbalance Rate

RMS, Root mean square

SAE, Society of Automotive Engineers

SOC, State of Charge

UG, Underground

VU, Voltage Unbalance

ZEV, Zero Emission Vehicle 


\section{CHAPTER 1 \\ INTRODUCTION}

\subsection{Background}

The traditional dependence on fossil fuels has undoubtedly made the transportation a primary contributor to the greenhouse emissions. As passenger vehicle is accounting for more than half of the total electrification of transportation energy requirement, it is the major consumer of the energy [1]. However the technological strides that are made and being made in the field of plug-in electric vehicles (PEVs) are becoming central to combating greenhouse gas emissions, namely the Battery Powered Electric Vehicle (BEV) and Plug-in Hybrid Electric Vehicle (PHEV).

The promising direction of PEVs for transportation is two-fold; PEVs can reduce the reliance on fossil fuels hence limiting the greenhouse gas emissions, as well, electricity as an energy source for passenger cars is less expensive per mile than fossil fuels [2]. While Hybrid Electric Vehicles (HEV) are earlier cousins of EVs, in comparison, PHEVs and BEVs have more onboard energy storage than HEVs, and also give owners the ability to charge the vehicle battery from a stationary electrical source for example, an outlet in the garage or a charging station at a work place. Lately there has been a widespread EV adoption by consumers, which is only expected to increase manifold in near future [3, 4]. Essentially such an adoption would put more stress on electric utilities particularly at the distribution level as more and more consumers expect to use more energy in the form of electricity. PEV chargers are the devices that transmit 
electric energy from grid into the PEV batteries. Currently there are three levels of battery charging techniques available to recharge the PEV batteries, classified as Level 1, Level 2 and Level 3 chargers [5]. Level 1 and 2 are single phase and Level 3 is three phase. Level 1 chargers are standard $120 \mathrm{~V} / 16 \mathrm{~A}$ wall outlet and has a corresponding charger rating of $1.8 \mathrm{KW}$ and are primarily located at homes [6]. Level 2 chargers have higher voltages, typically $208-240 \mathrm{~V}$ and draws more current up to $80 \mathrm{~A}$. They could be charged at home or at public chargers. They have shorter charging time than Level 1 chargers. Level 3 is a three phase battery charger and has a maximum capacity of $96 \mathrm{KW}$, rated at 208-600 V/400 A. Generally level 3 chargers are not available in residential areas, because this type of chargers draw much more current than Level 1 and 2 chargers, and hence require very short period of charging time [7, 8]. Of these three levels, only Level 1 and 2 chargers could impact a distribution system in terms of voltage unbalance and transformer overloading.

This study is focused on impact of Level 2 chargers on the residential distribution grid. While the potential societal and economic benefits of PEVs are undeniable, safe and reliable operation of the electrical network is still a primary utility concern due to expected stress on the grid. Thus, understanding and accurately predicting PEV electrical system impact on the grid is important for all the stake holders, namely automotive manufacturers, consumers, and more importantly the utility companies particularly at the distribution level [9].

\subsection{PEVs Market and Government Policy}

The goal set by the Obama administration is one million plug-in electric vehicles (PEV) on the road by 2015 in the US. This goal is being supported by government incentives and stimulus investments to accelerate market acceptance, including grants and loans to manufacturer 
and tax credits to consumers [10]. Projected market penetration of conventional vehicles (CVs), hybrid electric vehicles (HEVs), and PHEVs from 2010 to 2030 is illustrated in figure 1.1 [1113] with HEVs representing about $15 \%$ of the market new vehicle sales when PHEVs were expected to enter the market in 2010. PHEVs could reach a maximum of $10 \%$ new vehicle market share by 2015 timeframe [9].

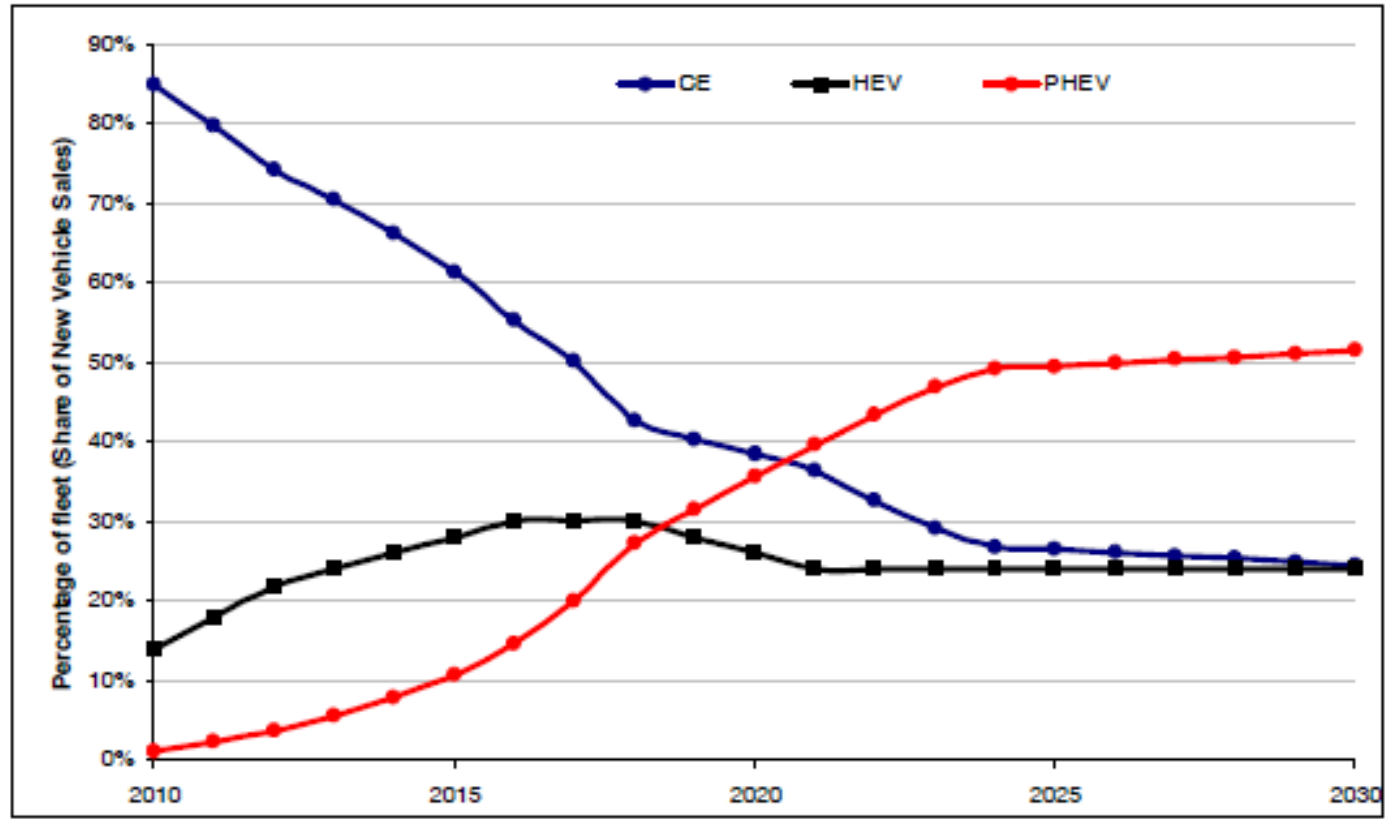

Figure 1.1 Projected New Vehicle Market Share Categories [9]

In addition, various U.S state governments have passed their own laws to promote PEVs by providing grants for electrical vehicle research, funding for PEV charging infrastructure, and loans or tax credits for "green technology" related businesses. PEVs cost more than a comparable conventional vehicle. The difference in cost is currently offset by Tax credit from the government. The Tax Credit provides a $\$ 2,500$ for vehicles with batteries of at least four 
$\mathrm{kWh}$. With the size of the battery credit steps up to a maximum of $\$ 7,500$ as battery size is major determinant of cost for PEV [14].

\subsection{Statement of the Problem}

From the consumer point of view, the PEV batteries have to be charged so the driver can drive off with a fully-charged battery. That brings in the question of place and time for charging these batteries. There are two main places where the PEV batteries can be recharged: either on a corporate or public car park, or at home. Irrespective of the location, uncoordinated power consumption that can result from this charging activity on a local scale can lead to grid problems. The charging of PEVs has an impact on the distribution grid because these vehicles consume a large amount of electrical energy and this demand of electrical power can lead to extra large and undesirable peaks in the energy consumption. The impact of these extra single phase electrical loads can be analyzed in terms of power losses and voltage unbalances [15].

From the distribution system operator point of view, the power losses during charging are of an economic concern and transformer and feeder overloads are of a reliability and safety concern [16]. In addition, power quality (e.g., voltage profile, unbalance, harmonics, etc.) is essential to the distribution grid operator as well as to grid customers. Voltage deviations are a definite power quality concern [17].

In this regard, measuring these voltage imbalances over a distribution grid due to wider consumption of electricity for charging PEVs is central in finding a solution such as "smart" or "coordinated charging". 


\subsection{Thesis Organization}

The primary objective of this study is to assess the impact of PEV battery charging on a residential distribution system, where the impact has been reported in terms of voltage unbalance and transformer overloading.

In the chapter 1, general introduction of PEVs, their market penetration, and specific statement of problem have been presented. Chapter 2 of this study contains a review of the literature on types of PEVs, their charging characteristics and their impact on electric grid. The focus of chapter 3 is modeling a distribution system using MATLAB-SIMULINK, with emphasis on components that are modeled such as single-phase distribution transformer, overhead and underground cables, and system breakers.

Chapter 4 consists of the estimation of reactive power consumed by the residential customers based on the load data provided by a power distributor. In chapter 5 , the testing and simulation of the developed model of $12.47 \mathrm{KV}$ distribution system has been presented along with comparison between simulated voltages and actual voltages (as provided by the power distributor). Various levels of PEV penetrations and voltage unbalance calculations are also shown in chapter 5.

Summary of the study findings and proposed recommendations to mitigate the potential impact of PEV on the distribution system and overall conclusions of this study are presented in Chapter 6. 


\section{CHAPTER 2}

\section{LITERATURE REVIEW}

\subsection{Types of Plug-in Electric Vehicles}

The drivetrain architecture of a Plug-in Electric Vehicle (PEV) typically includes the following components; an electric motor, a battery and a device to charge the battery through connecting to the electricity grid [4]. Depending on which of these components exist in and different drivetrain architectures, Plug-in Electric Vehicle (PEV) can be divided into BEVs, PHEVs, and Extended range electric vehicles (EREVs).

\subsubsection{Battery Electric Vehicles}

BEVs are pure electric vehicles i.e. with no internal combustion engine and require recharging at the end of their designed driving range. Given their complete dependency on battery, BEVs generally have the highest all-electric range (e.g., 60-100 miles) and the largest battery capacity (e.g., 25-35 kWh) [18]. Battery recharging time varies with the type and capacity of the EV battery and the output capacity of charger. Examples of BEV include Nissan Leaf and Tesla Roadster. Battery electric vehicle is often referred to as a zero-emission vehicle (ZEV), but this can be misleading as the entire energy cycle, including power plants or other generation units needed to produce electrical energy, must be considered to determine the emissions. 


\subsubsection{Plug-in Hybrid Electric Vehicles}

A PHEV is commonly equipped with a drivetrain that contains an internal combustion engine, an electrical motor, a battery storage system and means of recharging the battery system from an external source of electricity [19]. Its battery capacity is usually several kWhs or more, to power the vehicle in all electric drive mode [20] and its internal combustion engine can be engaged to extend its drive range when the battery's charge is not sufficient [21]. The modified Toyota Prius with plug-in capability is an example of PHEV.

Compared to BEVs, PHEVs have an extended range because they contain a small internal combustion engine for longer distances, and PHEVs also have a lower purchase price since the battery pack is the most expensive part of electric vehicles and BEV's battery pack is comparatively larger than that of PHEV. Larger battery pack of BEV's is more expensive and demands longer time to charge [22].

\subsubsection{Extended-Range Electric Vehicles}

An EREV is similar to a PHEV in terms of drivetrain architecture, i.e. it has an internal combustion engine, an electrical motor, and a battery. However it offers more pure electric driving capability in the initial driving range, referred to as all-electric range (AER). While PHEVs derive most of their power from a gas engine. EREVs are pure electric vehicles that utilize a small combustion generator to generate more electricity and extend the range of the vehicle beyond its battery pack. To realize pure electric driving in all driving conditions, EREVs are equipped with a full-sized traction motor powered by the battery pack. The large battery capacity allows all electric driving range of about 40-60 miles. However EREVs have increased 
system cost due to the full-sized traction motor and power requirements for the battery [23]. Chevrolet Volt, built by General Motors is an example of EREV.

\subsection{PEV Charging Characteristics}

The power needed to charge PEVs vary based on the specific battery pack and charging equipment and therefore it is desirable for the vehicle to control battery charging; currently charging systems are set to provide the maximum available current by default. However the functionality details in standards have been developed for the U.S. through Society of Automotive Engineers (SAE). The common electric vehicle conductive charging system architecture has been defined by SAE J1772 [11]. It covers the general physical, electrical, and performance requirements for the electric vehicle conductive charging system and coupler for use in North America. According to the SAE, the charging methods for electrical vehicle are classified into three types as follows; AC Level 1, AC Level 2 and AC Level 3 [7, 24]

\subsubsection{AC Level 1 Charger}

AC Level 1 charger uses a standard electrical outlet dedicated at 120V/16 A and has a capacity up to $2 \mathrm{KW}$, which is the most commonly found outlet in a household. Depending on the initial SOC (State of Charge) and capacity of the battery, Level 1 chargering takes about 5-8 hrs to fully charge the vehicle's battery $[7,9]$. While these chargers are ideal for overnight residential charging purposes, these are not suitable for quick commercial or public charging purposes due to the time required for the charging. 


\subsubsection{AC Level 2 Charger}

Level 2 charging is done using a $240 \mathrm{~V}$ electic out let, more like residential appliances such as: an electric hair dryer, electric oven or a central air conditiong system. It operates at 208$240 \mathrm{~V}$, power demand up to $15 \mathrm{KW}$ and a current level not greater than $80 \mathrm{~A} \mathrm{[7].} \mathrm{Level} 2$ offers a smaller window of charging time, usually half the requirement of Level 1. Level 2 chargers are the commonly found in homes and commercial areas and must be permanently hard-wired cord set into a special box with safety electronics [25] to the premise for EV charging purposes only. Vehicle owners seem likely to prefer Level 2 charging technology owing to its faster charging time and standardized vehicle-to-charger connection availability. This study focuses on voltage unbalance caused by Level 2 battery charging on a distribution system.

\section{Level 2}

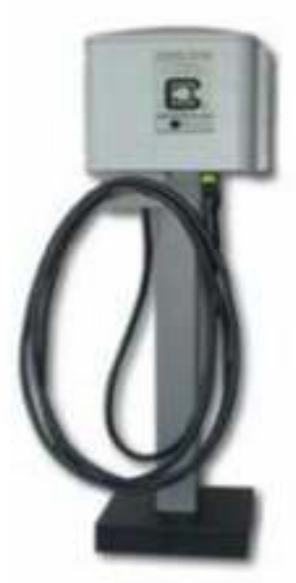

Figure 2.1 Level 2 charging station [26] 


\subsubsection{AC Level 3 Charger}

Level 3 is a 3-phase charger and rated at 208-600V AC, maximum current uptot $400 \mathrm{~A}$ and power demand greater than 15-96 KW. Level 3 is commericial fast charging and offers the possibility of charging time about 10-15 mins to fully charge a vehicle battery, depending on the capacity and state of charge of the battery $[3,8]$. Naturally these chargers use higher power in comparison with residential charging. A lower power demand of charger is an advantage for utilies, paticularly at distribution level seeking to minimize on-peak impact. High power penetration of charging can increase power demand and has the potential to quickly overload local distribution equipment at peak times [27]. Level 2 charging can increase distribution transformer losses, voltage unbalances, harmonic distortion, peak demand, and thermal loading on the distribution system [25]. Table 2.1 shows standard charging ratings for different charging levels.

Table 2.1 PEV charging characteristics for various levels

\begin{tabular}{|c|c|c|c|}
\hline Type & Nominal Voltage (V) & Max Current (A) & Power level \\
\hline AC Level 1 & $120 \mathrm{~V}, 1$ phase & $16 \mathrm{~A}$ & $2 \mathrm{KW}$ \\
\hline AC Level 2 & $208-240 \mathrm{~V}, 1$ phase & $32 \mathrm{~A}$ & $8 \mathrm{KW}$ \\
\hline AC Level 3 & $208-600 \mathrm{VAC}, 3$ phase & $400 \mathrm{~A}$ & $15-96 \mathrm{KW}$ \\
\hline
\end{tabular}

The new standard has an SAE J1772 [28] ac charge connector on top and a two-pin dc connector below and is intended to enable either ac or dc fast charging via a single connection, as shown in Figure 2.2. 


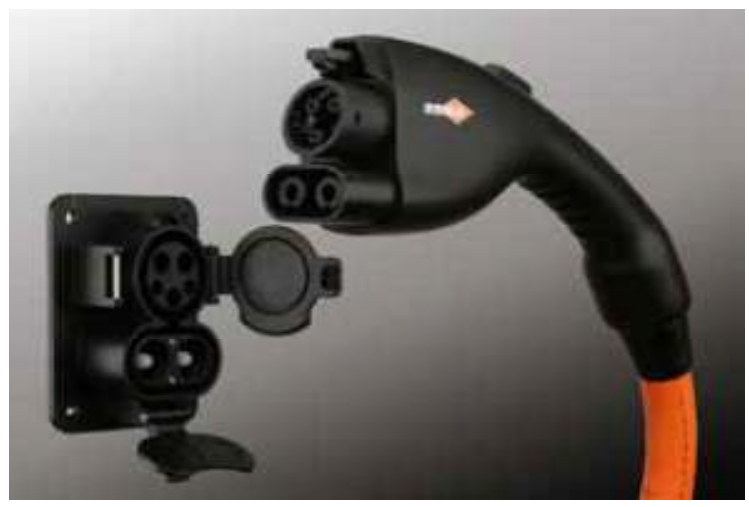

Figure 2.2 AC/DC Combo Coupler and Receptacle based on SAE 1772 TM [28]

\subsection{Impact of PEVs on the electric grid}

An electric grid consists of generation, transmission, and distribution systems. The generation system composed of power plants that generate electricity from a variety of sources such as coal, gas, solar, wind etc. The transmission system consists of transmission lines that transfers electricity between generation and distribution systems [29], and it also includes transformers to step up the electricity to the higher voltage. The distribution system mainly consists of substations, and transformers to step down the electricity to a level used by end-use customers; usually 120/240 V for residential customers, and larger voltage levels for some commercial and industrial customers. The impact of PEV charging on the electric grid as a whole is mainly influenced by two aspects; (1) the level of PEV penetration, and (2) the point in time and the duration of PEV charging.

\subsubsection{Impact on Generation}

A significant amount of increased PEV penetration would immediately result in extra energy requirement that must be generated by a generation system. Given the paucity of storage 
availability on an electric grid, it would result in challenge of instantaneous and continuous matching between demand and generation [30]. In addition, uncoordinated PEV charging in terms of time and duration may introduce new peak for the system load, which in turn may result in increased time during which the power plants may have to work at full power and thereby increasing costs and reduced system reliability [31].

\subsubsection{Impact on Transmission}

With increased PEV penetration, there will be a definite need for increased transmission capacity that is needed to meet the additional energy requirement of PEV charging [22]. Therefore without coordinated charging, the transformers may be overloaded for extended periods. This would result in reduced lifetime of the transformers as well as reliability constraints $[32,33]$.

\subsubsection{Impact on Distribution}

PEVs are likely to have more impact on the distribution system than they will have on the generation and the transmission systems. A distribution system can be affected by PEV charging by the same two elements explained above. It is important to know the relationship between the penetration level of PEVs and the components of a distribution system such as feeders, substations, and transformers; as with higher penetration levels of PEVs, the latter may become overloaded. Overloading of the transformer does not immediately result in device failure, but reduces its lifespan [16]. A low-voltage grid is not capable of handling situations where everyone is charging simultaneously. Local demand profiles will change significantly because of such simultaneous or uncoordinated charging. If many PEV owners charge their vehicle 
simultaneously in a district, it will have a major impact on local infrastructure and local peak demand. Several studies have concluded $[9,34]$ that PEVs will influence the distribution grid for certain. The extent of the impact depends on the penetration level of the PEVs and their charging behavior.

\subsection{Implications of voltage unbalance}

Voltage unbalance is a power quality problem that has a detrimental effect on the performance and efficiency of three phase induction motors. It is frequently encountered in weak networks at the industrial and distribution levels. It is caused by uneven distribution of singlephase loads over the three phases and by asymmetry of impedances over three phase lines. This problem is expected to worsen by PEV battery charging on the distribution system. The definition of voltage unbalance used by the power community is the ratio of negative sequence voltage to the positive sequence voltage [35]. National Electrical Manufacturer Association (NEMA) defines percentage voltage unbalance (\%PVU) as the ratio of maximum voltage deviation to the average of three phase voltages.

$$
\% \mathrm{PVU}=\frac{\text { Maximum voltage deviation from the average voltage }}{\text { Average voltage }} \times 100
$$

According to NEMA motor standard, a maximum unbalanced voltage up to 1 percent at the motor terminal is allowed. This recommendation is not suitable for all motors with different classes, sizes, and loads [36]. 


\section{CHAPTER 3}

\section{MODELING OF A DISTRIBUTION SYSTEM USING MATLAB - SIMULINK}

\subsection{Matlab - Simulink Software}

A $12.47 \mathrm{KV}$ distribution system in this study has been modeled and tested using Matlab/Simulink/SimPowerSystem (Version 7.12 R2011b), which is a modern design software that allows scientists and engineers to rapidly and easily build models that simulate power systems. The Simulink environment of MATLAB, not only allows the drawing of the circuit topology rapidly, but also the analysis of the circuit which can include its interactions with mechanical, thermal, control, and other disciplines. This is possible because all the electrical parts of the simulation interact with the extensive Simulink modeling library [37]. Simulink/SimPowerSystem has number of advantages over its contemporary simulation software (like PSPICE) due to its open architecture, a powerful graphical user interface and versatile analysis and graphics tools [38].

\subsection{Modeled Distribution System}

The existing distribution system consists of residential metered and primary metered customers. Like most distribution systems, the modeled system is a radial system, receiving power from a three phase source at $12.47 \mathrm{KV}$. Figure 3.1 shows a one line diagram of a distribution system provided by a power distributor for this study. 


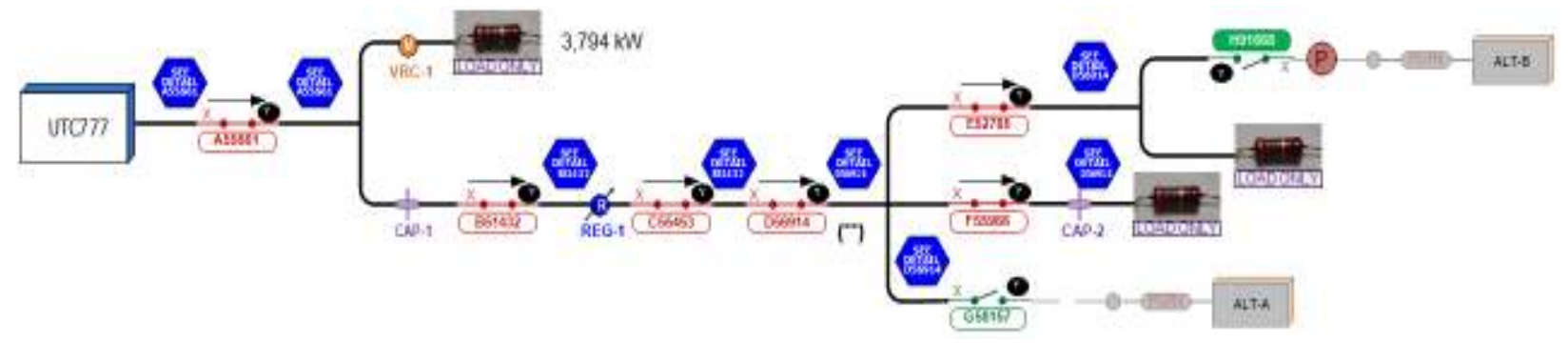

Figure 3.1 One line diagram of the studied distribution system

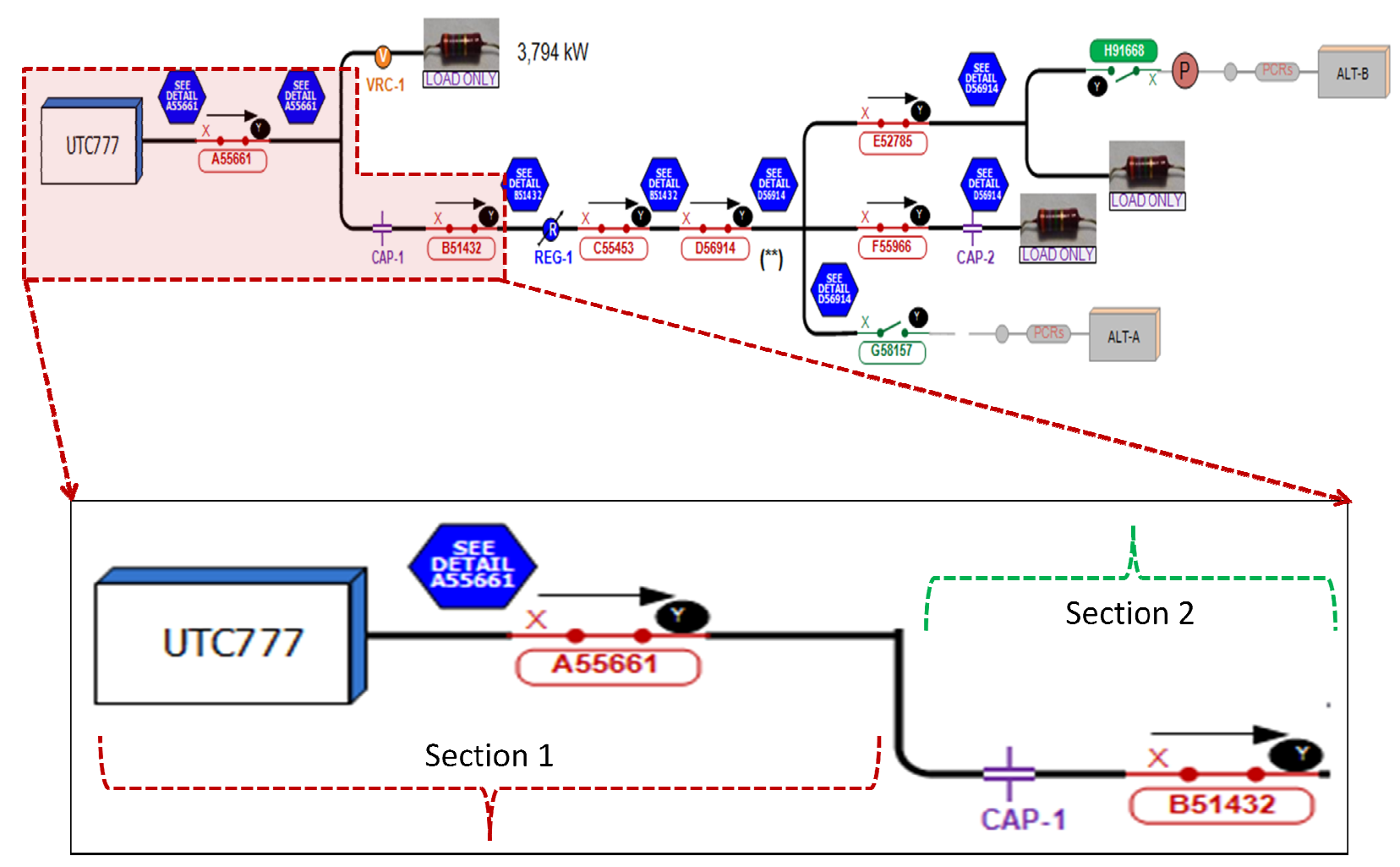

Figure 3.2 Two sections of one line diagram of the studied system

While the distribution system consists of several sections, this study is based on the first two sections of the system for the household metered customers (as shown in figure 3.2). The distribution system feeds power to the metered customers through a main feeder. The main feeder line consists of several branch lines. The main feeder has overhead $(\mathrm{OH})$ lines and the 
branch lines consists of overhead $(\mathrm{OH})$ lines and underground (UG) cables. Each service transformer serves the demand of the metered customers connected to it. The service transformer serves the customers at $480 \mathrm{~V}, 240 \mathrm{~V}$ and $120 \mathrm{~V}$. The modeled system is comprised of total 44 service transformers; of which 41 are single phase $(7200-120 / 240 \mathrm{~V})$ and 3 three phase transformers. Single phase transformers ratings range from 15-100 KVA and three phase transformers sizes ranging from 15-500 KVA.

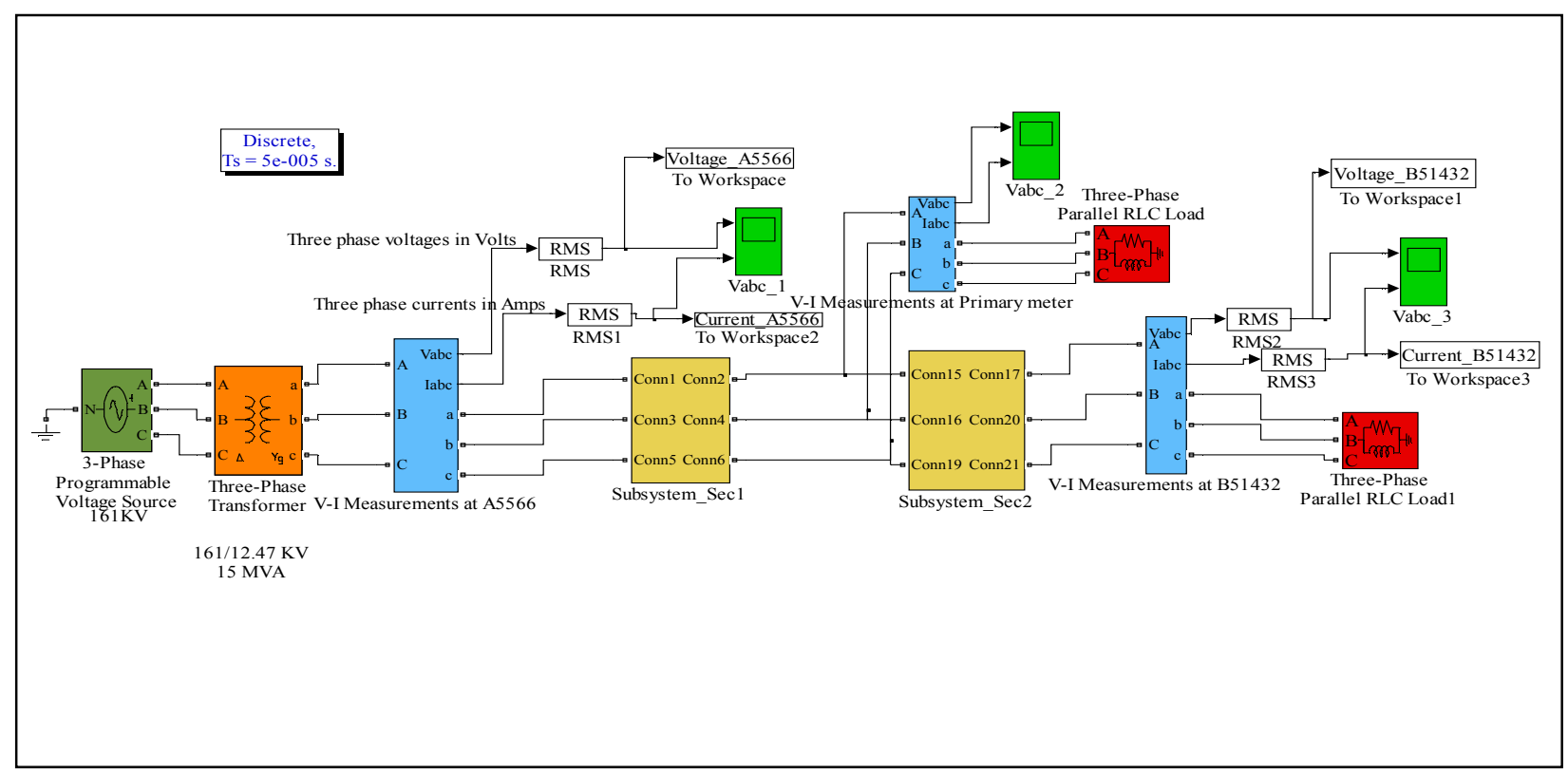

Figure 3.3 MATLAB-SIMULINK model of studied system

As shown in the figure 3.3, subsystems section 1 and section 2, are comprised of a primary and a secondary distribution feeder lines. The detailed view of the subsystem section 1 and 2 are shown in figure 3.5 and figure 3.6 respectively. As shown in figure 3.4, the modeled distribution system includes two circuit breakers one is located nearer to the substation bank and the other one is located at the end of the section 2 


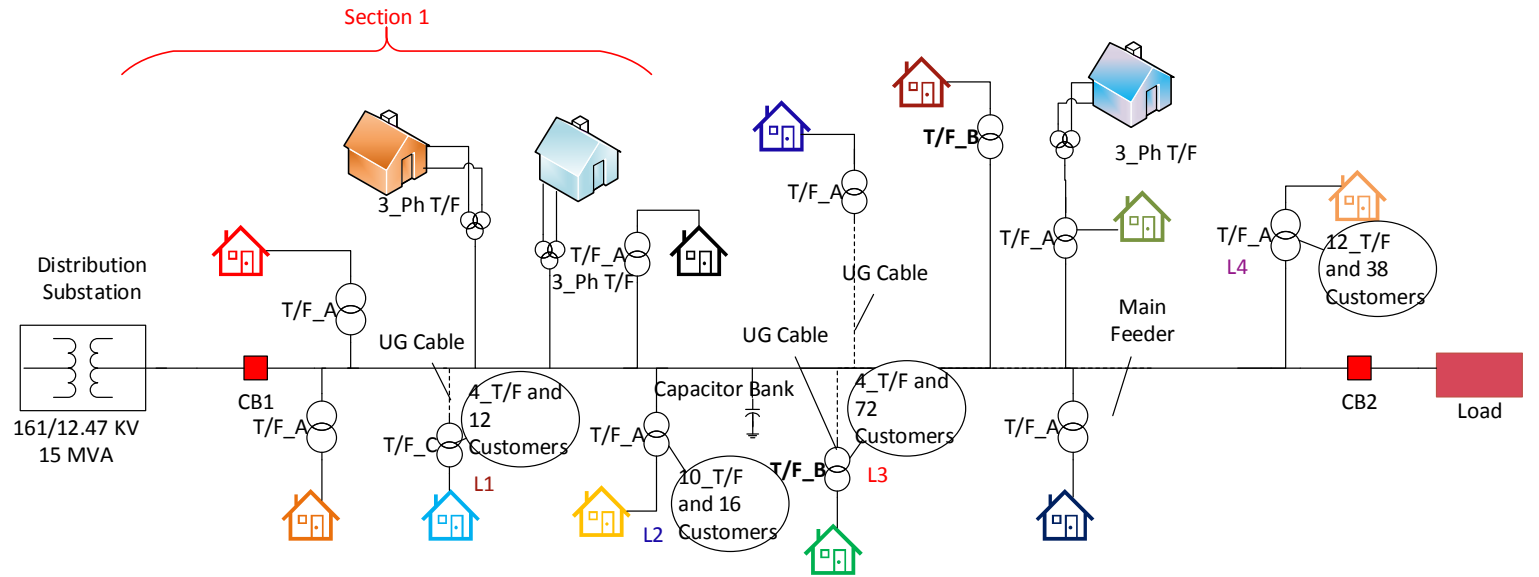

Section 2

Figure 3.4 Simplified one line diagram of distribution system layout

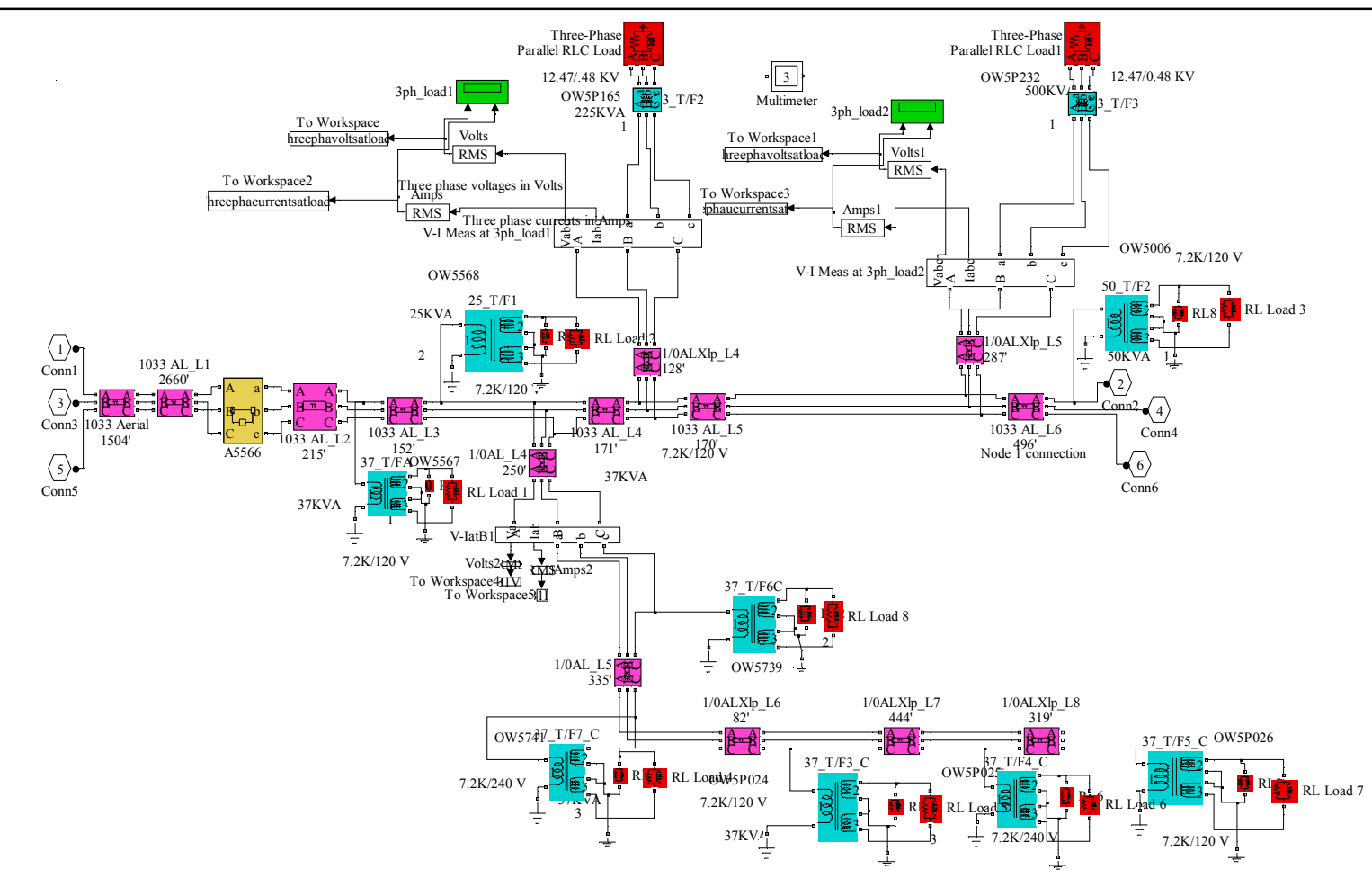

Figure 3.5 Simulink distribution system layout of subsystem section 1 


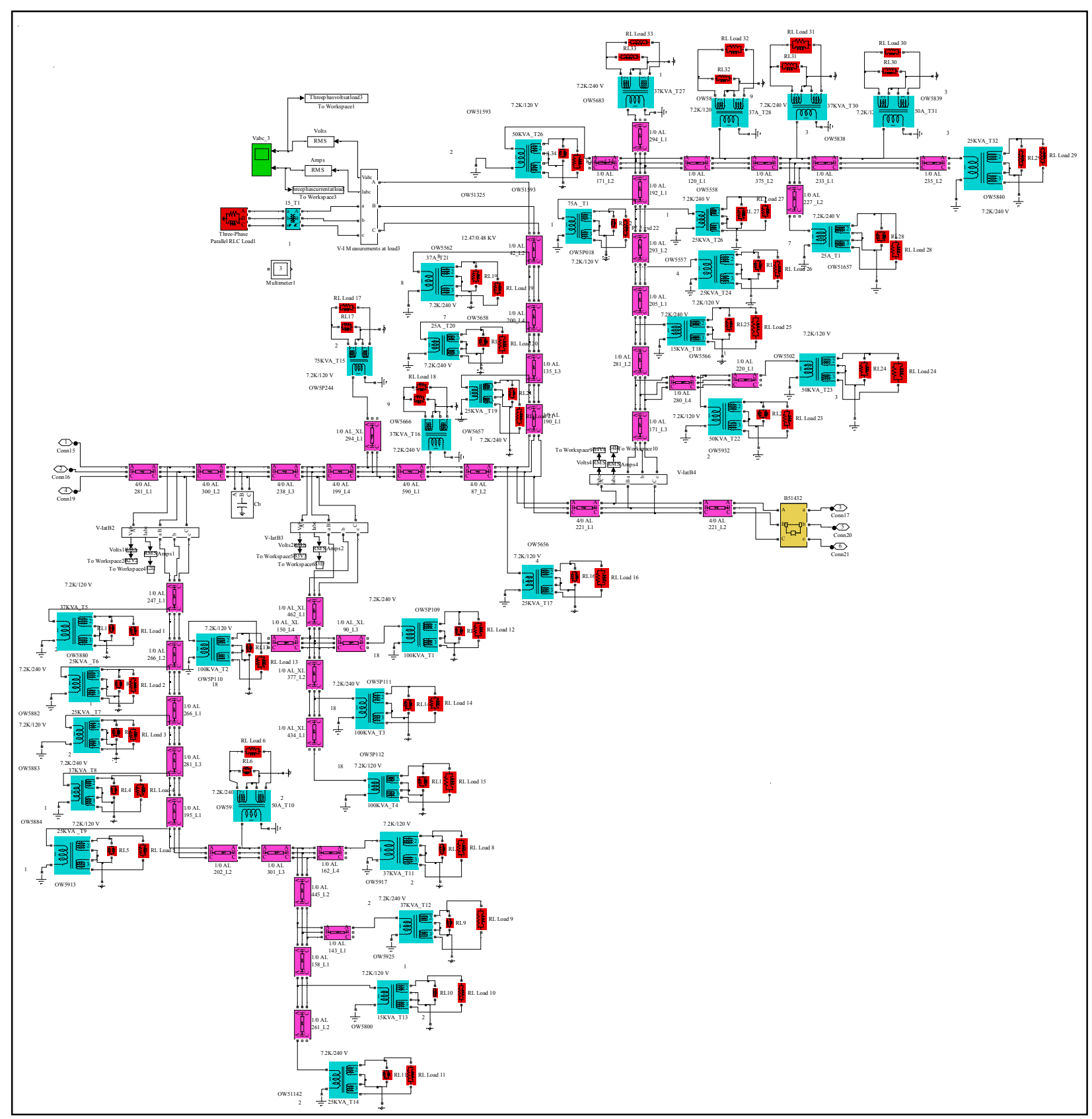

Figure 3.6 Simulink distribution system layout of subsystem section 2

\subsection{Overhead lines and Underground cables}

The distribution system is comprised of both $\mathrm{OH}$ lines and UG cables. The over head line conductor sizes ranging from 1033 aerial primary feeder to 4/0 aluminum. In the Simulink 
modeled system, $\mathrm{OH}$ lines and UG cables are represented by three phase pie section block as shown in figure 3.7. In this study, the transmission line is represented by its pie equivalent circuit. The pie model consists of one set of RL series elements connected between sending and receiving end terminals and two sets of shunt capacitances lumped at both ends of the line [37].

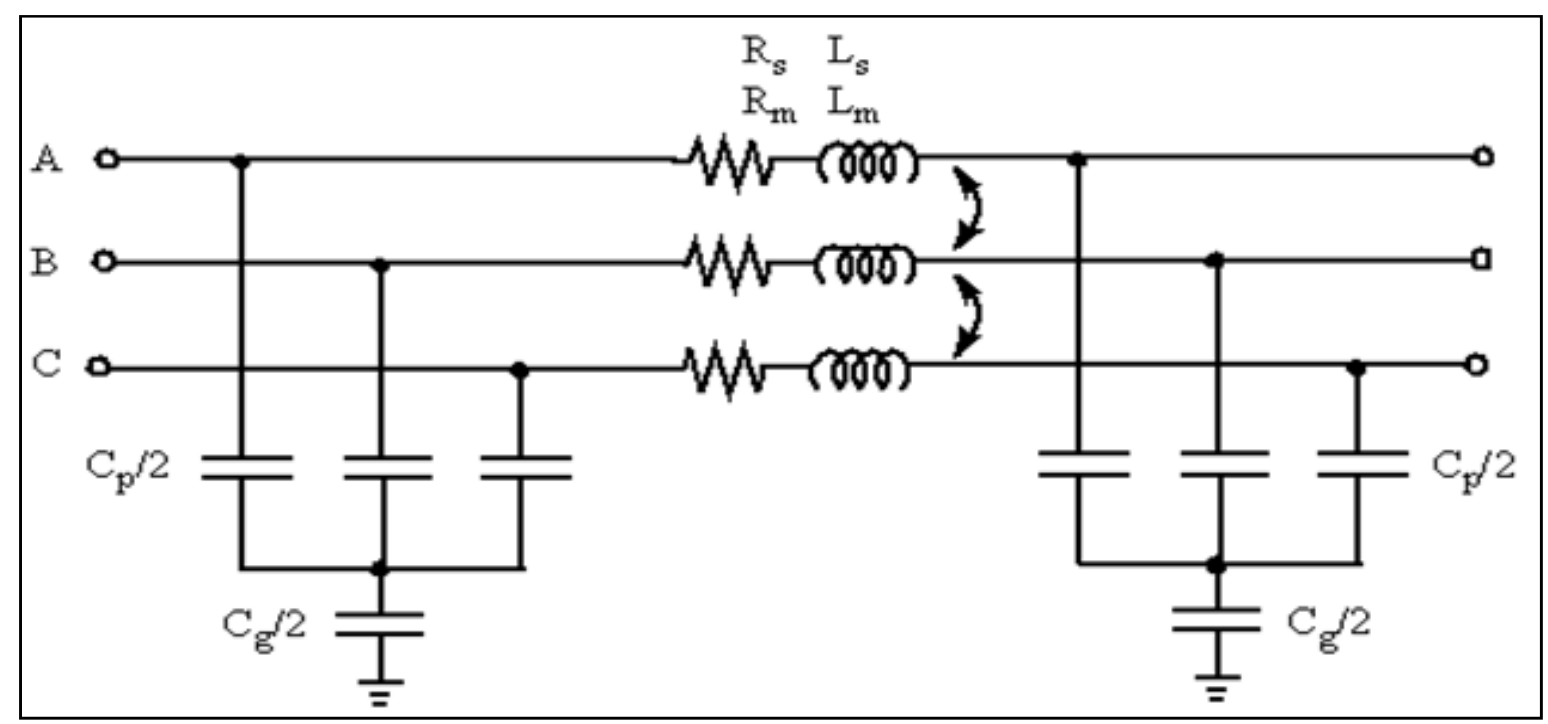

Figure 3.7 Three phase pie section line block [37]

Positive sequence and zero sequence impedances and admittances of the lines are provided by the power distributor are shown in table 3.1. The conductor impedance values are given in ohms/feet. However as PI model block requires the parameters to be in ohms/kilometers, the necessary conversion was performed. 
Table 3.1 Impedances of Overhead Lines

\begin{tabular}{|c|c|c|c|c|c|c|c|c|c|}
\hline $\begin{array}{c}\text { Size of the } \\
\text { conductor }\end{array}$ & Material & \multicolumn{2}{|c|}{$\begin{array}{c}\text { Positive Sequence } \\
\text { Impedance } \\
\text { (ohms/1000ft) }\end{array}$} & \multicolumn{2}{|c|}{$\begin{array}{c}\text { Zero Sequence } \\
\text { Impedance } \\
\text { (ohms/1000ft) }\end{array}$} & $\begin{array}{c}\text { Positive } \\
\text { Sequence } \\
\text { Admittance } \\
\text { (us/1000ft) }\end{array}$ & \multicolumn{2}{|c|}{$\begin{array}{c}\text { Zero } \\
\text { Sequence } \\
\text { Admittance } \\
\text { (us/1000ft) }\end{array}$} \\
\cline { 3 - 10 } & $\mathrm{R} 1$ & $\mathrm{X} 1$ & $\mathrm{R} 0$ & $\mathrm{X} 0$ & $\mathrm{G} 1$ & $\mathrm{~B} 1$ & $\mathrm{G} 0$ & $\mathrm{~B} 0$ \\
\hline 1033 & Aerial & 0.01777 & 0.1157 & 0.1233 & 0.3735 & 0 & 1.354 & 0 & 0.6314 \\
\hline $1033 \mathrm{AL}$ & Aluminum & 0.01800 & 0.1166 & 0.1138 & 0.3924 & 0 & 1.349 & 0 & 0.5870 \\
\hline $1 / 0 \mathrm{AL}$ & Aluminum & 0.16770 & 0.1437 & 0.2731 & 0.4014 & 0 & 1.086 & 0 & 0.5666 \\
\hline $4 / 0 \mathrm{AL}$ & Aluminum & 0.08376 & 0.1356 & 0.1892 & 0.3934 & 0 & 1.155 & 0 & 0.5847 \\
\hline
\end{tabular}

Table 3.2 shows the calculated values for positive and zero sequence resistances, inductances and capacitances in S.I units for the length of the conductor line. The 1/0 ALXLP (Aluminum Cross Linked Polyethylene) in table 3.2 represents an underground cable. The values for resistances, inductances and capacitances of this cable are provided by the power distributor.

Table 3.2 Resistances, Inductances and Capacitances of $\mathrm{OH}$ lines and UG cables

\begin{tabular}{|c|c|c|c|c|c|c|}
\hline \multirow{2}{*}{$\begin{array}{c}\text { Size of the } \\
\text { conductor }\end{array}$} & \multicolumn{6}{|c|}{ Positive Sequence and Zero Sequence Resistance, Inductance and Capacitance } \\
\cline { 2 - 7 } & $\mathrm{R} 1(\Omega / \mathrm{km})$ & $\mathrm{R} 0(\Omega / \mathrm{km})$ & $\mathrm{L} 1(\mathrm{H} / \mathrm{km})$ & $\mathrm{L} 0(\mathrm{H} / \mathrm{km})$ & $\mathrm{C} 1(\mathrm{~F} / \mathrm{km})$ & $\mathrm{C} 0(\mathrm{uF} / \mathrm{km})$ \\
\hline 1033 Aerial & 0.05830052 & 0.40452757 & 0.00100649 & 0.00324915 & 0.011778713 & 0.005492673 \\
& & & & & & \\
\hline $1033 \mathrm{Al}$ & 0.05905512 & 0.37335959 & 0.00101432 & 0.00341356 & 0.011735217 & 0.005106429 \\
\hline $1 / 0 \mathrm{Al}$ & 0.55019686 & 0.89599740 & 0.00125007 & 0.00349185 & 0.009447328 & 0.004928965 \\
\hline $4 / 0 \mathrm{Al}$ & 0.27480315 & 0.62073492 & 0.00117961 & 0.00342226 & 0.010047573 & 0.00508642 \\
\hline $1 / 0 \mathrm{AlXLP}$ & 0.56000000 & 0.96140000 & 0.00064935 & 0.00069257 & 0.06885428 & 0.026584886 \\
\hline
\end{tabular}




\subsection{Service Transformers}

In the modeled system, most of the service transformers are single phase and modeled as a three winding transformer, the primary side of the transformer is connected to $7.2 \mathrm{KV}$. The secondary side of the transformer consists of 120/240V. Typical single phase distribution transformer connection diagram shown in figure 3.8. Each service transformer parameters are manually entered on the transformer parameter block. A sample of the transformer parameter block of SimPowerSystems is shown in figure 3.9.

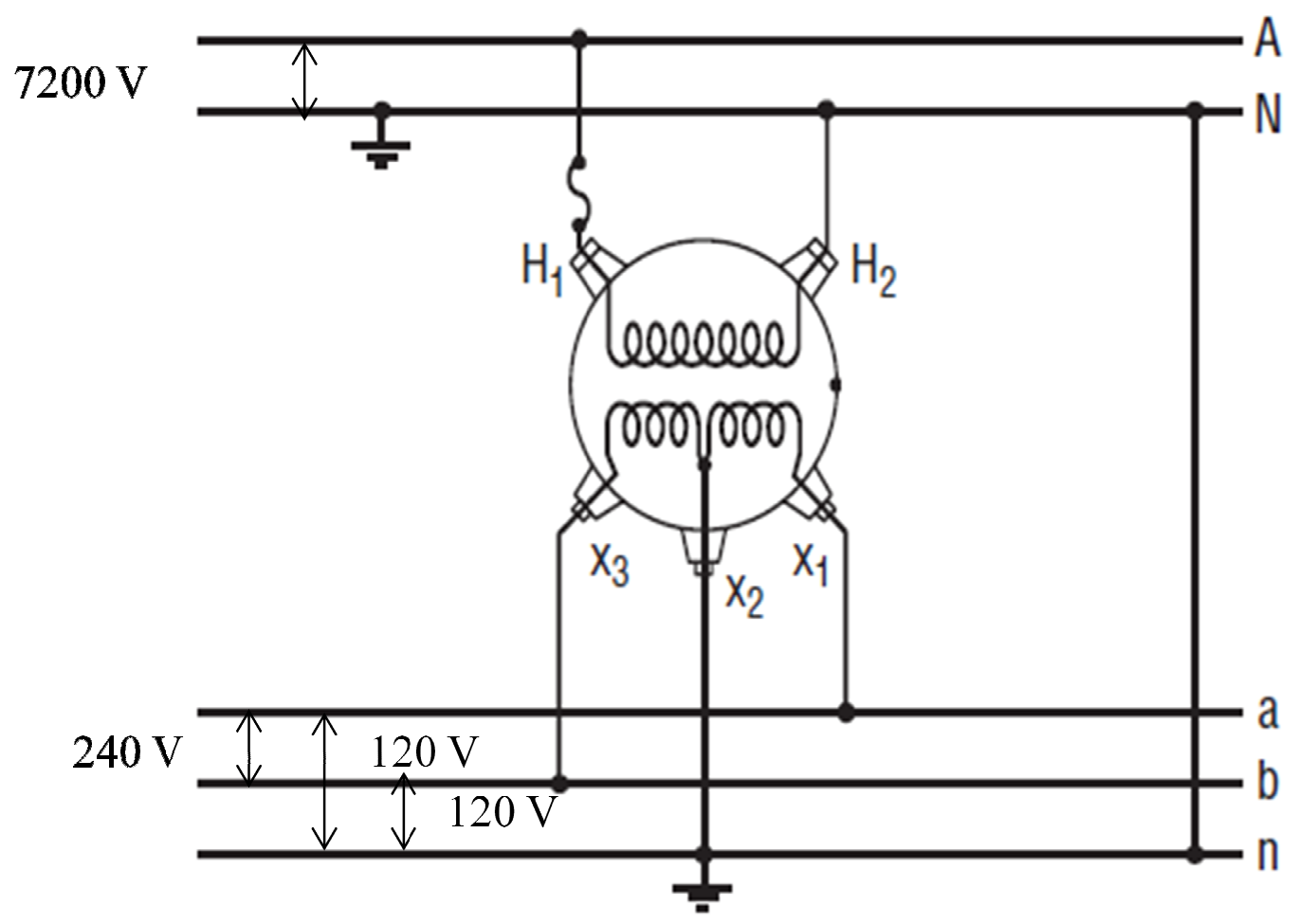

Figure 3.8 Connection diagram of a single phase transformer 


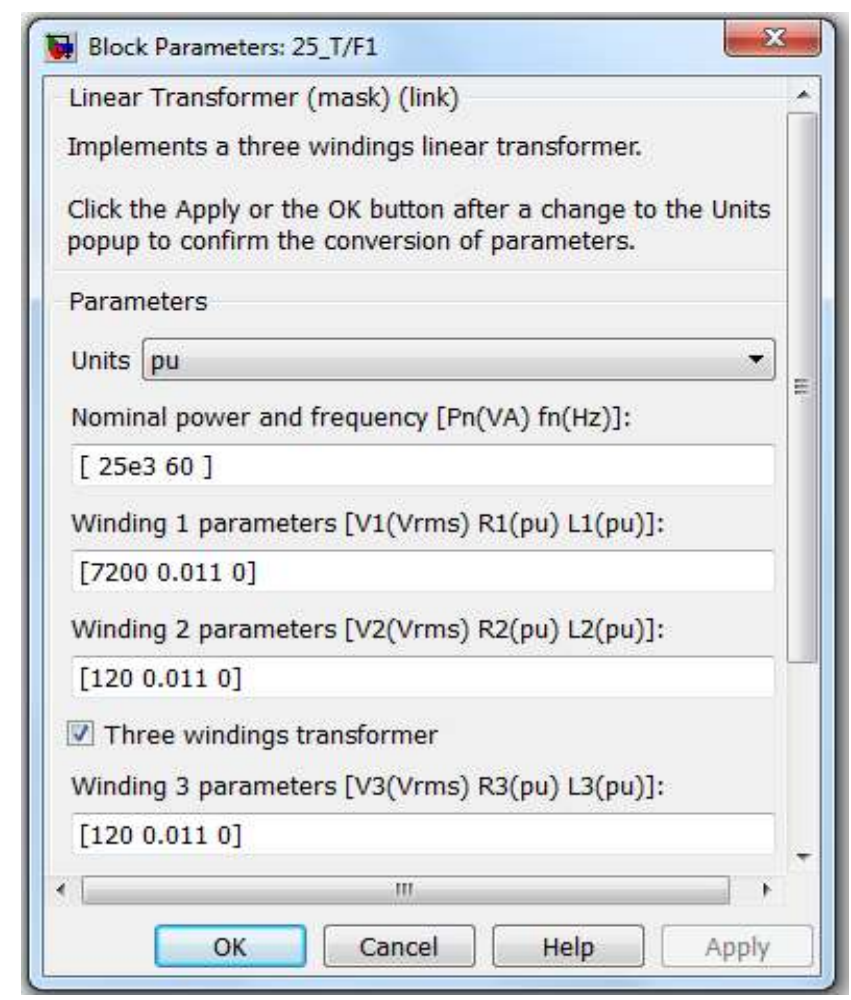

Figure 3.9 Sample SimPowerSystems block for the single phase transformer [37]

The modeled distribution system service transformer impedances provided by the power distributor, are listed by their rating as shown in the table 3.3.

Table 3.3 Service transformer Impedances by rating

\begin{tabular}{|c|c|c|c|}
\hline $\begin{array}{c}\text { Transformer } \\
\text { Rating (KVA) }\end{array}$ & $\begin{array}{c}\text { Positive Sequence } \\
\text { Impedance }(\% Z 1)\end{array}$ & $\begin{array}{c}\text { Zero Sequence } \\
\text { Impedance }(\% \text { Z) }\end{array}$ & X/R Ratio \\
\hline 15 & 2.5 & 2.5 & 4 \\
\hline $15(3$ phase) & 4.5 & 4.5 & 4 \\
\hline 25 & 4.5 & 4.5 & 4 \\
\hline 37 & 4.5 & 4.5 & 4 \\
\hline 50 & 4.5 & 4.5 & 4 \\
\hline 75 & 3.0 & 3.0 & 4 \\
\hline 100 & 4.5 & 4.5 & 4 \\
\hline 225 & 4.5 & 4.5 & 10 \\
\hline 500 & 3.94 & 3.94 & \\
\hline
\end{tabular}


For a single phase transformer supplying single-phase service, the full load current in amperes is calculated as follows:

$$
\text { Full load current }=\frac{\text { Transformer KVA rating } \times 1000}{\text { Voltage Rating }}
$$

Table 3.4 below lists full load current, shows the list of transformers used in this study.

Table 3.4 Nominal current ratings of single-phase transformers

\begin{tabular}{|c|c|c|c|}
\hline $\begin{array}{c}\text { Transformer } \\
\text { Rating (KVA) }\end{array}$ & $\begin{array}{c}\text { Current at 7200 V } \\
\text { (Amps) }\end{array}$ & $\begin{array}{c}\text { Current at 120 V } \\
\text { (Amps) }\end{array}$ & $\begin{array}{c}\text { Current at 240 V } \\
\text { (Amps) }\end{array}$ \\
\hline 15 & 2.08 & 125.00 & 62.50 \\
\hline 25 & 3.47 & 208.33 & 104.17 \\
\hline 37 & 5.14 & 308.33 & 154.17 \\
\hline 50 & 6.94 & 416.67 & 208.33 \\
\hline 75 & 10.40 & 625.00 & 312.50 \\
\hline 100 & 13.90 & 833.33 & 416.67 \\
\hline
\end{tabular}

\subsection{Distribution system load}

Fifteen minutes intervals load data of four days $(01 / 09 / 2013-01 / 12 / 2013)$ for the distribution system are provided by the power distributor. The load data measured at the substation include all residential metered customers and primary metered customers served by the system. Primary metered customers are major customers who purchase bulk energy. However the primary metered customers are not considered in the modeled system for this study because of lack of data for those customers. Figures 3.10 and 3.11 shown below are the active and reactive load profiles of the distribution system respectively. 


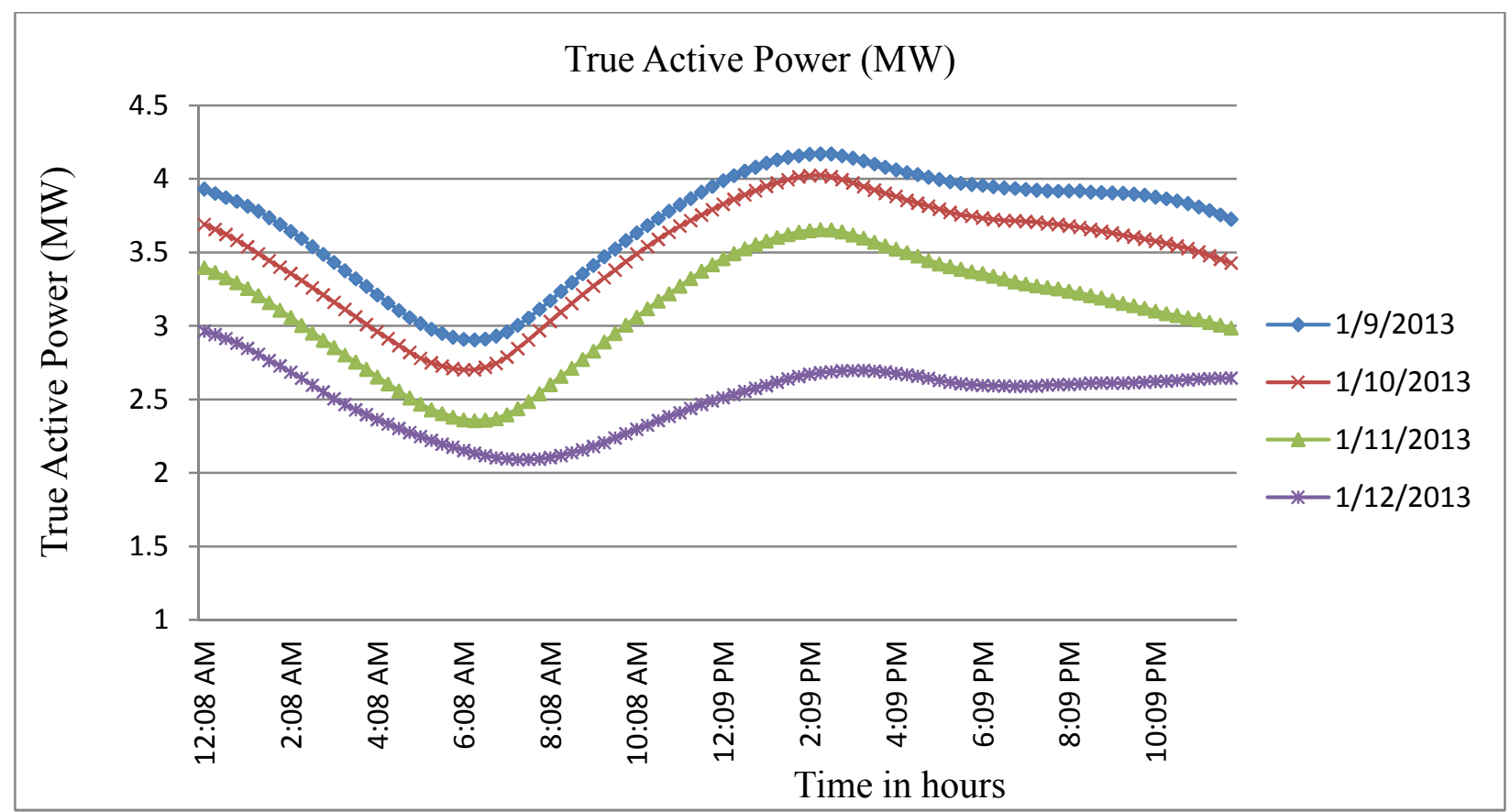

Figure 3.10 Total Active Power for 4 days

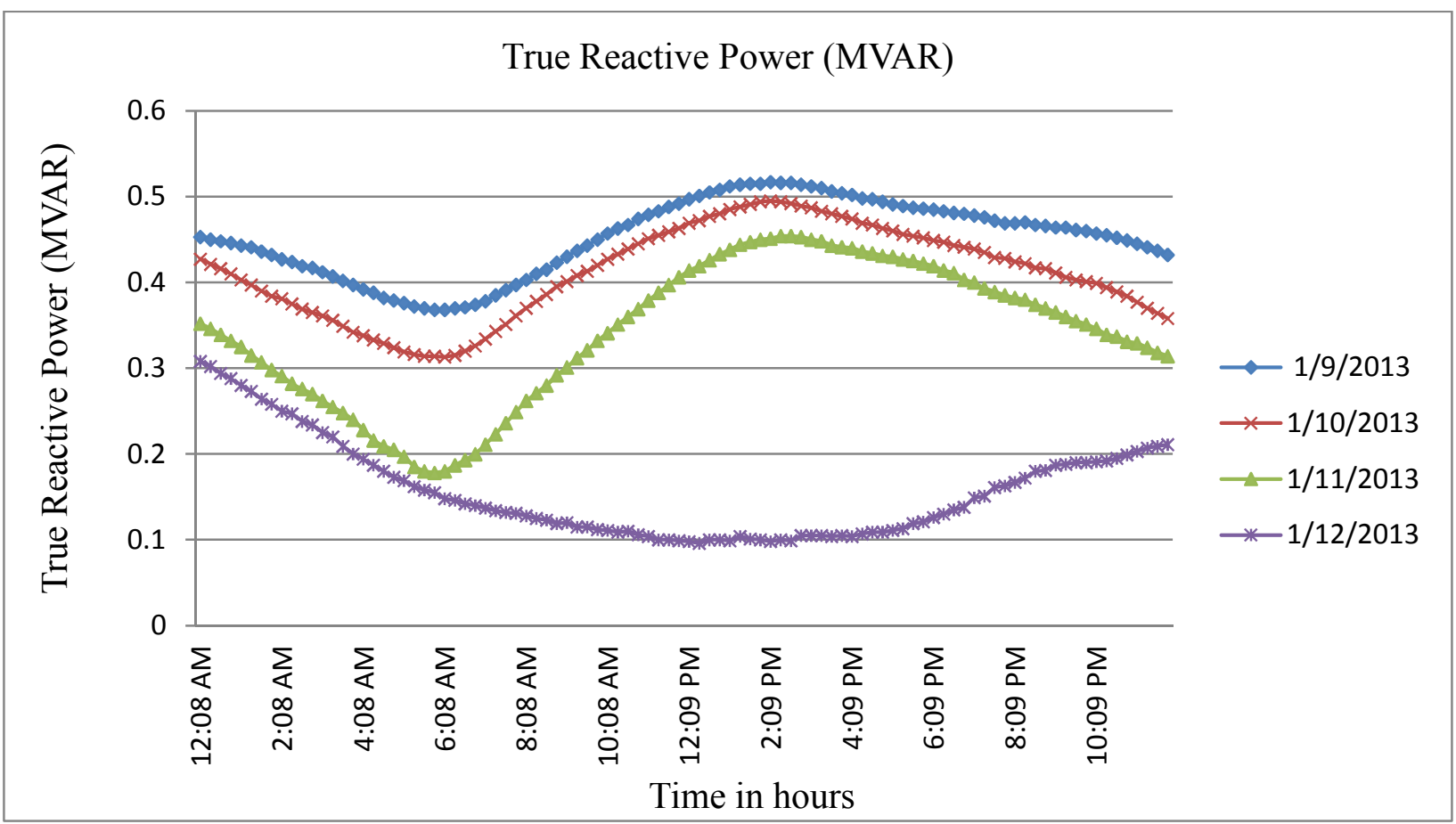

Figure 3.11 Total Reactive Power for 4 days 


\subsection{Residential Power Demand}

Power distributor provided the residential smart metered customers' load data at fifteen minutes intervals of 4 days $(01 / 09 / 2013$ - 01/12/2013) for the modeled system. The provided smart meters data was energy (watt hours) consumed by each residential metered customer. The data is then converted into real power (watts). The estimated reactive power (var) is chapter 4 .

\subsection{Level 2 battery charger model using MATLAB-SIMULINK}

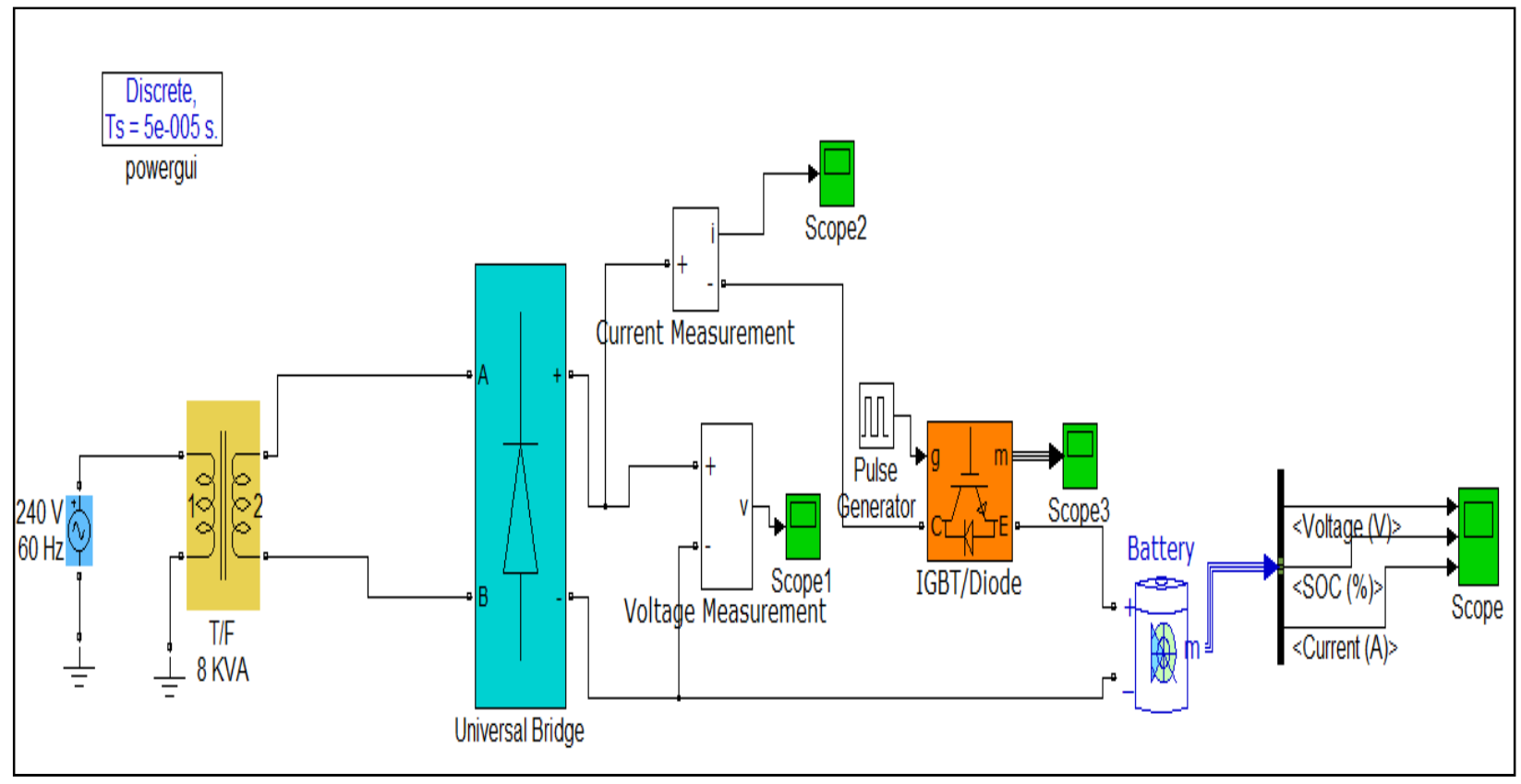

Figure 3.12 Battery charger model using MATLAB-SIMULINK

A level 2 battery charger has been modeled for this study using MATLAB-SIMULINK as shown in figure 3.12. Since level 2 charger is a single-phase AC charger and operated at 208$240 \mathrm{~V}, 32 \mathrm{~A}$ current rating and power level up to $8 \mathrm{KW}$, it is necessary to convert the current provided by an external energy source by a rectifier to direct current. The battery component for 
this model is sourced from MATLAB-SIMULINK. A simulation has been attempted by integrating the battery charger model with the modeled distribution system in this study. However the simulation has failed due to incompatibility of power electronics component of battery charger with the existing MATLAB-SIMULINK blocks. Hence the battery charger integrated with modeled distribution system has not been considered for this study, however it can be considered for future research. 


\section{CHAPTER 4}

\section{DISTRIBUTION SYSTEM LOAD DATA ANALYSIS}

\subsection{Introduction}

The studied model for the distribution system is shown in figure 4.1 below. By having total active and reactive load data for the entire system and knowing residential metered customers energy usage for the first two sections, calculations are made to estimate the reactive power consumed by the metered customers for those two sections of the system. Intellirupters A55661 and B51432 in figure 4.1 represents circuit breakers CB1 and CB2 respectively in the Simulink modeled system. The data provided at CB1 represents the load data for the entire system, whereas the data at CB2 represents the load data for the later part of the system. Given that the load data for the sections 1 and 2 that are part of this study, essentially represented by the difference of load data at CB1 and CB2.

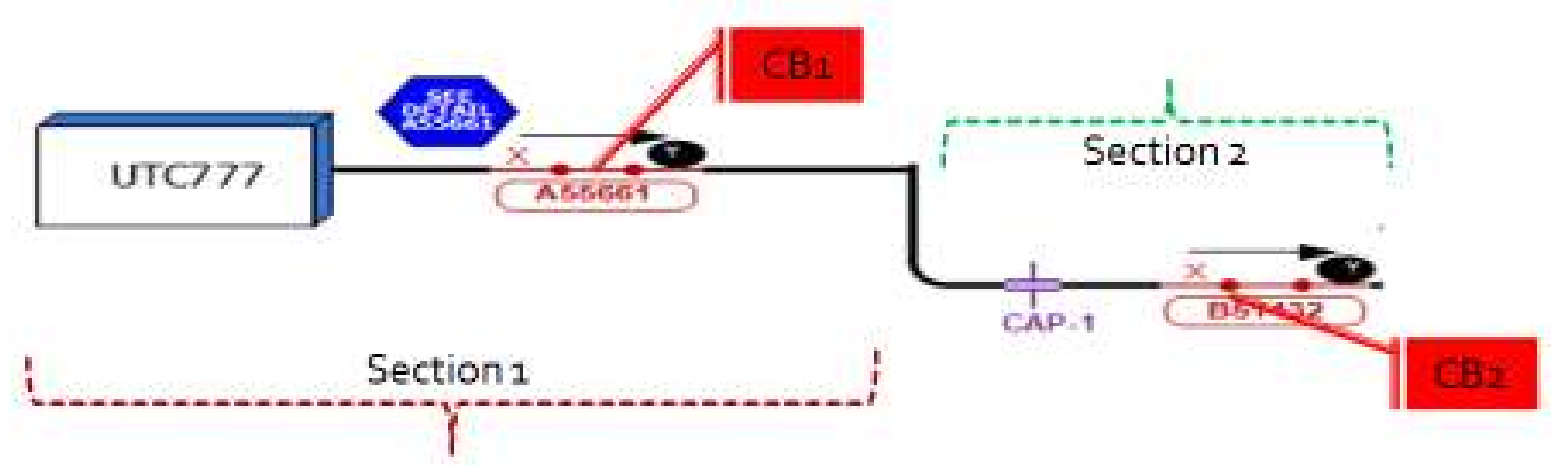

Figure 4.1 Two sections of one line diagram of studied system 
Out of four days (01/09/2013 - 01/12/2013) load profile data, one day's $(01 / 10 / 2013)$ load data has been selected for testing the Simulink modeled system and the simulation results are compared with real load data provided by the power distributor for that particular day. The objective of this study is to assess the impact of PEV on the distribution system during peak and off peak load demand. From the provided load data at CB1, it is observed that the peak demand occurred at around 2.30 PM and off peak demand at 6.30 AM on 01/10/2013 as shown in figure

\section{$4.2 \& 4.3$.}

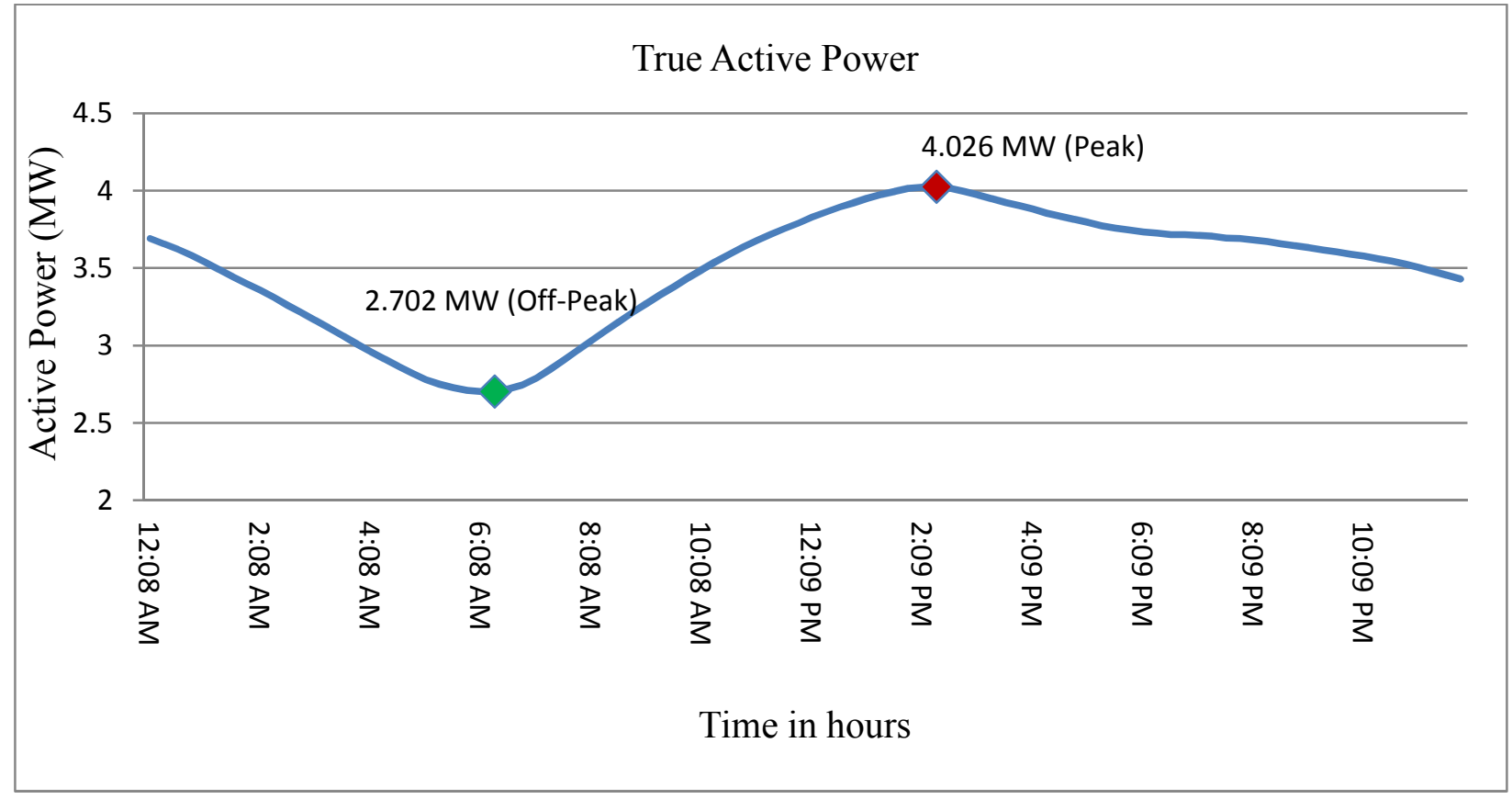

Figure 4.2 True Active Power at CB1 


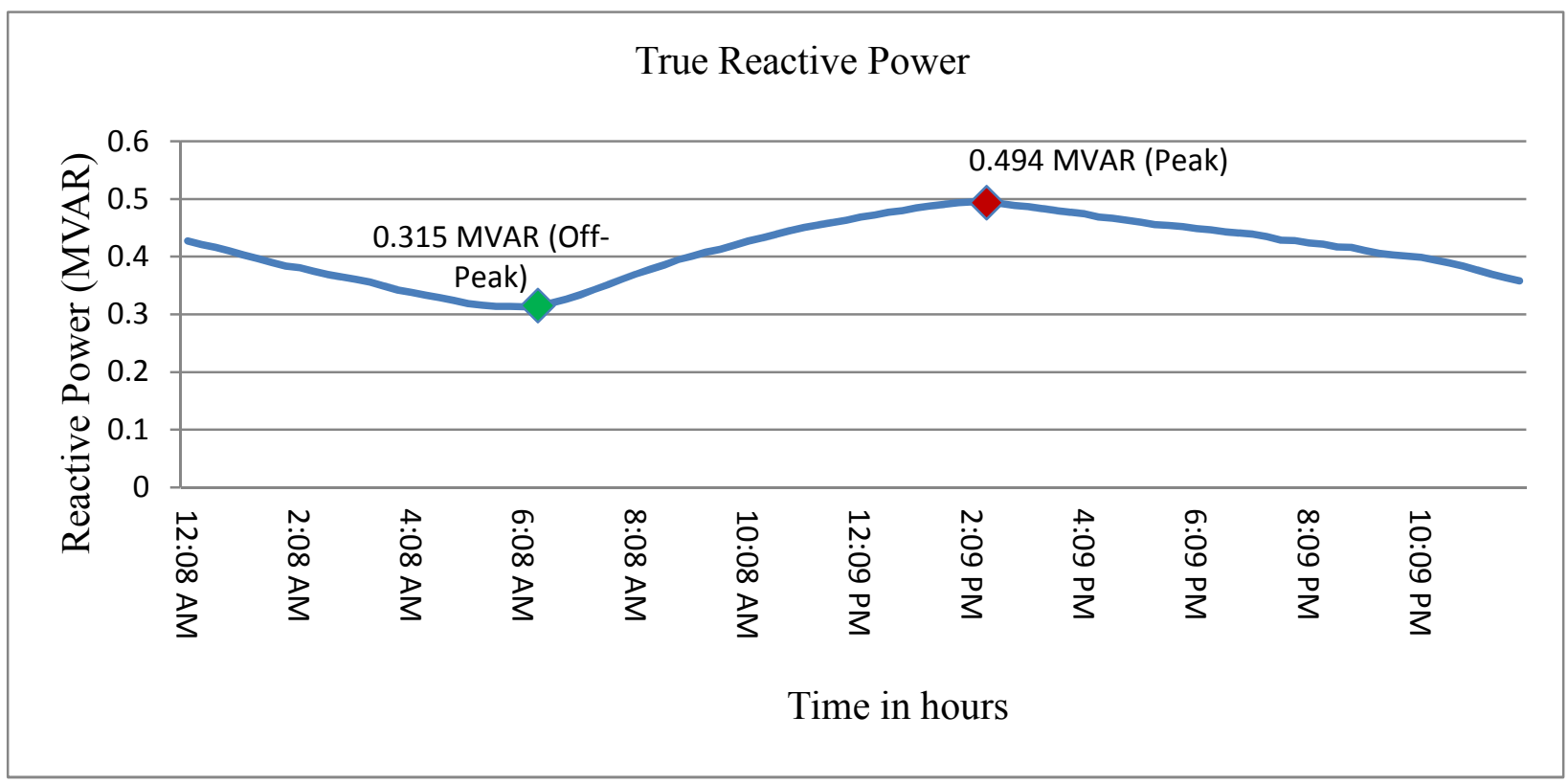

Figure 4.3 True Reactive Power at CB1 on 01/10/2013

\subsection{Reactive Power Calculations}

Since the peak and off-peak true active power and true reactive power for CB1 have been observed at 2:30 PM and 6:30 AM respectively, the true active power and true reactive power for CB2 observed at those same time points have been taken into consideration to estimate the reactive power consumed by the residential customers (Section $1 \& 2$ of the figure 4.1 ). The total active and reactive power consumed by the modeled system are calculated as below;

Total Active Power at CB1 - Total Active Power at CB2 = Total Active Power Consumed by the residential customers and primary metered customers.

Total Reactive Power at CB1 - Total Reactive Power at CB2 = Total Reactive Power Consumed by the residential customers and primary metered customers. 
By substituting the active and reactive power values at peak and off-peak power demands for CB1 and CB2 in equations (1) and (2) respectively, the resultant differences between CB1 and CB2 are presented below in the table 4.1 .

Table 4.1 Peak and Off-Peak Active and Reactive Powers for CB1, CB2

\begin{tabular}{|c|c|c|c|c|}
\hline Type of Load & Date: 01/10/2013 & CB1 & CB2 & CB1 - CB2 \\
\hline True Active Power (MW) & Peak (2:30 PM) & 4.026 & 1.303 & 2.723 \\
\cline { 2 - 5 } & Off-Peak (6:30 AM) & 2.702 & 1.048 & 1.654 \\
\hline True Reactive Power (MVAR) & Peak (2:30 PM) & 0.494 & 0.224 & 0.270 \\
\cline { 2 - 5 } & Off-Peak (6:30 AM) & 0.315 & 0.220 & 0.095 \\
\hline
\end{tabular}

\subsection{Active to Reactive Power Ratio at Peak and Off-Peak}

Table 4.2 Active to Reactive Power Ratio of the system

\begin{tabular}{|c|c|c|c|}
\hline Date: 01/10/2013 & Type of Load & CB1 - CB2 & $\begin{array}{c}\text { Active to Reactive } \\
\text { Power Ratio }\end{array}$ \\
\hline Peak (2:30 PM) & True Active Power (MW) & 2.723 & \multirow{2}{*}{10.085} \\
\cline { 2 - 3 } & True Reactive Power (MVAR) & 0.270 & \multirow{2}{*}{17.410} \\
\hline \multirow{2}{*}{ Off Peak (6:30 AM) } & True Active Power (MW) & 1.654 & \multirow{2}{*}{0.095} \\
\cline { 2 - 3 } & True Reactive Power (MVAR) & 0.095 \\
\hline
\end{tabular}


As presented in the table 4.2 above, at the peak, the ratio of active power to reactive power $=2.723 / 0.27=10.085$, and at the off-peak, the ratio of active power to reactive power $=$ $1.654 / 0.095=17.41$.

These peak and off-peak ratios of active power to reactive power $(10.085,17.41)$ include residential customers as well as primary customers. Due to lack of the load data of primary metered customers, for the purpose of this study, above estimated ratios of active power to reactive power are assumed to be only that of residential customers i.e. section 1 and 2 of modeled system (figure 4.1). With that assumption, based on these ratios of active power to reactive power, the reactive power consumed by the residential customers is calculated. Table 4.3 lists total real and reactive power for all service transformers (at peak and off-peak) and number of customers connected to the distribution transformers for section 1 and section 2 of the modeled system (figure 4.1). 
Table 4.3 Real and Reactive power demands for all service transformers

\begin{tabular}{|c|c|c|c|c|c|c|}
\hline \multirow{2}{*}{$\begin{array}{l}\text { Transformer } \\
\text { Labeling }\end{array}$} & \multirow{2}{*}{$\begin{array}{c}\text { Transformer } \\
\text { KVA } \\
\text { Rating }\end{array}$} & \multirow{2}{*}{$\begin{array}{c}\text { No. of } \\
\text { customers } \\
\text { connected }\end{array}$} & \multicolumn{2}{|c|}{ Peak demand (2.30PM) } & \multicolumn{2}{|c|}{ Off-Peak demand (6.30AM) } \\
\hline & & & $\begin{array}{c}\text { Real Power } \\
(\mathrm{KW})\end{array}$ & $\begin{array}{c}\text { Reactive Power } \\
\text { (KVAR) }\end{array}$ & $\begin{array}{l}\text { Real Power } \\
(\mathrm{KW})\end{array}$ & $\begin{array}{c}\text { Reactive Power } \\
\text { (KVAR) }\end{array}$ \\
\hline OW5006 & 50 & 1 & 1.094 & 0.108 & 0.986 & 0.057 \\
\hline OW51142 & 25 & 2 & 8.800 & 0.873 & 8.112 & 0.466 \\
\hline OW51325 & 15 & 1 & 0.252 & 0.025 & 0.288 & 0.017 \\
\hline OW5562 & 37 & 8 & 6.412 & 0.636 & 9.940 & 0.571 \\
\hline OW5567 & 37 & 1 & 0.652 & 0.065 & 2.448 & 0.141 \\
\hline OW5568 & 25 & 2 & 1.072 & 0.106 & 0.980 & 0.056 \\
\hline OW5656 & 25 & 4 & 7.536 & 0.747 & 1.760 & 0.101 \\
\hline OW5657 & 25 & 1 & 0.180 & 0.018 & 5.508 & 0.316 \\
\hline OW5658 & 25 & 7 & 3.088 & 0.306 & 13.328 & 0.766 \\
\hline OW5666 & 37 & 9 & 13.068 & 1.296 & 4.488 & 0.258 \\
\hline OW5739 & 37 & 2 & 1.472 & 0.146 & 2.192 & 0.126 \\
\hline OW5741 & 37 & 3 & 4.236 & 0.420 & 3.916 & 0.225 \\
\hline OW5800 & 15 & 1 & 0.272 & 0.027 & 0.032 & 0.002 \\
\hline OW5880 & 37 & 2 & 0.268 & 0.027 & 1.016 & 0.058 \\
\hline OW5882 & 25 & 1 & 3.484 & 0.345 & 0.700 & 0.040 \\
\hline OW5883 & 25 & 2 & 1.348 & 0.134 & 2.848 & 0.164 \\
\hline OW5884 & 37 & 1 & 0.448 & 0.044 & 0.392 & 0.023 \\
\hline OW5913 & 25 & 1 & 3.244 & 0.322 & 0.448 & 0.026 \\
\hline OW5915 & 50 & 2 & 1.116 & 0.111 & 1.096 & 0.063 \\
\hline OW5917 & 37 & 2 & 3.592 & 0.356 & 2.804 & 0.161 \\
\hline OW5925 & 37 & 2 & 3.100 & 0.307 & 5.876 & 0.338 \\
\hline OW5P024 & 37 & 1 & 6.404 & 0.635 & 0.248 & 0.014 \\
\hline OW5P025 & 37 & 3 & 5.404 & 0.536 & 6.540 & 0.376 \\
\hline OW5P026 & 50 & 3 & 5.072 & 0.503 & 7.588 & 0.436 \\
\hline OW5P109 & 100 & 18 & 24.888 & 2.468 & 19.348 & 1.111 \\
\hline OW5P110 & 100 & 18 & 22.152 & 2.197 & 21.960 & 1.261 \\
\hline OW5P111 & 100 & 18 & 15.412 & 1.528 & 19.988 & 1.148 \\
\hline OW5P112 & 100 & 18 & 12.556 & 1.245 & 25.560 & 1.468 \\
\hline OW5P232 & 500 & 1 & 0.264 & 0.026 & 0.128 & 0.007 \\
\hline OW5932 & 50 & 2 & 1.116 & 0.111 & 1.096 & 0.063 \\
\hline OW5502 & 50 & 3 & 1.094 & 0.108 & 0.986 & 0.057 \\
\hline OW51593 & 50 & 2 & 1.116 & 0.111 & 1.096 & 0.063 \\
\hline OW5566 & 15 & 1 & 0.272 & 0.027 & 0.032 & 0.002 \\
\hline OW5557 & 25 & 4 & 8.800 & 0.873 & 8.112 & 0.466 \\
\hline OW5558 & 25 & 1 & 1.072 & 0.106 & 0.980 & 0.056 \\
\hline OW5P018 & 75 & 1 & 1.304 & 0.129 & 4.896 & 0.281 \\
\hline OW5683 & 37 & 1 & 6.412 & 0.636 & 9.940 & 0.571 \\
\hline OW5835 & 37 & 9 & 0.652 & 0.065 & 2.448 & 0.141 \\
\hline OW5838 & 37 & 3 & 13.068 & 1.296 & 4.488 & 0.258 \\
\hline OW51657 & 25 & 7 & 7.536 & 0.747 & 1.760 & 0.101 \\
\hline OW5839 & 50 & 3 & 5.072 & 0.503 & 7.588 & 0.436 \\
\hline OW5840 & 25 & 2 & 0.180 & 0.018 & 5.508 & 0.316 \\
\hline OW5P165 & 225 & 1 & 0.325 & 0.032 & 0.156 & 0.009 \\
\hline OW5P244 & 75 & 2 & 0.756 & 0.075 & 1.620 & 0.093 \\
\hline
\end{tabular}


Figures 4.4 and 4.5 are the graphical representation for total real and reactive power of each distribution transformer modeled in the system, for peak and off-peak power demands. From the figure 4.4, it is observed that total real power demand for some service transformers are higher at 6.30AM (off-peak) than at 2.30PM (peak) and vice versa.

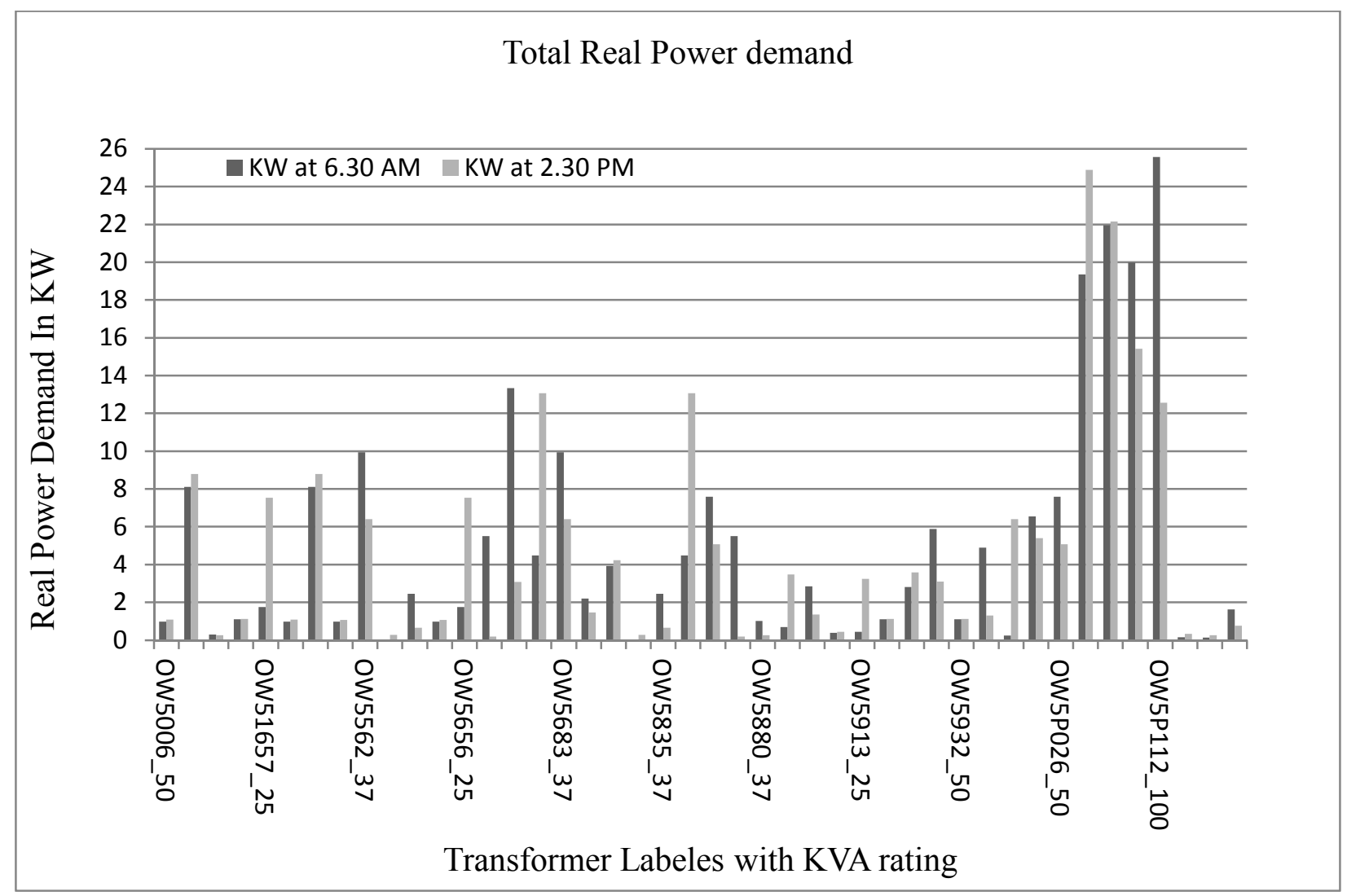

Figure 4.4 Total real power of each service transformer at peak and off-peak demand

Similarly from the figure 4.5 , it is observed that total reactive power demand for some service transformers are higher at 6.30AM (off-peak) than at 2.30PM (peak) and vice versa. 


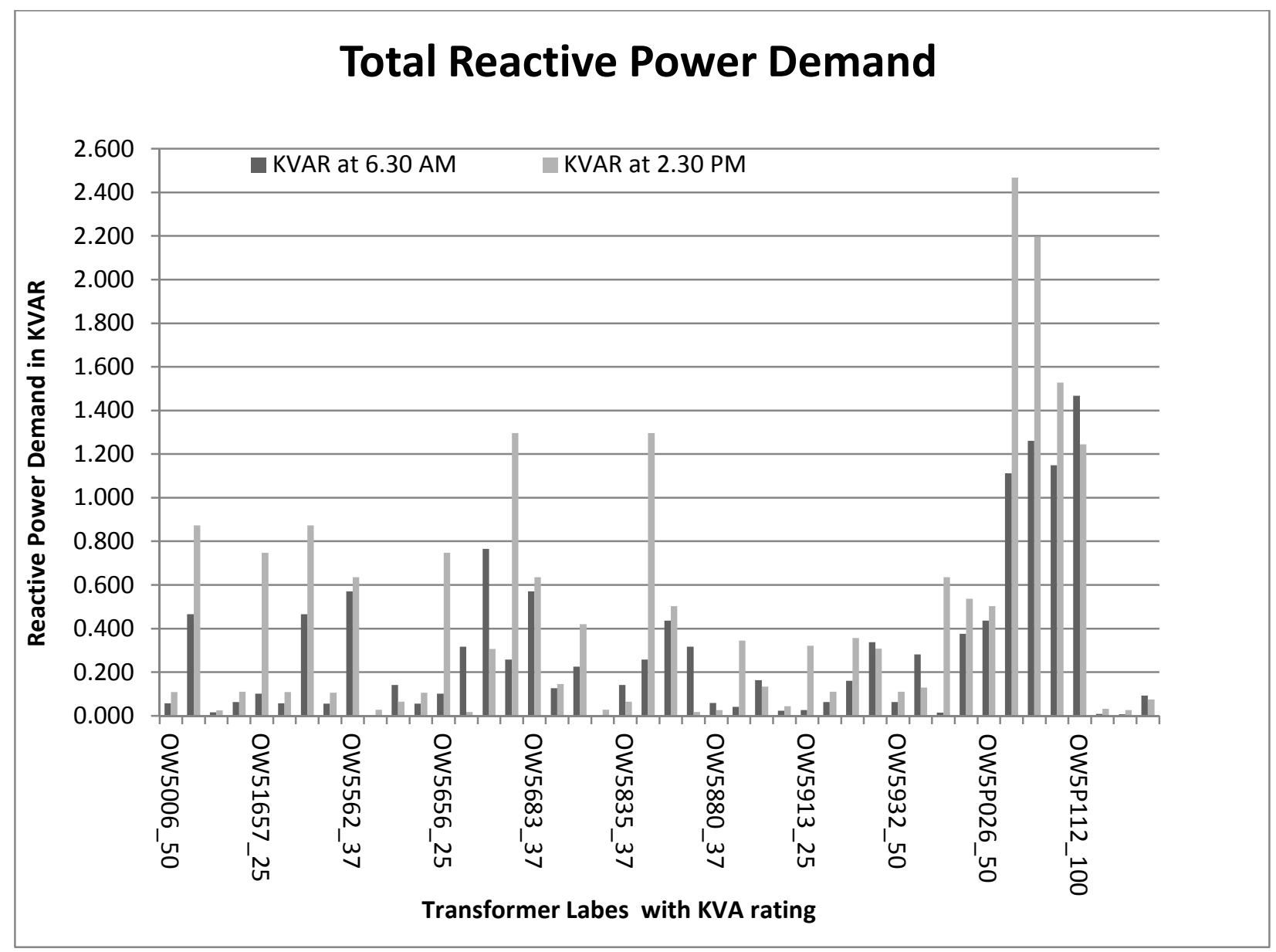

Figure 4.5 Total reactive power of each service transformer at peak and off-peak demand 


\section{CHATPER 5}

\section{CASE STUDY AND SIMULATION RESULTS}

As discussed in previous chapters, the modeled distribution system consists of two sections as shown in figure 5.1, which is a simplified drawing of the Simulink modeled distribution system. This system has a total of 177 customers, of which 174 customers are on single-phase and 3 customers are on three-phase for their daily use of electricity served by the 161/12.47 KV distribution substation. In order to assess the impact of PEV battery charging on the distribution system, various locations have been selected to measure the three-phase voltages based on the number of customers connected to the modeled $12.47 \mathrm{KV}$ distribution system at each of the selected locations.

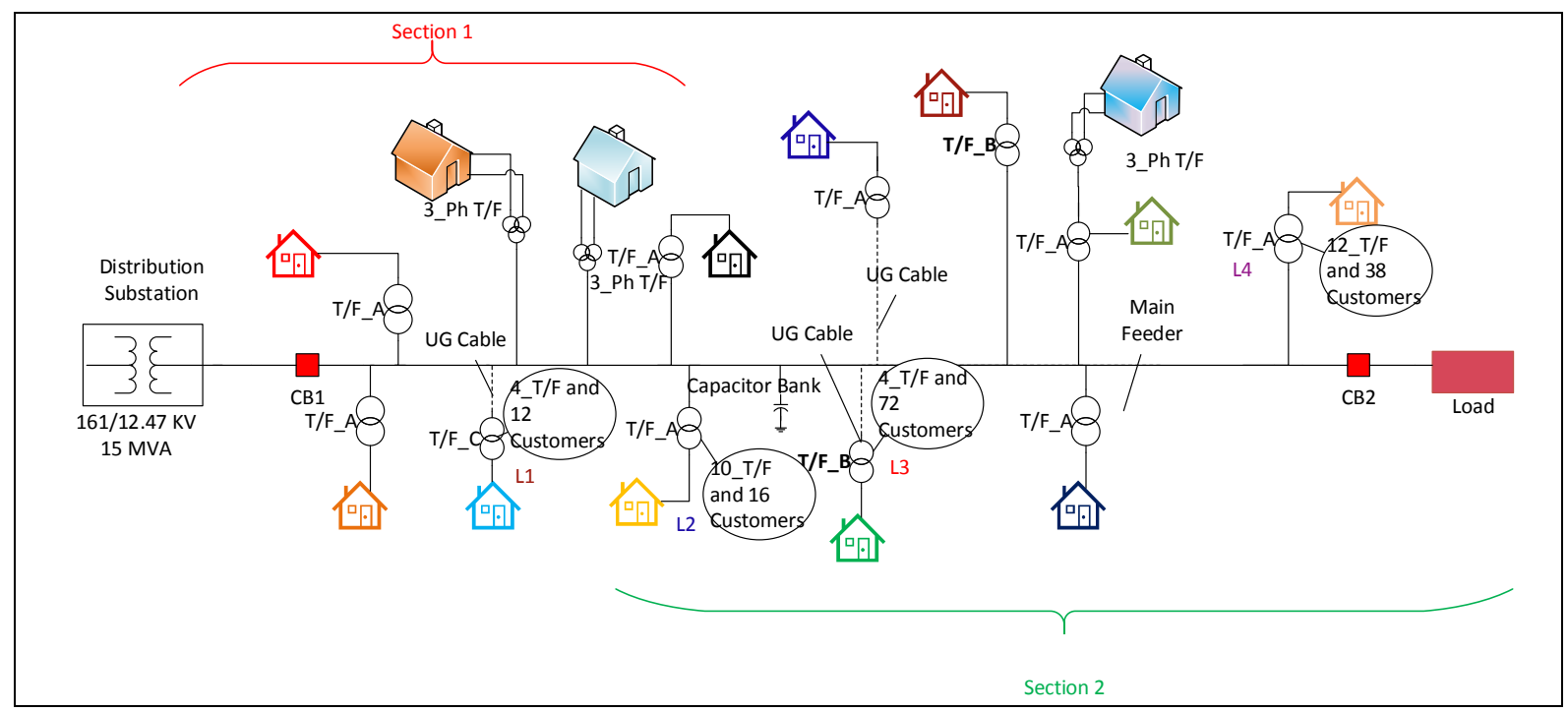

Figure 5.1 Simplified diagram of the modeled distribution system. 
In figure 5.1, L1, L2, L3, and L4 indicates the locations where the three-phase voltage and current measurements are being observed, because each of these locations have more than 10 customers connected to the sub branch line. The dotted lines in the figure 5.1 indicate underground cables. Also, three-phase measurements were observed at CB1 and CB2 to identify voltage variations at the beginning and at the end of the modeled system.

\subsection{Simulink model testing without PEV penetration}

\subsubsection{Voltages and currents at peak demand}

In order to establish a benchmark from which to compare PEV impact, the modeled distribution system is analyzed with no PEVs first. The distribution system is modeled for both peak and off-peak power demand. Figures 5.2 and 5.3 show three-phase peak voltages and currents measured at the beginning of the system (CB1) for peak demand (2.30 PM) on $01 / 10 / 2013$.

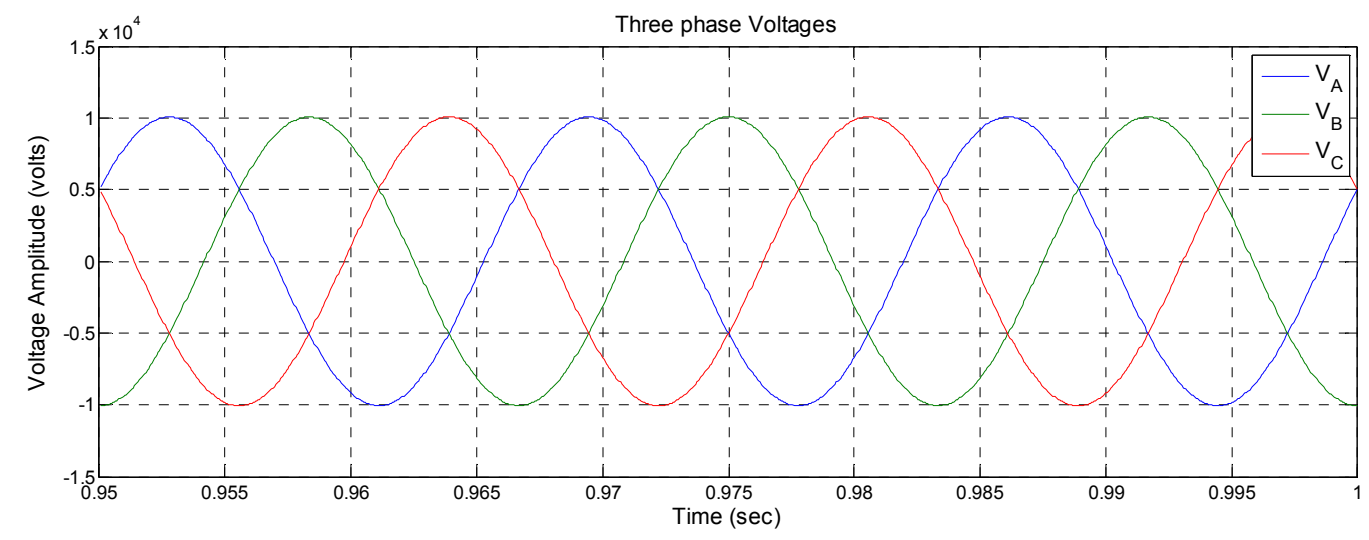

Figure 5.2 Measured three-phase voltages at CB1 of the system at peak demand 


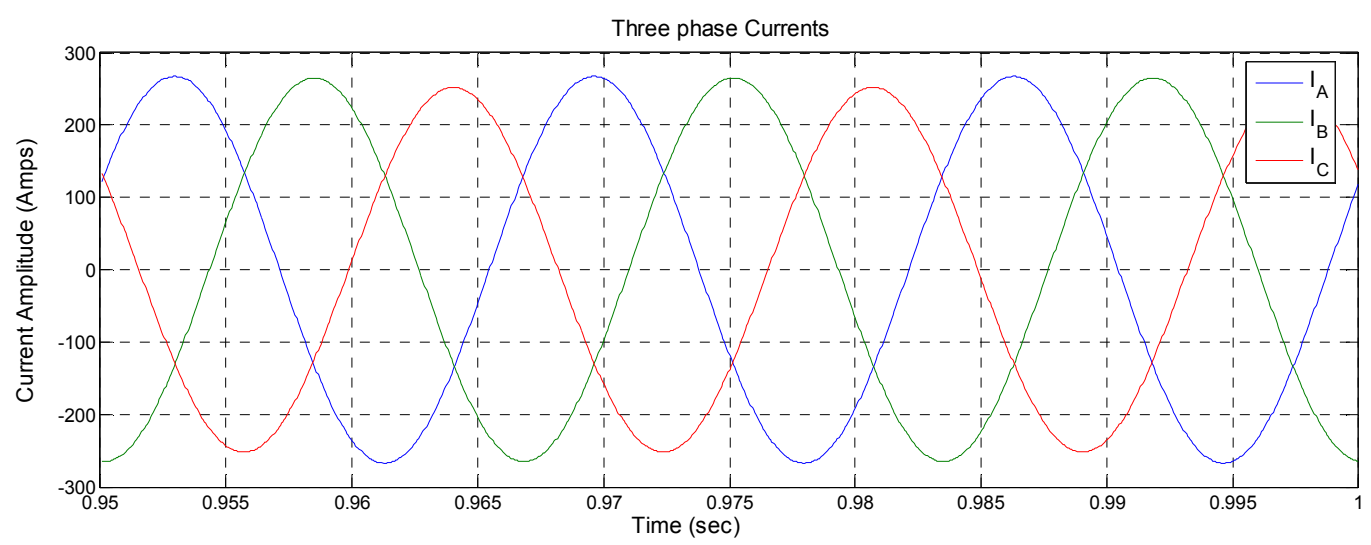

Figure 5.3 Measured three-phase currents at CB1 of the system at peak demand

Table 5.1 has the measured and actual voltages of phase to ground and phase currents at peak demand on 01/10/2013. Actual voltages shown in table 5.1 are provided by power distributor for the modeled distribution system. All voltages and currents shown in table 5.1 are measured in root mean square (RMS).

Table 5.1 Measured and actual phase voltages and currents at CB1 at peak demand

\begin{tabular}{|c|c|c|c|c|c|c|}
\hline At peak demand & \multicolumn{3}{|c|}{ Phase to ground voltages (KV) } & \multicolumn{3}{|c|}{ Phase currents (A) } \\
\hline \multirow[b]{2}{*}{ Measured Values } & $\mathrm{Va}$ & $\mathrm{Vb}$ & $\mathrm{Vc}$ & $\mathrm{Ia}$ & $\mathrm{Ib}$ & Ic \\
\hline & 7.112 & 7.113 & 7.117 & 189 & 187 & 178 \\
\hline Actual Values & 7.141 & 7.115 & 7.094 & 197 & 195 & 186 \\
\hline
\end{tabular}

Figures 5.4 and 5.5 show simulation results of three phase voltages and currents for CB2 at peak (2.30 AM) demand on 01/10/2013 for the modeled system respectively. 


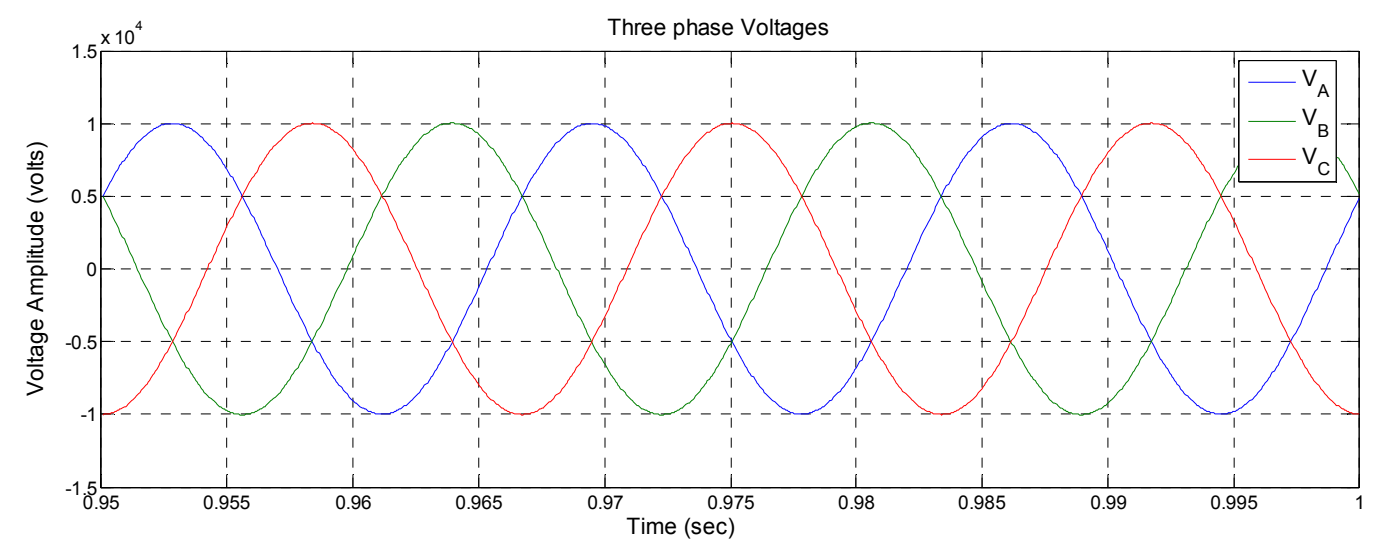

Figure 5.4 Measured three-phase voltages at CB2 of the system at peak demand

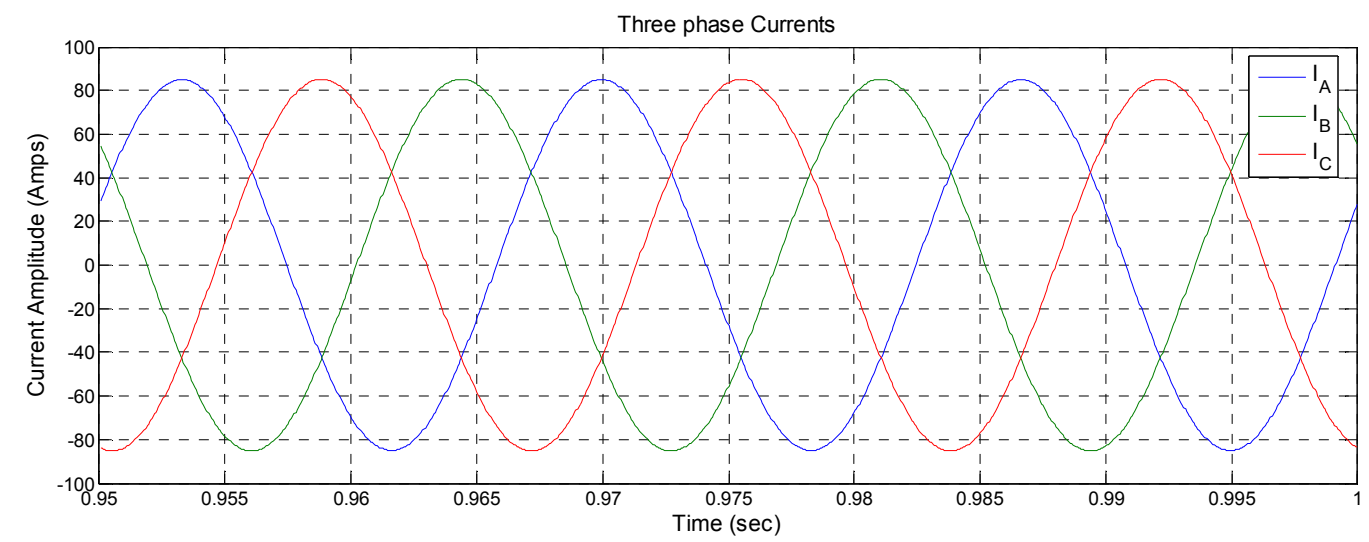

Figure 5.5 Measured three-phase currents at CB2 of the system at peak demand

Table 5.2 shows the measured and actual voltages of phase to ground and phase currents for peak demand on 01/10/2013.

Table 5.2 Measured and actual phase voltages and currents at CB2 at peak demand

\begin{tabular}{|c|c|c|c|c|c|c|}
\hline $\begin{array}{c}\text { At peak demand } \\
\text { for CB2 }\end{array}$ & \multicolumn{2}{|c|}{ Phase to ground rms voltages (KV) } & \multicolumn{3}{|c|}{ Phases currents (A) } \\
\hline \multirow{2}{*}{ Measured Values } & $\mathrm{Va}$ & $\mathrm{Vb}$ & $\mathrm{Vc}$ & $\mathrm{Ia}$ & $\mathrm{Ib}$ & $\mathrm{Ic}$ \\
\cline { 2 - 7 } & 7.066 & 7.087 & 7.081 & 60.1 & 60.26 & 60.21 \\
\hline Actual Values & 7.122 & 7.095 & 7.090 & 58.0 & 79.00 & 52.00 \\
\hline
\end{tabular}




\subsubsection{Voltages and currents at off-peak demand}

Figures 5.6 and 5.7 show measured three-phase peak voltages and currents at the beginning of the section (CB1) for off-peak power demand (6.30 AM) on 01/10/2013.

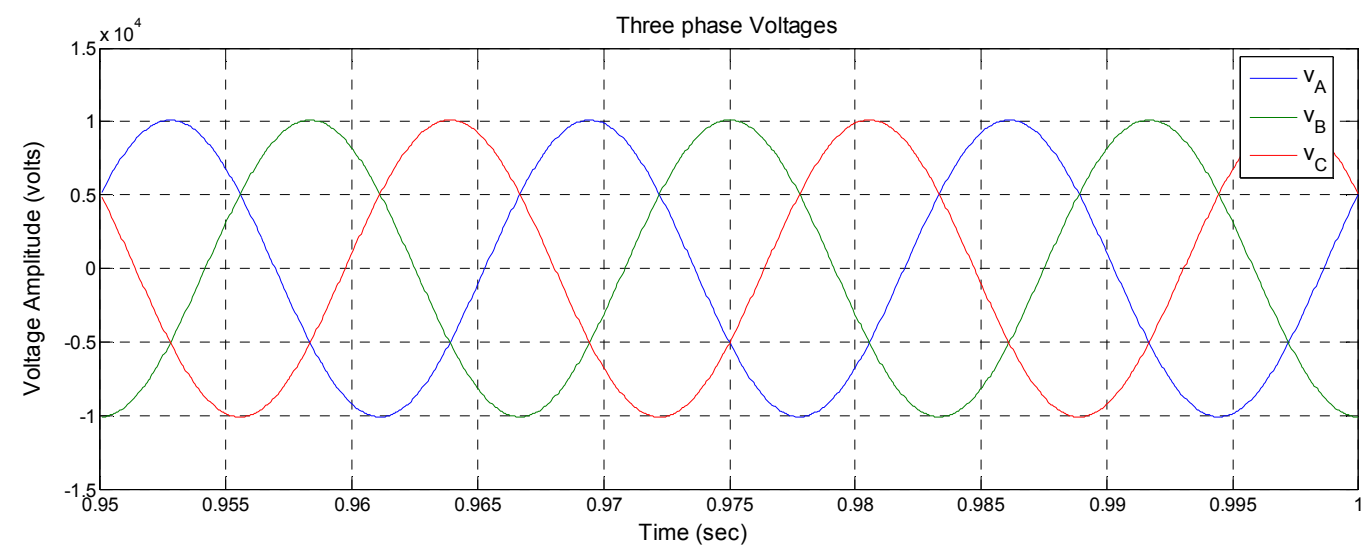

Figure 5.6 Measured three-phase voltages at CB1 of the system at off-peak demand

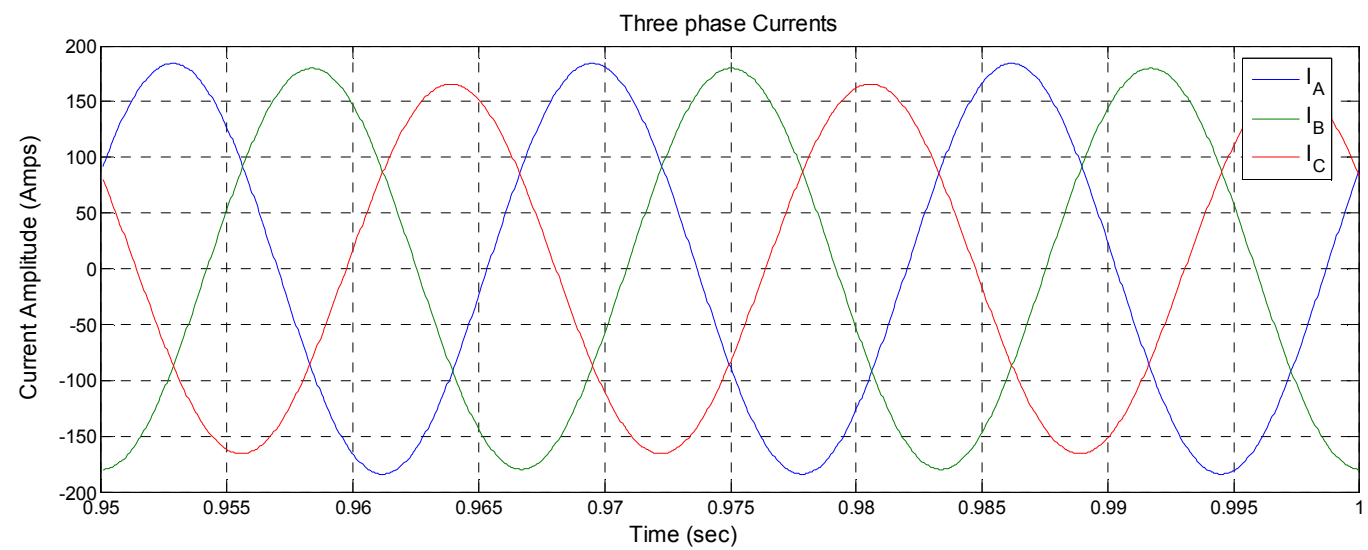

Figure 5.7 Measured three-phase currents at CB1 of the system at off- peak demand

Table 5.3 shows the measured and actual voltages of phase to ground and phase currents at off-peak demand on 01/10/2013. 
Table 5.3 Measured and actual phase voltages and currents at CB1 at off-peak demand

\begin{tabular}{|c|c|c|c|c|c|c|}
\hline $\begin{array}{c}\text { At off-peak demand } \\
\text { for CB1 }\end{array}$ & \multicolumn{2}{|l|}{ Phase to ground voltages (KV) } & \multicolumn{3}{|c|}{ Phase currents (A) } \\
\hline \multirow{2}{*}{ Measured Values } & 7.139 & 7.141 & 7.145 & 130.25 & 127.17 & 117.23 \\
\cline { 2 - 7 } & $\mathrm{Va}$ & $\mathrm{Vb}$ & $\mathrm{Vc}$ & $\mathrm{Ia}$ & $\mathrm{Ib}$ & $\mathrm{Ic}$ \\
\hline Actual Values & 7.120 & 7.100 & 7.069 & 135.00 & 131.00 & 123.00 \\
\hline
\end{tabular}

Figures 5.8 and 5.9 show simulation results of three phase voltages and currents for CB2 at off-peak (6.30 AM) demand on 01/10/2013 for the modeled system respectively.

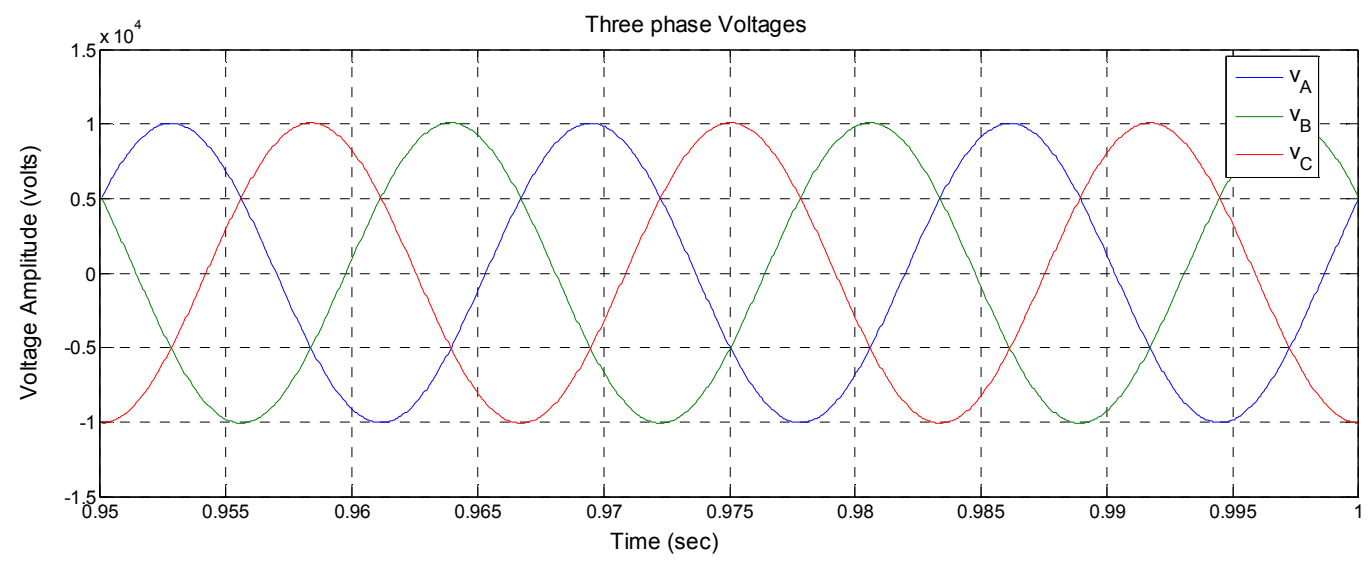

Figure 5.8 Measured three-phase voltages at CB2 of the system at off- peak demand 


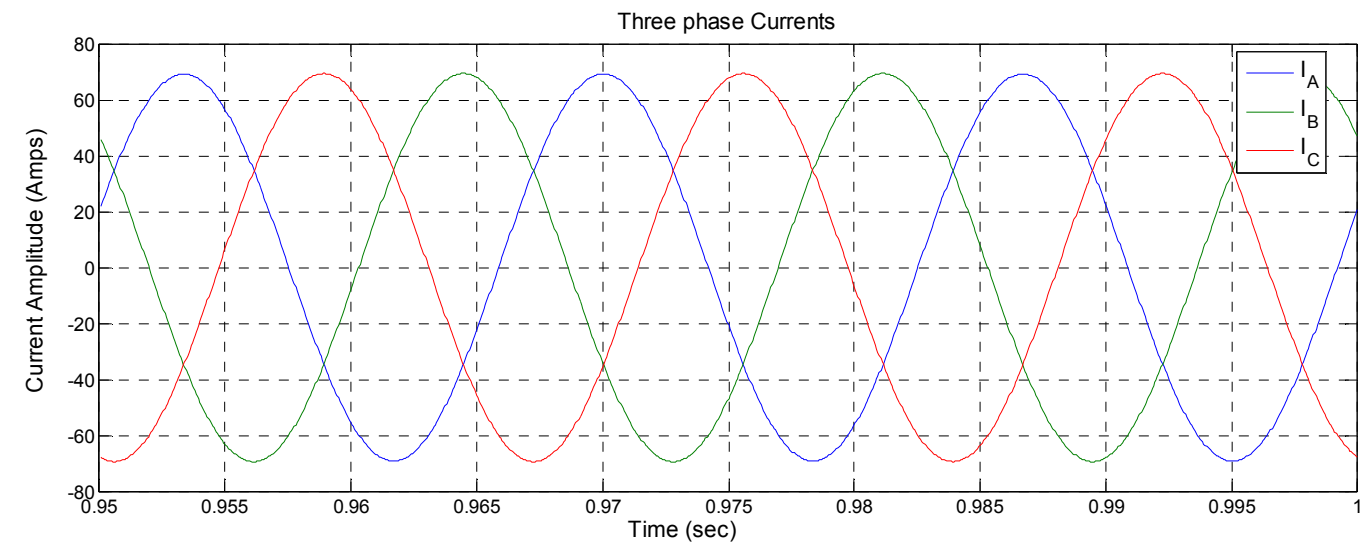

Figure 5.9 Measure three-phase currents at CB2 of the system at off- peak demand

Table 5.4 shows the measured and actual values of phase to ground voltages and phase to ground currents at off-peak demand on 01/10/2013.

Table 5.4 Measured and actual phase voltages and currents at CB2 at off-peak demand

\begin{tabular}{|c|c|c|c|c|c|c|}
\hline $\begin{array}{c}\text { At off-peak demand } \\
\text { For CB2 }\end{array}$ & \multicolumn{3}{|c|}{$\begin{array}{c}\text { Phase to ground rms voltages } \\
(\mathrm{KV})\end{array}$} & \multicolumn{3}{c|}{ Phase to ground rms currents (A) } \\
\hline \multirow{2}{*}{ Measured Values } & $\mathrm{Va}$ & $\mathrm{Vb}$ & $\mathrm{Vc}$ & $\mathrm{Ia}$ & $\mathrm{Ib}$ & Ic \\
\cline { 2 - 7 } & 7.106 & 7.127 & 7.124 & 48.93 & 49.01 & 49.06 \\
\hline Actual Values & 7.106 & 7.086 & 7.068 & 48.00 & 62.00 & 43.00 \\
\hline
\end{tabular}

\subsection{Simulink model testing with PEV penetration}

In this section, the modeled distribution system is being tested with Level 2 charging load during peak and off-peak power demand. As discussed in chapter 2, Level 2 charger has ratings of $240 \mathrm{~V}, 32 \mathrm{~A}$ and $7.680 \mathrm{KW}$. A single-phase level 2 charger can have significant impact on the distribution system, which is measured in terms of voltage unbalance. According to IEEE standards, voltage unbalance is defined as the ratio of maximum voltage deviation from the 
average phase voltage to the average phase voltage $[39,40]$. It is also known as the phase voltage unbalance rate (PVUR), and is given by

$$
\% \text { PVUR }=\frac{\text { Maximum voltage deviation from the average phase voltage }}{\text { Average phase voltage }} \times 100
$$

The IEEE uses the same definition of voltage unbalance as NEMA, the only difference being that the IEEE uses phase voltages rather than line-to-line voltages. In this study, percentage voltage unbalance (VU) calculations have been according to IEEE standards.

As discussed in initial section of this chapter, there are 174 single-phase residential customers utilizing electricity from the modeled distribution system. Out of these 174 customers, 81 customers have been drawing power from phase-A, 81 customers from phase-B, and 12 customers from phase-C.

\subsubsection{Studied system with $10 \%$ PEV penetration}

For $10 \%$ of PEV load, it is assumed that there are 17 customers $(\sim 10 \%$ of 174$)$ have a PEV in that neighborhood and recharge their PEV batteries. In this instance, for $10 \%$ of penetration level in simulation, out of 17 PEVs, 8 PEVs' load is added to the phase-A, 8 PEVs' load is added to the phase-B, and 1 PEV load is added to the phase-C. 


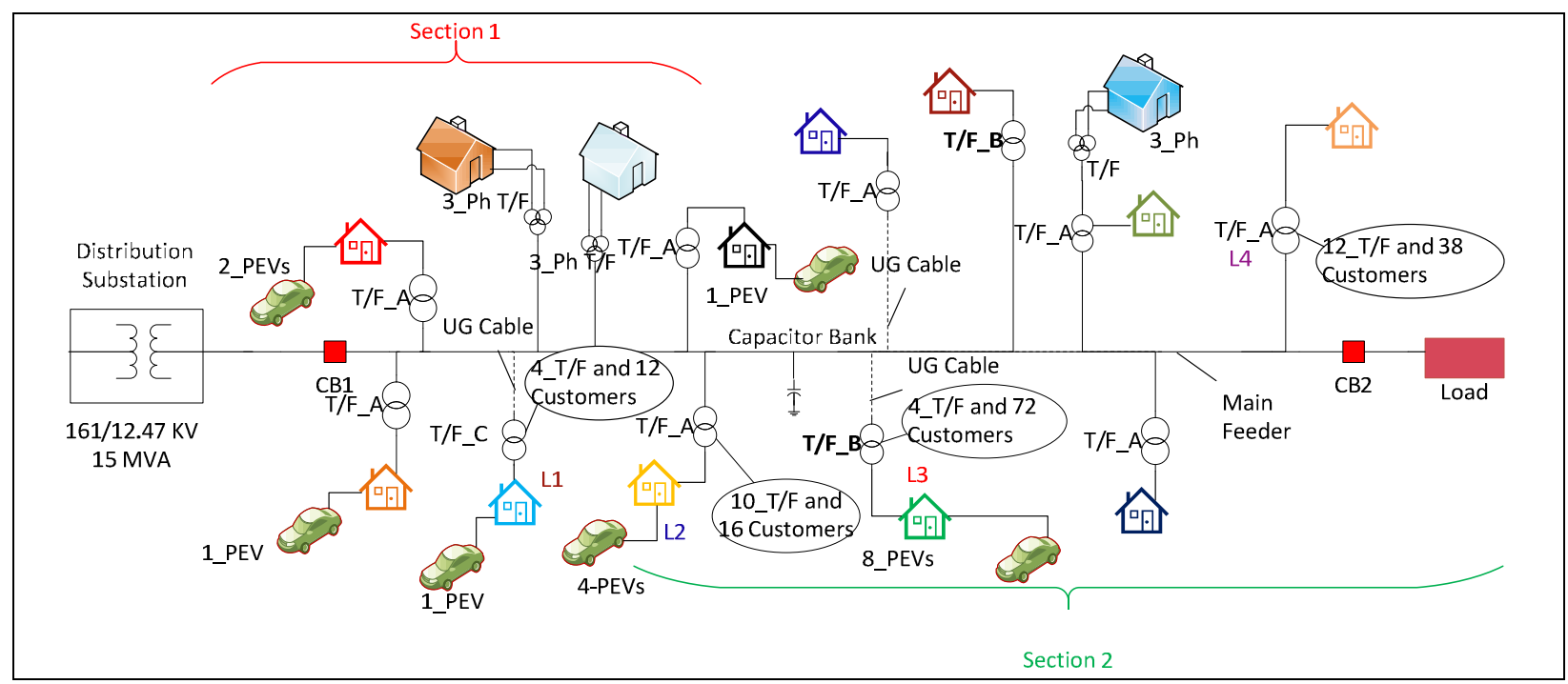

Figure 5.10 Distribution system model with 10\% of PEV penetration

Figure 5.10 shows distribution system model with $10 \%$ of penetration level, where the locations of PEV charging in each phase are shown with car symbols along with number of PEVs. Each phase in figure 5.10 can be identified based on ending character of transformers (example: The transformer "T/F_A" is in Phase-A).

Table 5.5 list the measured phase voltages, calculated voltage deviation, and percentage voltage unbalance for $10 \%$ penetration level of PEVs for both peak and off-peak power demand for all locations in the simulated system (CB1, L1, L2, L3, L4, CB2). 
Table 5.5 Phase voltages at peak and off-peak demand for $10 \%$ penetration of PEVs

\begin{tabular}{|c|c|c|c|c|c|c|c|c|c|}
\hline $\begin{array}{c}\text { PEV } \\
\text { Penetration } \\
\text { Level }\end{array}$ & $\begin{array}{c}\text { Power } \\
\text { Demand }\end{array}$ & & & CB1 & Location 1 & Location2 & Location3 & Location4 & CB2 \\
\hline \multirow{12}{*}{$10 \%$} & \multirow{6}{*}{ Peak } & \multirow{3}{*}{$\begin{array}{c}\text { Phase } \\
\text { Voltages } \\
\text { (V) } \\
\end{array}$} & VA & 7109.01 & 7079.03 & 7071.06 & 7067.06 & 7059.25 & 7057.80 \\
\hline & & & $\mathrm{VB}$ & 7109.73 & 7092.71 & 7088.25 & 7084.61 & 7079.27 & 7088.66 \\
\hline & & & $\mathrm{VC}$ & 7117.27 & 7101.14 & 7098.18 & 7096.43 & 7090.12 & 7077.80 \\
\hline & & \multicolumn{2}{|c|}{$\begin{array}{c}\text { Average } \\
\text { Voltage (V) }\end{array}$} & 7112.01 & 7090.96 & 7085.83 & 7082.70 & 7076.21 & 7074.76 \\
\hline & & \multicolumn{2}{|c|}{$\begin{array}{c}\text { Maximum } \\
\text { voltage } \\
\text { deviation (V) }\end{array}$} & 5.268 & 11.931 & 14.768 & 15.64 & 16.961 & 16.952 \\
\hline & & \multicolumn{2}{|c|}{$\begin{array}{l}\text { \% Voltage } \\
\text { Unbalance }\end{array}$} & 0.074 & 0.168 & 0.208 & 0.221 & 0.239 & 0.239 \\
\hline & \multirow{6}{*}{ Off-Peak } & \multirow{3}{*}{$\begin{array}{l}\text { Phase } \\
\text { Voltages } \\
\text { (V) }\end{array}$} & VA & 7135.93 & 7114.94 & 7108.81 & 7105.19 & 7098.32 & 7097.10 \\
\hline & & & VB & 7137.36 & 7131.29 & 7129.06 & 7126.07 & 7122.10 & 7129.21 \\
\hline & & & $\mathrm{VC}$ & 7145.30 & 7138.31 & 7137.11 & 7135.90 & 7130.44 & 7120.86 \\
\hline & & \multicolumn{2}{|c|}{$\begin{array}{c}\text { Average } \\
\text { Voltage (V) }\end{array}$} & 7139.53 & 7128.18 & 7125.02 & 7122.39 & 7116.95 & 7115.72 \\
\hline & & \multicolumn{2}{|c|}{$\begin{array}{c}\text { Maximum } \\
\text { voltage } \\
\text { deviation (V) }\end{array}$} & 5.766 & 13.236 & 16.206 & 17.199 & 18.63 & 18.623 \\
\hline & & \multicolumn{2}{|c|}{$\begin{array}{l}\% \text { Voltage } \\
\text { Unbalance }\end{array}$} & 0.081 & 0.186 & 0.227 & 0.241 & 0.262 & 0.262 \\
\hline
\end{tabular}

For $10 \%$ penetration level of PEVs, following deviations are observed from the beginning of simulated system (CB1) to the end of simulated system (CB2) at both the peak and off-peak demands.

At peak demand;

The increase in Maximum Voltage Deviation(V) from $\mathrm{CB} 1$ to $\mathrm{CB} 2=16.952-5.268=11.684 \mathrm{~V}$

The increase in \%Voltage Unbalance from CB1 to CB2 $=0.239-0.074=0.165$

At off-peak demand;

The increase in Maximum Voltage Deviation(V) from CB1 to CB2 $=18.623-5.766=12.857 \mathrm{~V}$

The increase in \%Voltage Unbalance from CB1 to CB2 $=0.262-0.081=0.181$ 
From the above, the increases in Maximum Voltage Deviation and \%Voltage Unbalance from $\mathrm{CB} 1$ to $\mathrm{CB} 2$ are almost similar at peak and off-peak demand for $10 \%$ level of PEV penetration.

\subsubsection{Studied system with 30\% PEV penetration}

For $30 \%$ of PEV load, it is assumed that there are 51 customers $(\sim 30 \%$ of 174$)$ have a PEV in that neighborhood and recharge their PEV batteries. In this instance, for $30 \%$ of penetration level in simulation, out of 51 PEVs, 24 PEVs' load is added to the phase-A, 24 PEVs' load is added to the phase-B, and 3 PEVs load is added to the phase-C.

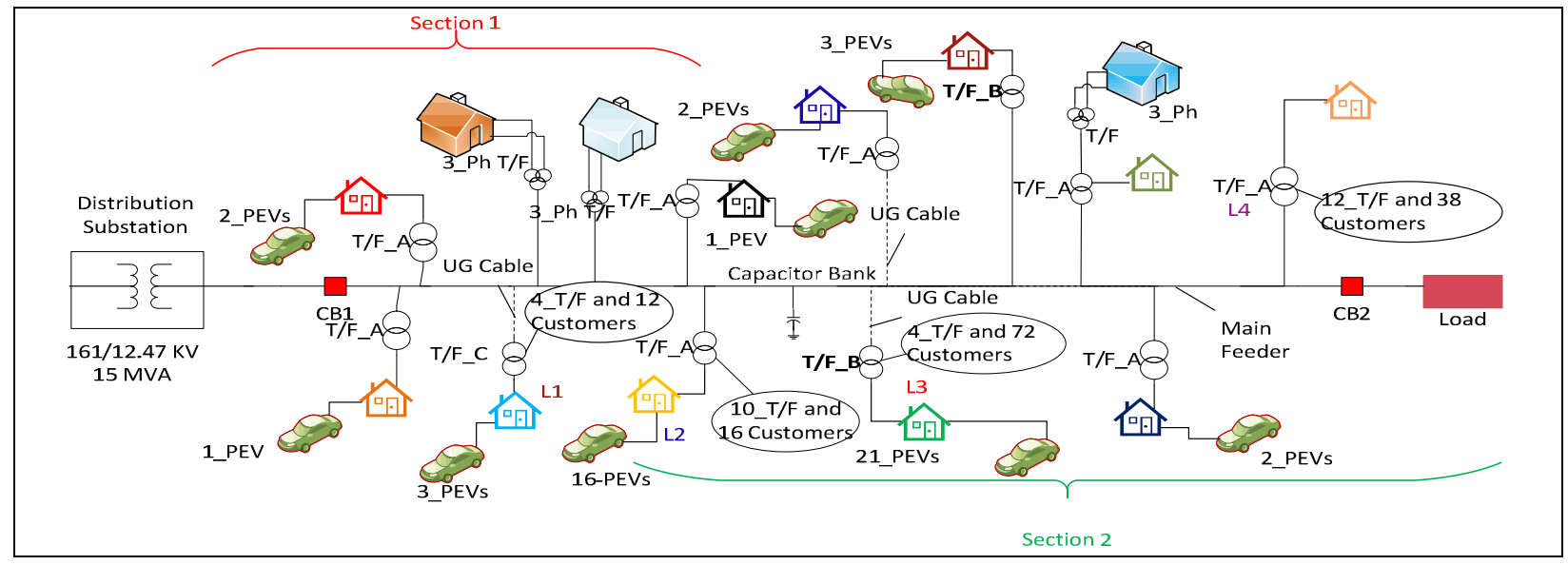

Figure 5.11 Distribution system model with $30 \%$ of PEV penetration

Figure 5.11 shows distribution system model with $30 \%$ of penetration level, where the locations of PEV charging in each phase are shown with car symbols along with number of 
PEVs. Each phase in figure 5.11 can be identified based on ending character of transformers (example: The transformer "T/F_A" is in Phase-A).

Tables 5.6 list the measured phase voltages, calculated voltage deviation, and percentage voltage unbalance for 30\% penetration level of PEVs for both peak and off-peak power demand for all locations in the simulated system (CB1, L1, L2, L3, L4, CB2).

Table 5.6 Phase voltages at peak and off-peak demand for 30\% penetration of PEVs

\begin{tabular}{|c|c|c|c|c|c|c|c|c|c|}
\hline $\begin{array}{c}\text { PEV } \\
\text { Penetration } \\
\text { Level }\end{array}$ & $\begin{array}{l}\text { Power } \\
\text { Demand }\end{array}$ & & & CB1 & Location 1 & Location2 & Location3 & Location 4 & CB2 \\
\hline \multirow{12}{*}{$30 \%$} & \multirow{6}{*}{ Peak } & \multirow{3}{*}{$\begin{array}{c}\text { Phase } \\
\text { Voltages } \\
\text { (V) }\end{array}$} & VA & 7101.68 & 7064.26 & 7053.91 & 7049.18 & 7041.02 & 7039.57 \\
\hline & & & VB & 7102.26 & 7087.14 & 7083.12 & 7078.62 & 7073.16 & 7091.48 \\
\hline & & & $\mathrm{VC}$ & 7116.29 & 7102.39 & 7100.20 & 7099.13 & 7092.94 & 7071.60 \\
\hline & & \multicolumn{2}{|c|}{$\begin{array}{l}\text { Average } \\
\text { Voltage }\end{array}$} & 7106.74 & 7084.60 & 7079.08 & 7075.65 & 7069.04 & 7067.58 \\
\hline & & \multicolumn{2}{|c|}{$\begin{array}{c}\text { Maximum } \\
\text { voltage } \\
\text { deviation } \\
\end{array}$} & 9.55 & 20.34 & 25.16 & 26.46 & 28.02 & 28.00 \\
\hline & & \multicolumn{2}{|c|}{$\begin{array}{l}\text { \% Voltage } \\
\text { Unbalance }\end{array}$} & 0.134 & 0.287 & 0.355 & 0.374 & 0.396 & 0.396 \\
\hline & \multirow{6}{*}{ Off-Peak } & \multirow{3}{*}{$\begin{array}{c}\text { Phase } \\
\text { Voltages } \\
\text { (V) }\end{array}$} & VA & 7128.48 & 7099.98 & 7091.43 & 7087.07 & 7079.98 & 7078.76 \\
\hline & & & VB & 7129.83 & 7125.88 & 7124.12 & 7120.28 & 7116.47 & 7131.73 \\
\hline & & & $\mathrm{VC}$ & 7144.32 & 7139.49 & 7139.12 & 7138.52 & 7132.96 & 7115.22 \\
\hline & & \multicolumn{2}{|c|}{$\begin{array}{l}\text { Average } \\
\text { Voltage }\end{array}$} & 7134.24 & 7121.78 & 7118.22 & 7115.29 & 7109.80 & 7108.57 \\
\hline & & \multicolumn{2}{|c|}{$\begin{array}{l}\text { Maximum } \\
\text { voltage } \\
\text { deviation }\end{array}$} & 10.10 & 21.80 & 26.79 & 28.21 & 29.82 & 29.81 \\
\hline & & \multicolumn{2}{|c|}{$\begin{array}{l}\text { \% Voltage } \\
\text { Unbalance }\end{array}$} & 0.142 & 0.306 & 0.376 & 0.397 & 0.419 & 0.419 \\
\hline
\end{tabular}

For $30 \%$ penetration level of PHEVs, following deviations are observed from the beginning of simulated system (CB1) to the end of simulated system (CB2) at both the peak and off-peak demands.

At peak demand;

The increase in Maximum Voltage Deviation from $\mathrm{CB} 1$ to $\mathrm{CB} 2=28.006-9.55=18.456 \mathrm{~V}$ 
The increase in \%Voltage Unbalance from CB1 to CB2 $=0.396-0.134=0.262$

At off-peak demand;

The increase in Maximum Voltage Deviation (V) from CB1 to CB2 $=29.812-10.109=19.7 \mathrm{~V}$

The increase in \%Voltage Unbalance from CB1 to CB2 $=0.419-0.142=0.277$

From the above, the increases in Maximum Voltage Deviation (V) and \%Voltage Unbalance from CB1 to CB2 are almost similar at peak and off-peak demand for $30 \%$ level of PEV penetration. However from $10 \%$ level of PEV penetration, there is a significant increase $(>50 \%)$ in the differences between $\mathrm{CB} 1$ and CB2. For example: The difference in increase in Maximum Voltage Deviation from CB1 to CB2 at 30\% level of PEV penetration at peak demand $(18.456 \mathrm{~V})$ and at $10 \%$ level of PHEV penetration $(11.684 \mathrm{~V})$ is $6.772 \mathrm{~V}$.

\subsubsection{Studied system with 50\% PEV penetration}

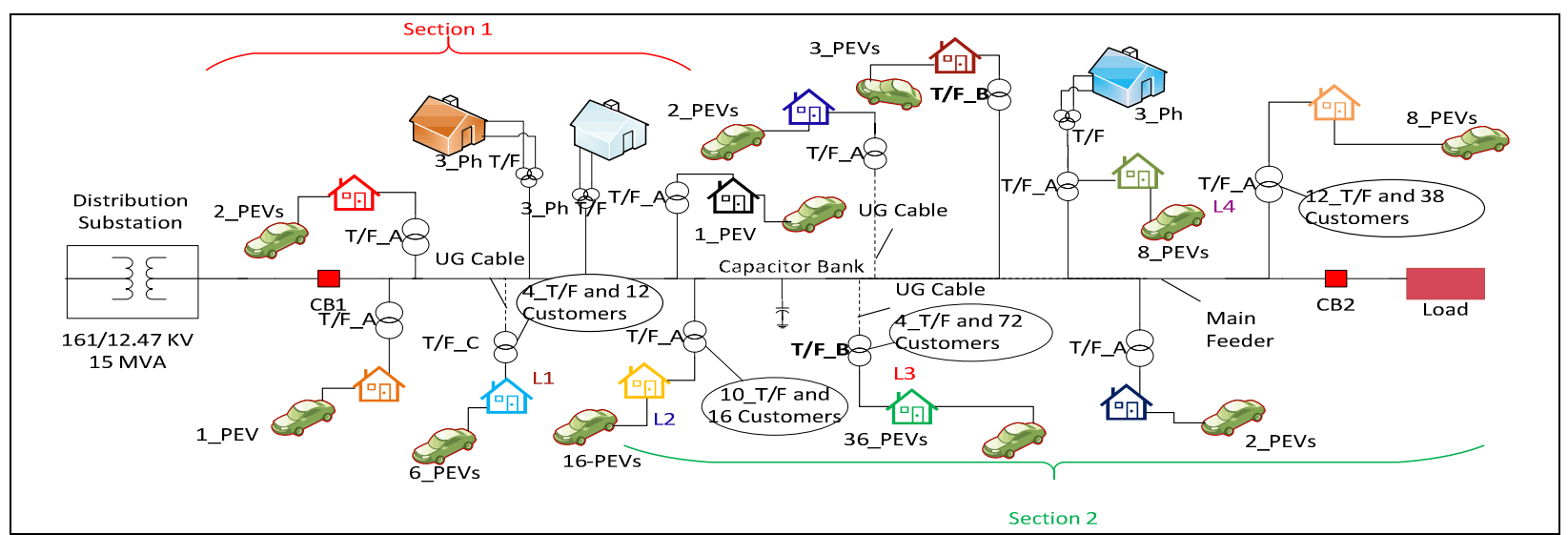

Figure 5.12 Distribution system model with 50\% of PEV penetration

For $50 \%$ of PEV load, it is assumed that there are 87 customers (50\% of 174) have a PEV in that neighborhood and recharge their PEV batteries. In this instance, for $50 \%$ of penetration 
level in simulation, out of 87 PEVs, 40 PEVs' load is added to the phase-A, 41 PEVs' load is added to the phase-B, and 6 PEVs load is added to the phase-C. Figure 5.12 shows distribution system model with $50 \%$ of penetration level, where the locations of PEV charging in each phase are shown with car symbols along with number of PEVs. Each phase in figure 5.12 can be identified based on ending character of transformers (example: The transformer "T/F_A" is in Phase-A).

Table 5.7 list the measured phase voltages, calculated voltage deviation, and percentage voltage unbalance for 50\% penetration level of PEVs for both peak and off-peak power demand for all locations in the simulated system (CB1, L1, L2, L3, L4, CB2).

Table 5.7 Phase voltages at peak and off-peak demand for 50\% penetration of PEVs

\begin{tabular}{|c|c|c|c|c|c|c|c|c|c|}
\hline $\begin{array}{c}\text { PEV } \\
\text { Penetration } \\
\text { Level }\end{array}$ & $\begin{array}{l}\text { Power } \\
\text { Demand }\end{array}$ & & & CB1 & Location 1 & Location2 & Location3 & Location4 & CB2 \\
\hline \multirow{12}{*}{$50 \%$} & \multirow{6}{*}{ Peak } & \multirow{3}{*}{$\begin{array}{l}\text { Phase } \\
\text { Voltages } \\
\text { (KV) }\end{array}$} & VA & 7094.424 & 7050.019 & 7037.273 & 7031.041 & 7020.987 & 7019.549 \\
\hline & & & VB & 7094.866 & 7081.291 & 7077.707 & 7072.955 & 7068.919 & 7092.325 \\
\hline & & & $\mathrm{VC}$ & 7114.866 & 7102.936 & 7101.580 & 7100.835 & 7093.779 & 7067.438 \\
\hline & & \multicolumn{2}{|c|}{$\begin{array}{l}\text { Average } \\
\text { Voltage }\end{array}$} & 7101.385 & 7078.082 & 7072.187 & 7068.277 & 7061.228 & 7059.771 \\
\hline & & \multicolumn{2}{|c|}{$\begin{array}{l}\text { Maximum } \\
\text { voltage } \\
\text { deviation }\end{array}$} & 13.481 & 28.063 & 34.913 & 37.236 & 40.242 & 40.221 \\
\hline & & \multicolumn{2}{|c|}{$\begin{array}{l}\% \text { Voltage } \\
\text { Unbalance }\end{array}$} & 0.19 & 0.396 & 0.494 & 0.527 & 0.57 & 0.57 \\
\hline & \multirow{6}{*}{ Off-Peak } & \multirow{3}{*}{$\begin{array}{c}\text { Phase } \\
\text { Voltages } \\
(\mathrm{KV}) \\
\end{array}$} & $\mathrm{VA}$ & 7121.093 & 7085.254 & 7074.208 & 7068.297 & 7059.022 & 7057.805 \\
\hline & & & VB & 7122.37 & 7120.225 & 7118.953 & 7114.854 & 7112.393 & 7132.717 \\
\hline & & & $\mathrm{VC}$ & 7142.898 & 7140.043 & 7140.518 & 7140.257 & 7133.948 & 7111.138 \\
\hline & & \multicolumn{2}{|c|}{$\begin{array}{l}\text { Average } \\
\text { Voltage }\end{array}$} & 7128.787 & 7115.174 & 7111.226 & 7107.803 & 7101.788 & 7100.553 \\
\hline & & \multicolumn{2}{|c|}{$\begin{array}{l}\text { Maximum } \\
\text { voltage } \\
\text { deviation }\end{array}$} & 14.111 & 29.92 & 37.018 & 39.506 & 42.765 & 42.748 \\
\hline & & \multicolumn{2}{|c|}{$\begin{array}{l}\% \text { Voltage } \\
\text { Unbalance }\end{array}$} & 0.198 & 0.421 & 0.521 & 0.556 & 0.602 & 0.602 \\
\hline
\end{tabular}


For $50 \%$ penetration level of PEVs, following deviations are observed from the beginning of simulated system (CB1) to the end of simulated system (CB2) at both the peak and off-peak demands.

At peak demand;

The increase in Maximum Voltage Deviation (V) from CB1 to CB2 $=40.221-13.48=26.74 \mathrm{~V}$

The increase in \%Voltage Unbalance from $\mathrm{CB} 1$ to $\mathrm{CB} 2=0.57-0.19=0.38$

At off-peak demand;

The increase in Maximum Voltage Deviation (V) from CB1 to CB2 $=42.748-4.111=28.637 \mathrm{~V}$

The increase in \%Voltage Unbalance from CB1 to CB2 $=0.602-0.198=0.404 \mathrm{~V}$

From the above, the increases in Maximum Voltage Deviation and \%Voltage Unbalance from CB1 to CB2 vary slightly at peak and off-peak demand for 50\% level of PEV penetration. In addition, from $30 \%$ level of PEV penetration, there is an increase observed in the differences between $\mathrm{CB} 1$ and $\mathrm{CB} 2$ at peak and off-peak demand.

\subsubsection{Simulink model with 60\% PEV penetration}

For $60 \%$ of PEV load, it is assumed that there are 104 customers $(\sim 60 \%$ of 174$)$ have a PEV in that neighborhood and recharge their PEV batteries. In this instance, for $60 \%$ of penetration level in simulation, out of 104 PEVs, 49 PEVs' load is added to the phase-A, 48 PEVs' load is added to the phase- $\mathrm{B}$, and 7 PEVs load is added to the phase-C. Figure 5.13 shows distribution system model with $60 \%$ of penetration level, where the locations of PEV charging in each phase are shown with car symbols along with number of PEVs. Each phase in figure 5.13

can be identified based on ending character of transformers (example: The transformer "T/F_A" is in Phase-A). 


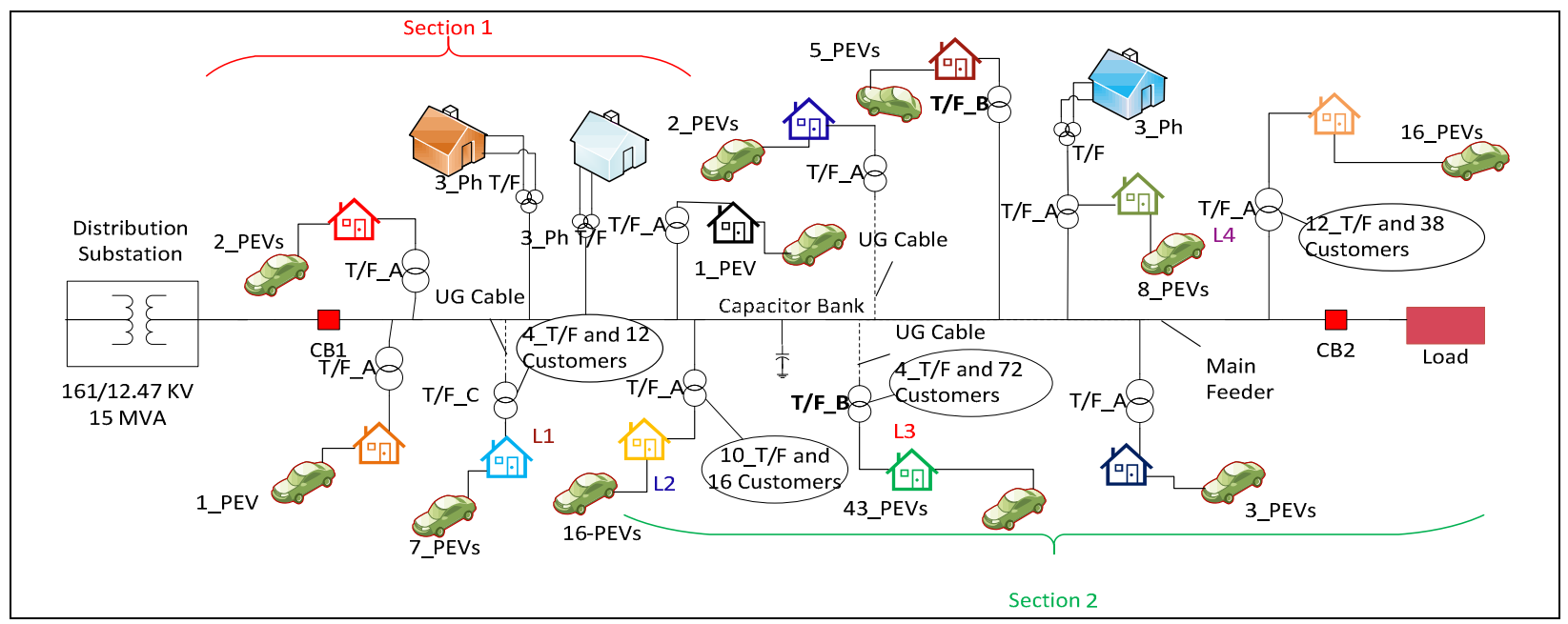

Figure 5.13 Distribution system model with $60 \%$ of PEV penetration

Table 5.8 Phase voltages at peak and off-peak demand for $60 \%$ penetration of PEVs

\begin{tabular}{|c|c|c|c|c|c|c|c|c|c|}
\hline $\begin{array}{c}\text { PEV } \\
\text { Penetration } \\
\text { Level } \\
\end{array}$ & $\begin{array}{c}\text { Power } \\
\text { Demand }\end{array}$ & & & CB1 & Location 1 & Location 2 & Location3 & Location4 & CB2 \\
\hline \multirow{12}{*}{$60 \%$} & \multirow{6}{*}{ Peak } & \multirow{3}{*}{$\begin{array}{c}\text { Phase } \\
\text { Voltages } \\
\text { (V) }\end{array}$} & VA & 7090.940 & 7041.760 & 7027.563 & 7020.452 & 7008.996 & 7007.563 \\
\hline & & & VB & 7091.205 & 7078.525 & 7075.160 & 7070.284 & 7066.857 & 7093.987 \\
\hline & & & $\mathrm{VC}$ & 7114.402 & 7104.084 & 7103.236 & 7102.709 & 7095.439 & 7065.371 \\
\hline & & \multicolumn{2}{|c|}{$\begin{array}{l}\text { Average } \\
\text { Voltage }\end{array}$} & 7098.849 & 7074.790 & 7068.653 & 7064.482 & 7057.097 & 7055.641 \\
\hline & & \multicolumn{2}{|c|}{$\begin{array}{c}\text { Maximum } \\
\text { voltage } \\
\text { deviation } \\
\end{array}$} & 15.553 & 33.029 & 41.09 & 44.029 & 48.101 & 48.077 \\
\hline & & \multicolumn{2}{|c|}{$\begin{array}{l}\% \text { Voltage } \\
\text { Unbalance }\end{array}$} & 0.219 & 0.467 & 0.581 & 0.623 & 0.682 & 0.681 \\
\hline & \multirow{6}{*}{ Off-Peak } & \multirow{3}{*}{$\begin{array}{c}\text { Phase } \\
\text { Voltages } \\
\text { (V) }\end{array}$} & VA & 7117.607 & 7076.512 & 7063.89 & 7057.045 & 7046.21 & 7044.997 \\
\hline & & & $\mathrm{VB}$ & 7118.662 & 7117.495 & 7116.451 & 7112.223 & 7110.273 & 7134.771 \\
\hline & & & $\mathrm{VC}$ & 7142.443 & 7141.386 & 7142.419 & 7142.402 & 7136.001 & 7109.015 \\
\hline & & \multicolumn{2}{|c|}{$\begin{array}{l}\text { Average } \\
\text { Voltage }\end{array}$} & 7126.237 & 7111.797 & 7107.586 & 7103.89 & 7097.495 & 7096.261 \\
\hline & & \multicolumn{2}{|c|}{$\begin{array}{l}\text { Maximum } \\
\text { voltage } \\
\text { deviation }\end{array}$} & 16.206 & 35.286 & 43.697 & 46.845 & 51.285 & 51.264 \\
\hline & & \multicolumn{2}{|c|}{$\begin{array}{l}\text { \% Voltage } \\
\text { Unbalance }\end{array}$} & 0.227 & 0.496 & 0.615 & 0.659 & 0.723 & 0.722 \\
\hline
\end{tabular}


Table 5.8 list the measured phase voltages, calculated voltage deviation, and percentage voltage unbalance for $60 \%$ penetration level of PEVs for both peak and off-peak power demand for all locations in the simulated system (CB1, L1, L2, L3, L4, CB2).

For $60 \%$ penetration level of PEVs, following deviations are observed from the beginning of simulated system (CB1) to the end of simulated system (CB2) at both the peak and off-peak demands.

At peak demand;

The increase in Maximum Voltage Deviation (V) from CB1 to CB2 $=48.077-15.553=32.524 \mathrm{~V}$

The increase in \%Voltage Unbalance from CB1 to CB2 $=0.681-0.219=0.462$

At off-peak demand;

The increase in Maximum Voltage Deviation from CB1 to CB2 $=51.264-16.206=35.058 \mathrm{~V}$

The increase in \%Voltage Unbalance from CB1 to CB2 $=0.722-0.227=0.495 \mathrm{~V}$

From the above, the increases in Maximum Voltage Deviation and \%Voltage Unbalance from $\mathrm{CB} 1$ to $\mathrm{CB} 2$ vary at peak and off-peak demand for $60 \%$ level of PEV penetration. In addition, from $50 \%$ level of PEV penetration, there is an increase observed in the differences between $\mathrm{CB} 1$ and $\mathrm{CB} 2$ at peak and off-peak demand.

As shown in above table 5.9, almost all the Phase-B transformers in simulated system are either overloaded (measured currents in red colored cells) or close to be overloaded (measured currents in orange colored cells) by the PEV penetration level of $60 \%$. The ratings against which these loads are compared are highlighted in blue colored cells. 
Table 5.9 Rated and Measured Currents for Phase-B Transformers in the simulated system

\begin{tabular}{|c|c|c|c|c|c|c|c|c|}
\hline Phase & $\begin{array}{c}\text { Power } \\
\text { demand }\end{array}$ & $\begin{array}{l}\text { Transformer } \\
\text { KVA rating }\end{array}$ & $\begin{array}{c}\text { No. of } \\
\text { Customers } \\
\text { Connected }\end{array}$ & $\begin{array}{l}\text { Rated } \\
\text { Current } \\
\text { at } 240 \mathrm{~V} \\
\text { (Amps) }\end{array}$ & $\begin{array}{c}\text { Measured } \\
\text { Current at } \\
240 \mathrm{~V} \\
\text { (Amps) } \\
\text { At } 10 \% \\
\text { PEV } \\
\text { penetration }\end{array}$ & $\begin{array}{c}\text { Measured } \\
\text { Current at } \\
240 \mathrm{~V} \\
\text { (Amps) } \\
\text { At } 30 \% \\
\text { PEV } \\
\text { penetration }\end{array}$ & $\begin{array}{c}\text { Measured } \\
\text { Current at } \\
240 \mathrm{~V} \\
\text { (Amps) } \\
\text { At } 50 \% \\
\text { PEV } \\
\text { penetration }\end{array}$ & $\begin{array}{c}\text { Measured } \\
\text { Current at } \\
240 \mathrm{~V} \\
\text { (Amps) } \\
\text { At } 60 \% \\
\text { PEV } \\
\text { penetration }\end{array}$ \\
\hline \multirow{10}{*}{ B } & \multirow{5}{*}{ Peak } & 37 & 9 & 154.17 & 80.190 & 141.52 & 141.52 & 171.82 \\
\hline & & 100 & 18 & 416.67 & 214.98 & 307.14 & 398.59 & 428.86 \\
\hline & & 100 & 18 & 416.67 & 198.30 & 290.59 & 382.17 & 412.48 \\
\hline & & 100 & 18 & 416.67 & 157.13 & 280.53 & 402.60 & 463.12 \\
\hline & & 100 & 18 & 416.67 & 139.66 & 232.41 & 385.44 & 446.02 \\
\hline & \multirow{5}{*}{$\begin{array}{l}\text { Off- } \\
\text { peak }\end{array}$} & 37 & 9 & 154.17 & 27.730 & 27.710 & 151.78 & 151.78 \\
\hline & & 100 & 18 & 416.67 & 181.99 & 305.99 & 398.01 & 458.92 \\
\hline & & 100 & 18 & 416.67 & 197.98 & 321.81 & 413.72 & 444.07 \\
\hline & & 100 & 18 & 416.67 & 185.89 & 309.81 & 401.77 & 462.62 \\
\hline & & 100 & 18 & 416.67 & 219.95 & 343.50 & 404.60 & 495.86 \\
\hline
\end{tabular}

Given that it has been deemed for simulation that no more PEV loads can be added to Phase - B for additional levels of PEV penetration, i.e. during the $70 \%$ and $80 \%$ PEV penetration levels, the number of PEVs added to Phase - B remain constant at 48.

\subsubsection{Studied system with 70\% PEV penetration}

For $70 \%$ of PEV load, it is assumed that there are 122 customers $(\sim 70 \%$ of 174$)$ have a PEV in that neighborhood and recharge their PEV batteries. In this instance, for $70 \%$ of penetration level in simulation, out of 122 PEVs, 64 PEVs' load is added to the phase-A, 48 PEVs' load is added to the phase-B (same as at $60 \%$ penetration level), and 10 PEVs load is added to the phase-C. 


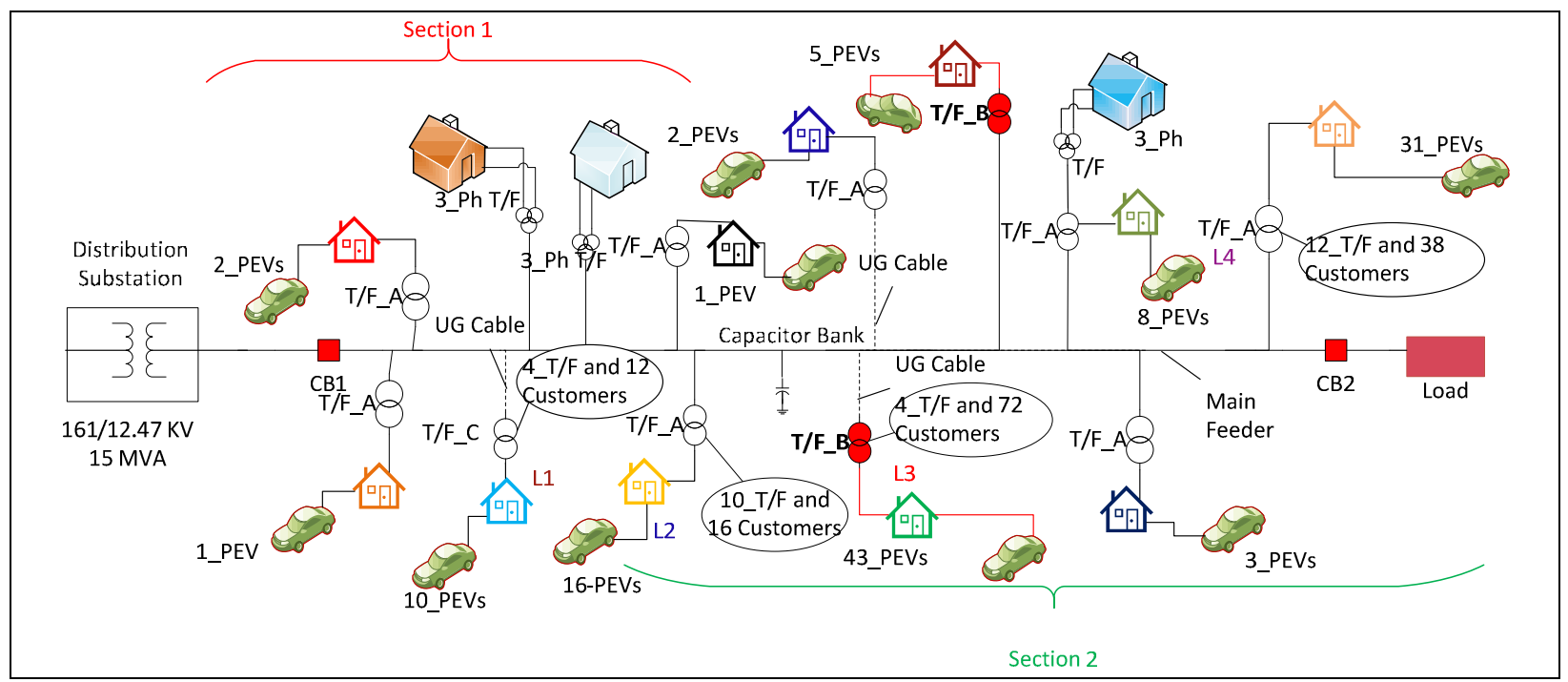

Figure 5.14 Distribution system model with $70 \%$ of PEV penetration

Figure 5.14 shows distribution system model with $70 \%$ of penetration level, where the locations of PEV charging in each phase are shown with car symbols along with number of PEVs. Each phase in figure 5.14 can be identified based on ending character of transformers (example: The transformer "T/F_A" is in Phase-A).

Table 5.9 list the measured phase voltages, calculated voltage deviation, and percentage voltage unbalance for $70 \%$ penetration level of PEVs for both peak and off-peak power demand for all locations in the simulated system (CB1, L1, L2, L3, L4, CB2). 
Table 5.10 Phase voltages at peak and off-peak demand for $70 \%$ penetration of PEVs

\begin{tabular}{|c|c|c|c|c|c|c|c|c|c|}
\hline $\begin{array}{c}\text { PEV } \\
\text { Penetration } \\
\text { Level }\end{array}$ & $\begin{array}{c}\text { Power } \\
\text { Demand }\end{array}$ & & & CB1 & Location 1 & Location 2 & Location3 & Location4 & $\mathrm{CB} 2$ \\
\hline \multirow{12}{*}{$70 \%$} & \multirow{6}{*}{ Peak } & \multirow{3}{*}{$\begin{array}{c}\text { Phase } \\
\text { Voltages } \\
(\mathrm{KV})\end{array}$} & VA & 7079.695 & 7021.441 & 7004.331 & 6995.801 & 6981.459 & 6980.02 \\
\hline & & & VB & 7091.011 & 7087.645 & 7086.564 & 7082.330 & 7080.233 & 7085.12 \\
\hline & & & $\mathrm{VC}$ & 7112.217 & 7096.153 & 7094.765 & 7094.107 & 7086.556 & 7078.73 \\
\hline & & \multicolumn{2}{|c|}{$\begin{array}{l}\text { Average } \\
\text { Voltage }\end{array}$} & 7094.308 & 7068.413 & 7061.887 & 7057.412 & 7049.416 & 7047.96 \\
\hline & & \multicolumn{2}{|c|}{$\begin{array}{l}\text { Maximum } \\
\text { voltage } \\
\text { deviation } \\
\end{array}$} & 17.909 & 46.972 & 57.556 & 61.612 & 67.957 & 67.932 \\
\hline & & \multicolumn{2}{|c|}{$\begin{array}{l}\text { \% Voltage } \\
\text { Unbalance }\end{array}$} & 0.252 & 0.665 & 0.815 & 0.873 & 0.964 & 0.964 \\
\hline & \multirow{6}{*}{$\begin{array}{l}\text { Off- } \\
\text { Peak }\end{array}$} & \multirow{3}{*}{$\begin{array}{c}\text { Phase } \\
\text { Voltages } \\
(\mathrm{KV})\end{array}$} & VA & 7105.309 & 7052.781 & 7036.366 & 7027.333 & 7012.374 & 7011.16 \\
\hline & & & $\mathrm{VB}$ & 7118.477 & 7127.993 & 7129.957 & 7126.819 & 7126.873 & 7125.64 \\
\hline & & & $\mathrm{VC}$ & 7140.687 & 7134.027 & 7134.146 & 7133.801 & 7126.862 & 7125.60 \\
\hline & & \multicolumn{2}{|c|}{$\begin{array}{l}\text { Average } \\
\text { Voltage }\end{array}$} & 7121.491 & 7104.934 & 7100.156 & 7095.985 & 7088.703 & 7087.47 \\
\hline & & \multicolumn{2}{|c|}{$\begin{array}{c}\text { Maximum } \\
\text { voltage } \\
\text { deviation } \\
\end{array}$} & 19.196 & 52.153 & 63.79 & 68.651 & 76.329 & 76.307 \\
\hline & & \multicolumn{2}{|c|}{$\begin{array}{l}\% \text { Voltage } \\
\text { Unbalance }\end{array}$} & 0.27 & 0.734 & 0.898 & 0.967 & 1.077 & 1.077 \\
\hline
\end{tabular}

For $70 \%$ penetration level of PEVs, following deviations are observed from the beginning of simulated system (CB1) to the end of simulated system (CB2) at both the peak and off-peak demands.

At peak demand;

The increase in Maximum Voltage Deviation from CB1 to CB2 $=67.932-17.909=50.023 \mathrm{~V}$

The increase in \%Voltage Unbalance from CB1 to CB2 $=0.964-0.252=0.712$

At off-peak demand;

The increase in Maximum Voltage Deviation from CB1 to CB2 $=76.307-19.196=57.111 \mathrm{~V}$

The increase in \%Voltage Unbalance from CB1 to CB2 $=1.077-0.27=0.807 \mathrm{~V}$

From the above, the increases in Maximum Voltage Deviation and \%Voltage Unbalance from $\mathrm{CB} 1$ to $\mathrm{CB} 2$ vary significantly at peak and off-peak demand for $70 \%$ level of PEV 
penetration. There is a $10-15 \%$ difference between peak and off-peak demands, with off-peak increases being greater. In addition, from $60 \%$ level of PEV penetration, there is a significant increase $(>50 \%)$ observed in the differences between $\mathrm{CB} 1$ and $\mathrm{CB} 2$ at peak and off-peak demand.

\subsubsection{Studied system with $80 \%$ PEV penetration}

For $80 \%$ of PEV load, it is assumed that there are 139 customers $(\sim 80 \%$ of 174$)$ have a PEV in that neighborhood and recharge their PEV batteries. In this instance, for $80 \%$ of penetration level in simulation, out of 139 PEVs, 79 PEVs' load is added to the phase-A, 48 PEVs' load is added to the phase-B (same as at $60 \%$ penetration level), and 12 PEVs load is added to the phase-C. Figure 5.15 shows distribution system model with $80 \%$ of penetration level, where the locations of PEV charging in each phase are shown with car symbols along with number of PEVs. Each phase in figure 5.15 can be identified based on ending character of transformers (example: The transformer "T/F_A" is in Phase-A).

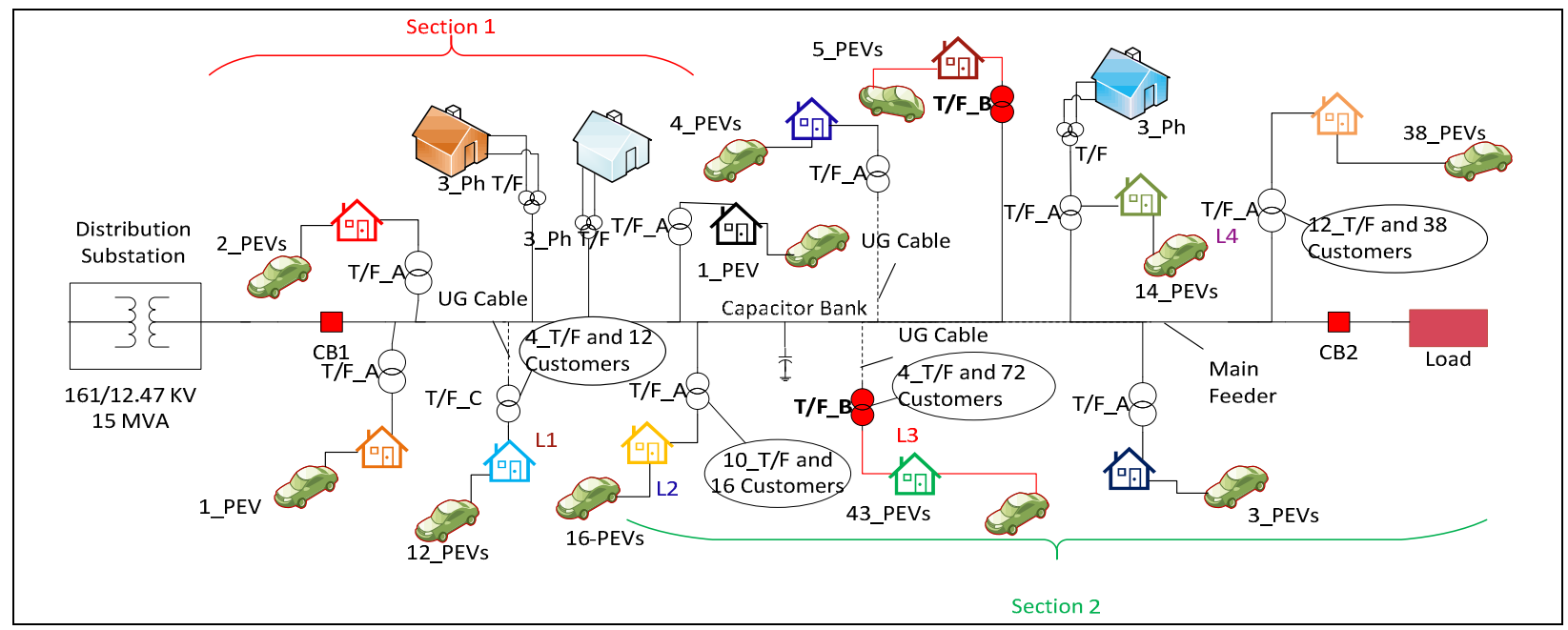

Figure 5.15 Distribution system model with $80 \%$ of PEV penetration 
Table 5.10 list the measured phase voltages, calculated voltage deviation, and percentage voltage unbalance for $80 \%$ penetration level of PEVs for both peak and off-peak power demand for all locations in the simulated system (CB1, L1, L2, L3, L4, CB2).

Table 5.11 Phase voltages at peak and off-peak demand for $80 \%$ penetration of PEVs

\begin{tabular}{|c|c|c|c|c|c|c|c|c|c|}
\hline $\begin{array}{c}\text { PEV } \\
\text { Penetration } \\
\text { Level }\end{array}$ & $\begin{array}{l}\text { Power } \\
\text { Demand }\end{array}$ & & & CB1 & Location1 & Location2 & Location 3 & Location4 & $\mathrm{CB} 2$ \\
\hline \multirow{12}{*}{$80 \%$} & \multirow{6}{*}{ Peak } & \multirow{3}{*}{$\begin{array}{c}\text { Phase } \\
\text { Voltages } \\
(\mathrm{KV})\end{array}$} & VA & 7071.13 & 7004.91 & 6985.404 & 6975.693 & 6958.987 & 6957.56 \\
\hline & & & VB & 7090.84 & 7095.57 & 7096.792 & 7093.188 & 7092.376 & 7080.03 \\
\hline & & & $\mathrm{VC}$ & 7112.29 & 7092.82 & 7090.353 & 7089.471 & 7081.461 & 7090.87 \\
\hline & & \multicolumn{2}{|c|}{$\begin{array}{l}\text { Average } \\
\text { Voltage }\end{array}$} & 7091.42 & 7064.43 & 7057.516 & 7052.784 & 7044.275 & 7042.82 \\
\hline & & \multicolumn{2}{|c|}{$\begin{array}{l}\text { Maximum } \\
\text { voltage } \\
\text { deviation }\end{array}$} & 20.877 & 59.52 & 72.11 & 77.09 & 85.29 & 85.26 \\
\hline & & \multicolumn{2}{|c|}{$\begin{array}{l}\% \text { Voltage } \\
\text { Unbalance }\end{array}$} & 0.294 & 0.843 & 1.022 & 1.093 & 1.211 & 1.211 \\
\hline & \multirow{6}{*}{ Off-Peak } & \multirow{3}{*}{$\begin{array}{c}\text { Phase } \\
\text { Voltages } \\
(\mathrm{KV})\end{array}$} & VA & 7097.61 & 7040.432 & 7022.654 & 7013.23 & 6997.789 & 6996.57 \\
\hline & & & $\mathrm{VB}$ & 7118.37 & 7135.082 & 7138.816 & 7135.95 & 7136.343 & 7120.21 \\
\hline & & & $\mathrm{VC}$ & 7140.73 & 7129.934 & 7129.009 & 7128.526 & 7121.424 & 7135.06 \\
\hline & & \multicolumn{2}{|c|}{$\begin{array}{l}\text { Average } \\
\text { Voltage }\end{array}$} & 7118.90 & 7101.816 & 7096.827 & 7092.568 & 7085.185 & 7083.95 \\
\hline & & \multicolumn{2}{|c|}{$\begin{array}{l}\text { Maximum } \\
\text { voltage } \\
\text { deviation }\end{array}$} & 21.825 & 61.384 & 74.173 & 79.339 & 87.397 & 87.375 \\
\hline & & \multicolumn{2}{|c|}{$\begin{array}{l}\% \text { Voltage } \\
\text { Unbalance }\end{array}$} & 0.307 & 0.864 & 1.045 & 1.119 & 1.234 & 1.233 \\
\hline
\end{tabular}

For $80 \%$ penetration level of PEVs, following deviations are observed from the beginning of simulated system (CB1) to the end of simulated system (CB2) at both the peak and off-peak demands.

At peak demand;

The increase in Maximum Voltage Deviation from CB1 to CB2 $=85.26-20.877=64.383 \mathrm{~V}$

The increase in \%Voltage Unbalance from CB1 to CB2 $=1.211-0.294=0.917$ 
At off-peak demand;

The increase in Maximum Voltage Deviation from $\mathrm{CB} 1$ to $\mathrm{CB} 2=87.375-21.825=65.55 \mathrm{~V}$

The increase in \%Voltage Unbalance from $\mathrm{CB} 1$ to $\mathrm{CB} 2=1.233-0.307=0.926 \mathrm{~V}$

From the above, the increases in Maximum Voltage Deviation and \%Voltage Unbalance from $\mathrm{CB} 1$ to $\mathrm{CB} 2$ are almost similar at peak and off-peak demand for $80 \%$ level of PEV penetration. However, from $70 \%$ level of PEV penetration, there is an increase observed in the differences between CB1 and CB2 at peak and off-peak demand.

Since Phase-A (79 out of 81 customers), and Phase-C (12 out of 12 customers) are almost maxed out the number of PEVs can be added to the simulated system, further levels of penetration $(90 \%, 100 \%)$ cannot be simulated in this study. The primary reason behind Phase-A and Phase-C being maxed out is that after $60 \%$ penetration level no more customers could have been added to Phase-B.

\subsection{Impact of PEV Penetration on Simulated System}

As Maximum Voltage Deviation and \%Voltage Unbalance are two primary metrics that have been used to assess the impact of increased levels of PEV penetration $(10 \%, 30 \%, 50 \%$, $60 \%, 70 \%$, and $80 \%$ ) in the simulated system for this study. Figures 5.16 and 5.17 respectively present the progression of Maximum Voltage Deviation and \%Voltage Unbalance for the CB1 and the CB2 of the simulated system at peak and off-peak power demands. 


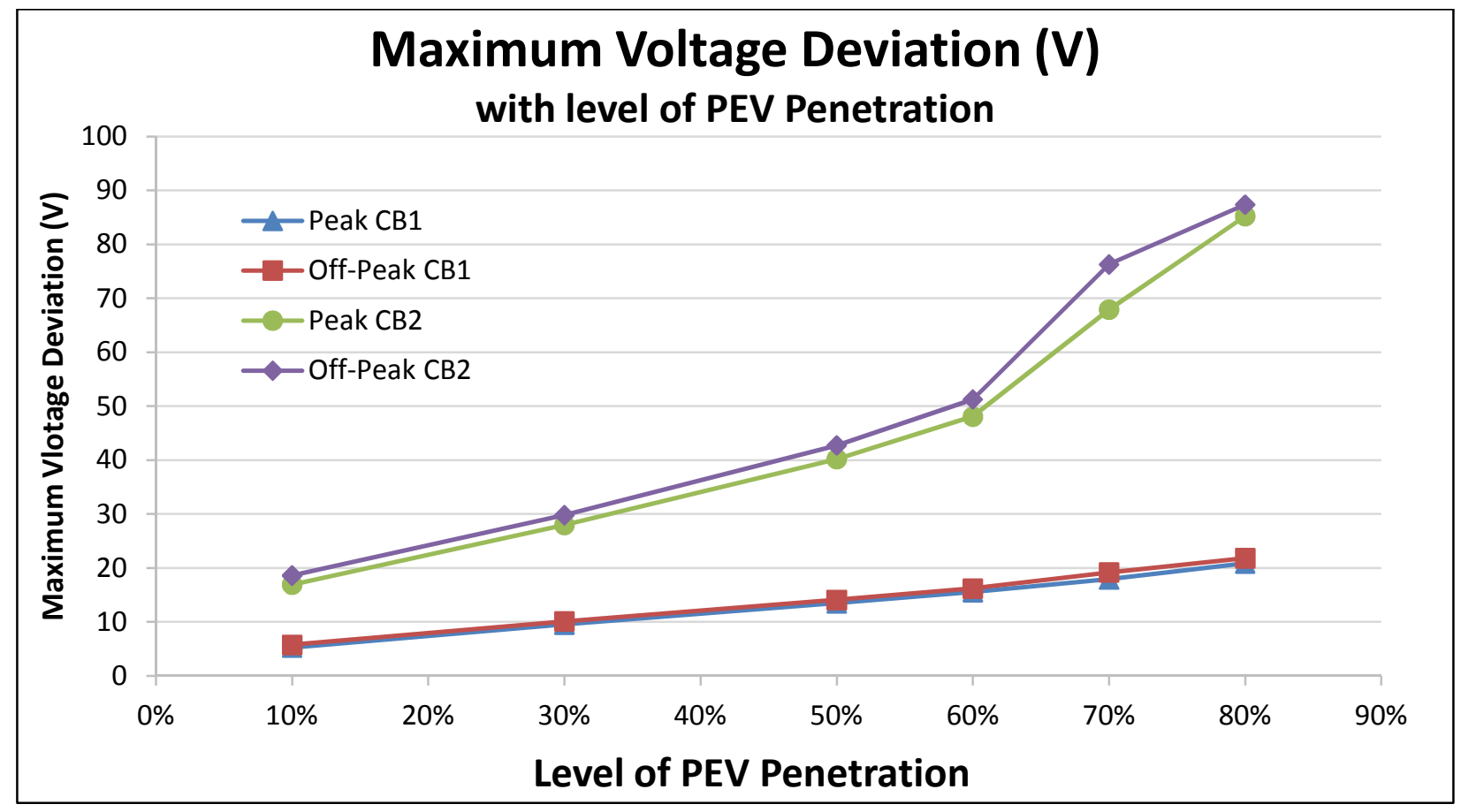

Figure 5.16 Maximum Voltage Deviation with level of PEV Penetration

From figure 5.16, it can be observed that for the peak and off-peak demands, Maximum Voltage Deviation is constantly increased with every level of increase in PEV penetration, hence displaying a significantly positive correlation between PEV penetration and Maximum Voltage Deviation. Identical pattern can be observed for \%Voltage Unbalance from figure 5.17 below, as $\%$ Voltage Unbalance is derived from Maximum Voltage Deviation as a proportion of Average Phase Voltage. 


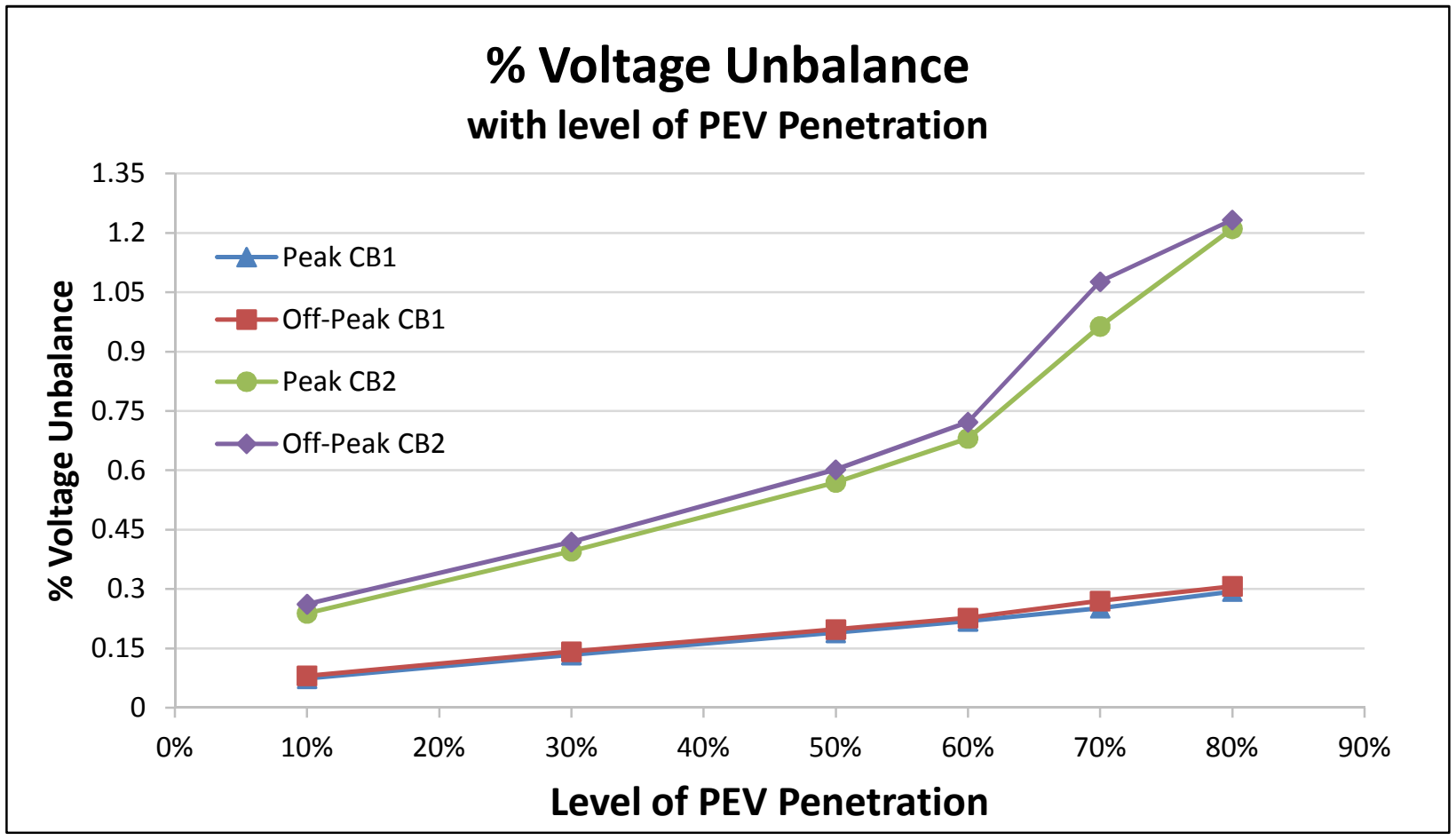

Figure $5.17 \%$ Voltage Unbalance with level of PEV Penetration

\subsection{Impact of PEV Penetration on one phase}

In the simulations conducted on phase $\mathrm{A}, \mathrm{B}$, and $\mathrm{C}$ of the distribution system with varying penetration of $10-80 \%$, the highest voltage unbalance observed was $1.23 \%$. For comparison purpose an additional study was conducted with $81 \mathrm{PEV}$ 's battery load connected to phase A and no PEV penetration on the other two phases. It is observed that the highest voltage unbalance for this case was $1.5 \%$. 


\section{CHAPTER 6}

\section{CONCLUSION}

PEVs are projected to become a means of electrification of road transportation on the heels of technological advances and demand for eco-friendly energy solutions. The adoption of these vehicles will pose a challenge to the existing infrastructure of the electrical grid in terms of generation, transmission, more importantly distribution; as higher penetration of PEVs and their charging in an uncoordinated manner may introduce new peaks into the system, which have the potential to overload electrical distribution components and cause power pollution problems.

This study examines the impacts of PEV battery charging on a $12.47 \mathrm{KV}$ distribution system at various penetration levels of PEVs. An existing residential distribution system is modeled and simulated using MATLAB-SIMULINK software. This study is focused on maximum voltage deviation, percentage voltage unbalance, and service transformers overloading. It has been found that maximum voltage deviation and percentage voltage unbalance are negatively impacted by increased PEV penetration levels in the residential distribution grid. Transformer overload has also been observed for one of the phases of simulated distribution system at a higher penetration level of PEVs.

Since these challenges will be inevitable with projected adoption of PEVs, smart or coordinated charging, grid reinforcements, optimization of electric grid will become indispensable to meet the new energy requirements without straining the infrastructure. 


\section{REFERENCES}

[1] G. A. Putrus, P. Suwanapingkarl, D. Johnston, E. C. Bentley, and M. Narayana, "Impact of electric vehicles on power distribution networks," in Vehicle Power and Propulsion Conference, 2009. VPPC '09. IEEE, 2009, pp. 827-831.

[2] C. H. Stephan and J. Sullivan, "Environmental and energy implications of plug-in hybridelectric vehicles.," Environ. Sci. Technol., vol. 42(4), pp. 1185-1190, 2008.

[3] M. Brenna, F. Foiadelli, and D. Zaninelli, "Power and energy estimation for Plug-in electric vehicles recharge in metropolitan area," in Electrical Power Quality and Utilisation (EPQU), 2011 11th International Conference on, 2011, pp. 1-6.

[4] N. Rotering and M. Ilic, "Optimal Charge Control of Plug-In Hybrid Electric Vehicles in Deregulated Electricity Markets," Power Systems, IEEE Transactions on, vol. 26, pp. 1021-1029, 2011.

[5] S. Haghbin, S. Lundmark, M. Alakula, and O. Carlson, "Grid-Connected Integrated Battery Chargers in Vehicle Applications: Review and New Solution," Industrial Electronics, IEEE Transactions on, vol. 60, pp. 459-473, 2013.

[6] E. Sortomme, M. M. Hindi, S. D. J. MacPherson, and S. S. Venkata, "Coordinated Charging of Plug-In Hybrid Electric Vehicles to Minimize Distribution System Losses," Smart Grid, IEEE Transactions on, vol. 2, pp. 198-205, 2011.

[7] C. Pang, P. Dutta, and M. Kezunovic, "BEVs/PHEVs as Dispersed Energy Storage for V2B Uses in the Smart Grid," Smart Grid, IEEE Transactions on, vol. 3, pp. 473-482, 2012.

[8] Z. Darabi and M. Ferdowsi, "Aggregated Impact of Plug-in Hybrid Electric Vehicles on Electricity Demand Profile," Sustainable Energy, IEEE Transactions on, vol. 2, pp. 501508, 2011.

[9] J. Taylor, A. Maitra, M. Alexander, D. Brooks, and M. Duvall, "Evaluation of the impact of plug-in electric vehicle loading on distribution system operations," in Power \& Energy Society General Meeting, 2009. PES '09. IEEE, 2009, pp. 1-6.

[10] J. T. Salihi, "1974 Energy Requirements for Electric Cars and Their Impact on Electric Power Generation and Distribution Systems," Industry Applications, IEEE Transactions on, vol. IA-20, pp. 1095-1095, 1984. 
[11] "J1772TM, new fast-charging "Combo Coupler" standard for PHEVs and EVs," Ground Vehicle Standards Newsletter., vol. 3, pp. 1-2, November 2012.

[12] M. Kinter-Meyer, K. Schneider, and R. Pratt, "Impacts Assessment of Plug-In Hybrid Electric Vehicles on Electric Utilities and Regional U.S. Power Grids, Part 1: Technical Analysis," Pacific Northwest National Laboratory, Richland, WA, 2007., 2007.

[13] Electric Power Research Institute, "Environmental Assessment of Plug-In Hybrid Electric Vehicles," July 2007.

[14] Deborah gordon, Daniel sperling, and D. livingston, "Policy Priorities for Advancing the U.S. Electric Vehicle Market," September 2012.

[15] K. Clement-Nyns, E. Haesen, and J. Driesen, "The Impact of Charging Plug-In Hybrid Electric Vehicles on a Residential Distribution Grid," Power Systems, IEEE Transactions on, vol. 25, pp. 371-380, 2010.

[16] C. Farmer, P. Hines, J. Dowds, and S. Blumsack, "Modeling the Impact of Increasing PHEV Loads on the Distribution Infrastructure," in System Sciences (HICSS), 2010 43rd Hawaii International Conference on, 2010, pp. 1-10.

[17] F. Geth, N. Leemput, V. J. Roy, J. Büsche, R. Ponnette, and J. Driesen, "Voltage Droop Charging of Electric Vehicles in a Residential Distribution Feeder," presented at the IEEE PES ISGT Europe, Berlin, Germany, 2012.

[18] KEMA, Inc, and ISO/RTO Council, "Assessment of Plug-in Electric Vehicle Integration with ISO/RTO Systems," March 2010.

[19] A. K. Srivastava, B. Annabathina, and S. Kamalasadan, "The Challenges and Policy Options for Integrating Plug-in Hybrid Electric Vehicle into the Electric Grid," Electricity Journal, vol. 23, pp. 83-91, April 20102010.

[20] T. H. Bradley and A. A. Frank, "Design, demonstrations and sustainability impact assessments for plug-in hybrid electric vehicles," Renewable \& Sustainable Energy Reviews, vol. 13, pp. 115-128, Jan 2009.

[21] S. S. Williamson, "Electric Drive Train Efficiency Analysis Based on Varied Energy Storage System Usage for Plug-In Hybrid Electric Vehicle Applications," in Power Electronics Specialists Conference, 2007. PESC 2007. IEEE, 2007, pp. 1515-1520.

[22] P. Denholm and W. Short, "An Evaluation of Utility System Impacts and Benefits of Optimally Dispatched Plug-In Hybrid Electric Vehicles," National Renewable Energy Laboratory, Tech. Rep., October 2006.

[23] Z. Menyang, Y. Yan, and C. C. Mi, "Analytical Approach for the Power Management of Blended-Mode Plug-In Hybrid Electric Vehicles," Vehicular Technology, IEEE Transactions on, vol. 61, pp. 1554-1566, 2012. 
[24] B. Sanzhong, Y. Du, and S. Lukic, "Optimum design of an EV/PHEV charging station with DC bus and storage system," in Energy Conversion Congress and Exposition (ECCE), 2010 IEEE, 2010, pp. 1178-1184.

[25] M. Yilmaz and P. T. Krein, "Review of Battery Charger Topologies, Charging Power Levels, and Infrastructure for Plug-In Electric and Hybrid Vehicles," Power Electronics, IEEE Transactions on, vol. 28, pp. 2151-2169, 2013.

[26] P. E. Mike Waters, "Plug-in Vehicles \& the Grid," in NC Sustainable Energy Conference, April 26 th, 2011.

[27] M. Etezadi-Amoli, K. Choma, and J. Stefani, "Rapid-Charge Electric-Vehicle Stations," Power Delivery, IEEE Transactions on, vol. 25, pp. 1883-1887, 2010.

[28] Jack Pokrzywa. ( August 2011), "SAE's J1772 'combo connector' for ac and dc charging advances with IEEE's help". Available: http://ev.sae.org/article/10128/

[29] L. L. Grigsby, Electric Power Generation, Transmission, and Distribution: CRC Press, May 2007.

[30] W. Kempton and J. Tomic, "Vehicle-to-grid power fundamentals: Calculating capacity and net revenue," Journal of Power Sources, vol. 144, pp. 268-279, Jun 2005.

[31] S. Hadley, "Potential impacts of plug-in hybrid electric vehicles on regional power generation," in Oak Ridge National Laboratory, U.S. Department of Energy, Tech. Rep, ed, 2008.

[32] S. Blumsack, C. Samaras, and P. Hines, "Long-term electric system investments to support Plug-in Hybrid Electric Vehicles," in Power and Energy Society General Meeting - Conversion and Delivery of Electrical Energy in the 21st Century, 2008 IEEE, 2008, pp. 1-6.

[33] C. Camus, C. M. Silva, T. L. Farias, and J. Esteves, "Impact of Plug-in Hybrid Electric Vehicles in the Portuguese electric utility system," in Power Engineering, Energy and Electrical Drives, 2009. POWERENG '09. International Conference on, 2009, pp. 285290.

[34] A. Maitra, J. Taylor, D. Brooks, M. Alexander, and M. Duvall, "Integrating plug-inelectric vehicles with the distribution system," in Electricity Distribution - Part 1, 2009. CIRED 2009. 20th International Conference and Exhibition on, 2009, pp. 1-5.

[35] Ahmed Eltom and Mohammed A. Aziz, "The economics of energy efficient motors during unbalanced voltage conditions," in Power Engineering Society Inaugural Conference and Exposition in Africa, 2005 IEEE, 2005, pp. 378-384. 
[36] Nader S. Moharari, "Microprocessor Based Protection Of Induction Motors, Using Thermal, Mechanical, And Skin Effect Electrical Models to Predict Motor Temperature Rise," Master of Science in Engineering, Electrical Engineering, The University of Tennessee, Chattanooga, 1989.

[37] Available:

http://www.mathworks.com/help/releases/R13sp2/pdf_doc/physmod/powersys/power_co nversion.pdf.

[38] U. A. Khan, J. K. Seong, S. H. Lee, S. H. Lim, and B. W. Lee, "Feasibility Analysis of the Positioning of Superconducting Fault Current Limiters for the Smart Grid Application Using Simulink and SimPowerSystem," Applied Superconductivity, IEEE Transactions on, vol. 21, pp. 2165-2169, 2011.

[39] M. Manyage and P. Pillay, "Power Engineering Review, IEEE " vol. 22, pp. 49-50, 2002.

[40] K. Lee, G. Venkataramanan, and T. M. Jahns, "Modeling Effects of Voltage Unbalances in Industrial Distribution Systems With Adjustable-Speed Drives," Industry Applications, IEEE Transactions on, vol. 44, pp. 1322-1332, 2008. 
APPENDIX A

DISTRIBUTION SYSTEM FOR VOLTAGE STUDY 


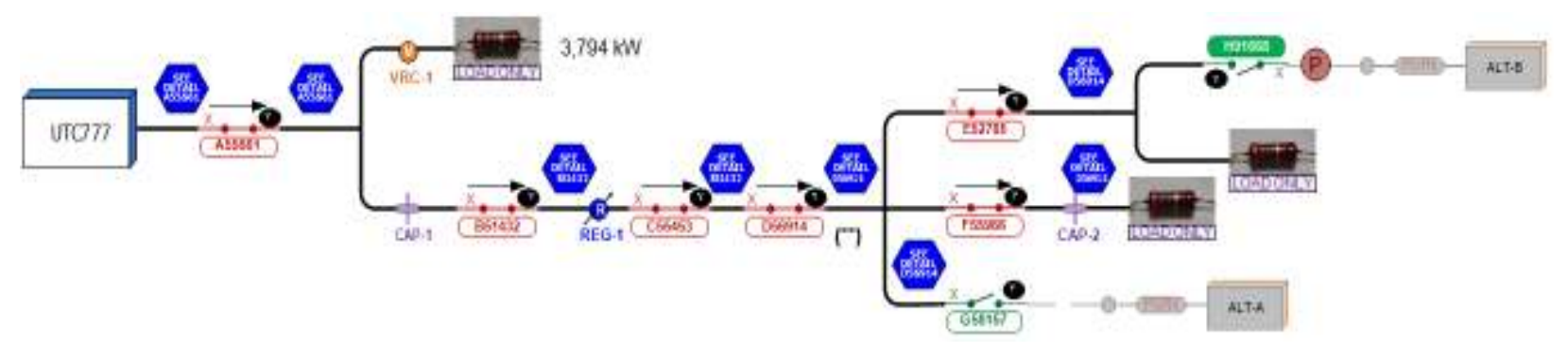

One line diagram of distribution system for voltage study

Impedances of Overhead Lines

\begin{tabular}{|l|c|c|c|c|c|c|c|c|c|}
\hline $\begin{array}{l}\text { Size of the } \\
\text { conductor }\end{array}$ & Material & \multicolumn{2}{|c|}{$\begin{array}{c}\text { Positive Sequence } \\
\text { Impedance } \\
\text { (ohms/1000ft) }\end{array}$} & \multicolumn{2}{|c|}{$\begin{array}{c}\text { Zero Sequence } \\
\text { Impedance } \\
\text { (ohms/1000ft) }\end{array}$} & \multicolumn{2}{|c|}{$\begin{array}{c}\text { Positive } \\
\text { Sequence } \\
\text { Admittance } \\
\text { (us/1000ft) }\end{array}$} & \multicolumn{2}{c|}{$\begin{array}{c}\text { Zero } \\
\text { Sequence } \\
\text { Admittance } \\
\text { (us/1000ft) }\end{array}$} \\
\cline { 3 - 10 } & & $\mathrm{R} 1$ & $\mathrm{X} 1$ & $\mathrm{R} 0$ & $\mathrm{X} 0$ & $\mathrm{G} 1$ & $\mathrm{~B} 1$ & $\mathrm{G} 0$ & $\mathrm{~B} 0$ \\
\hline 1033 & Aerial & 0.01777 & 0.1157 & 0.1233 & 0.3735 & 0 & 1.354 & 0 & 0.6314 \\
\hline $1033 \mathrm{AL}$ & Aluminum & 0.01800 & 0.1166 & 0.1138 & 0.3924 & 0 & 1.349 & 0 & 0.587 \\
\hline $1 / 0 \mathrm{AL}$ & Aluminum & $0.1677 \mathrm{o}$ & 0.1437 & 0.2731 & 0.4014 & 0 & 1.086 & 0 & 0.5666 \\
\hline $4 / 0 \mathrm{AL}$ & Aluminum & 0.08376 & 0.1356 & 0.1892 & 0.3934 & 0 & 1.155 & 0 & 0.5847 \\
\hline
\end{tabular}

Service transformer Impedances by rating

\begin{tabular}{|c|c|c|c|}
\hline $\begin{array}{c}\text { Transformer } \\
\text { Rating (KVA) }\end{array}$ & $\begin{array}{c}\text { Positive Sequence } \\
\text { Impedance (\%Z1) }\end{array}$ & $\begin{array}{c}\text { Zero Sequence } \\
\text { Impedance (\%Z0) }\end{array}$ & X/R Ratio \\
\hline 15 & 2.5 & 2.5 & 4 \\
\hline $15(3$ phase) & 4.5 & 4.5 & 4 \\
\hline 25 & 4.5 & 4.5 & 4 \\
\hline 37 & 4.5 & 4.5 & 4 \\
\hline 50 & 4.5 & 4.5 & 4 \\
\hline 75 & 3.0 & 3.0 & 4 \\
\hline 100 & 4.5 & 4.5 & 4 \\
\hline 225 & 4.5 & 4.5 & 10 \\
\hline 500 & 3.94 & 3.94 & 4 \\
\hline
\end{tabular}




\section{Real power demand of all service transformers}

\begin{tabular}{|c|c|c|c|c|}
\hline \multirow[t]{2}{*}{$\begin{array}{c}\text { Transformer } \\
\text { Labeling }\end{array}$} & \multirow{2}{*}{$\begin{array}{c}\text { Transformer } \\
\text { KVA } \\
\text { Rating }\end{array}$} & \multirow{2}{*}{$\begin{array}{l}\text { No. of } \\
\text { customers } \\
\text { connected }\end{array}$} & $\begin{array}{l}\text { Peak demand } \\
(2.30 \mathrm{PM})\end{array}$ & $\begin{array}{l}\text { Off-Peak demand } \\
(6.30 \mathrm{AM})\end{array}$ \\
\hline & & & Real Power (KW) & Real Power (KW) \\
\hline OW5006 & 50 & 1 & 1.094 & 0.986 \\
\hline OW51142 & 25 & 2 & 8.800 & 8.112 \\
\hline OW51325 & 15 & 1 & 0.252 & 0.288 \\
\hline OW5562 & 37 & 8 & 6.412 & 9.940 \\
\hline OW5567 & 37 & 1 & 0.652 & 2.448 \\
\hline OW5568 & 25 & 2 & 1.072 & 0.980 \\
\hline OW5656 & 25 & 4 & 7.536 & 1.760 \\
\hline OW5657 & 25 & 1 & 0.180 & 5.508 \\
\hline OW5658 & 25 & 7 & 3.088 & 13.328 \\
\hline OW5666 & 37 & 9 & 13.068 & 4.488 \\
\hline OW5739 & 37 & 2 & 1.472 & 2.192 \\
\hline OW5741 & 37 & 3 & 4.236 & 3.916 \\
\hline OW5800 & 15 & 1 & 0.272 & 0.032 \\
\hline OW5880 & 37 & 2 & 0.268 & 1.016 \\
\hline OW5882 & 25 & 1 & 3.484 & 0.700 \\
\hline OW5883 & 25 & 2 & 1.348 & 2.848 \\
\hline OW5884 & 37 & 1 & 0.448 & 0.392 \\
\hline OW5913 & 25 & 1 & 3.244 & 0.448 \\
\hline OW5915 & 50 & 2 & 1.116 & 1.096 \\
\hline OW5917 & 37 & 2 & 3.592 & 2.804 \\
\hline OW5925 & 37 & 2 & 3.100 & 5.876 \\
\hline OW5P024 & 37 & 1 & 6.404 & 0.248 \\
\hline OW5P025 & 37 & 3 & 5.404 & 6.540 \\
\hline OW5P026 & 50 & 3 & 5.072 & 7.588 \\
\hline OW5P109 & 100 & 18 & 24.888 & 19.348 \\
\hline OW5P110 & 100 & 18 & 22.152 & 21.960 \\
\hline OW5P111 & 100 & 18 & 15.412 & 19.988 \\
\hline OW5P112 & 100 & 18 & 12.556 & 25.560 \\
\hline OW5P232 & 500 & 1 & 0.264 & 0.128 \\
\hline OW5932 & 50 & 2 & 1.116 & 1.096 \\
\hline OW5502 & 50 & 3 & 1.094 & 0.986 \\
\hline OW51593 & 50 & 2 & 1.116 & 1.096 \\
\hline OW5566 & 15 & 1 & 0.272 & 0.032 \\
\hline OW5557 & 25 & 4 & 8.800 & 8.112 \\
\hline OW5558 & 25 & 1 & 1.072 & 0.980 \\
\hline OW5P018 & 75 & 1 & 1.304 & 4.896 \\
\hline OW5683 & 37 & 1 & 6.412 & 9.940 \\
\hline OW5835 & 37 & 9 & 0.652 & 2.448 \\
\hline OW5838 & 37 & 3 & 13.068 & 4.488 \\
\hline OW51657 & 25 & 7 & 7.536 & 1.760 \\
\hline OW5839 & 50 & 3 & 5.072 & 7.588 \\
\hline OW5840 & 25 & 2 & 0.180 & 5.508 \\
\hline OW5P165 & 225 & 1 & 0.325 & 0.156 \\
\hline OW5P244 & 75 & 2 & 0.756 & 1.620 \\
\hline
\end{tabular}


APPENDIX B

INTELLIRUPTERS DATA 
Voltages and currents at peak and off-peak demand on 01/10/2013 for A55661

\begin{tabular}{|c|c|c|c|c|c|}
\hline Intellirupters & $\begin{array}{l}\text { Power } \\
\text { Demand }\end{array}$ & & & $X$-side & Y-side \\
\hline \multirow{12}{*}{ A55661 } & \multirow{6}{*}{ Peak } & \multirow{3}{*}{$\begin{array}{l}\text { Phase } \\
\text { Voltages (KV) }\end{array}$} & VA & 7.143 & 7.141 \\
\hline & & & $\mathrm{VB}$ & 7.102 & 7.115 \\
\hline & & & $\mathrm{VC}$ & 7.097 & 7.094 \\
\hline & & \multirow{3}{*}{$\begin{array}{l}\text { Phase } \\
\text { Currents(A) }\end{array}$} & IA & \multicolumn{2}{|c|}{197} \\
\hline & & & IB & \multicolumn{2}{|c|}{195} \\
\hline & & & $\mathrm{IC}$ & \multicolumn{2}{|c|}{186} \\
\hline & \multirow{6}{*}{ Off-Peak } & \multirow{3}{*}{$\begin{array}{l}\text { Phase } \\
\text { Voltages (KV) }\end{array}$} & $\mathrm{VA}$ & 7.122 & 7.120 \\
\hline & & & VB & 7.087 & 7.100 \\
\hline & & & $\mathrm{VC}$ & 7.072 & 7.069 \\
\hline & & \multirow{3}{*}{$\begin{array}{l}\text { Phase } \\
\text { Currents(A) }\end{array}$} & IA & \multicolumn{2}{|c|}{135} \\
\hline & & & IB & \multicolumn{2}{|c|}{131} \\
\hline & & & IC & \multicolumn{2}{|c|}{123} \\
\hline
\end{tabular}

Voltages and currents at peak and off-peak demand on 01/10/2013 for A55661

\begin{tabular}{|c|c|c|c|c|c|}
\hline Intellirupters & $\begin{array}{l}\text { Power } \\
\text { Demand }\end{array}$ & & & $\mathrm{X}$-side & Y-side \\
\hline \multirow{12}{*}{ B51432 } & \multirow{6}{*}{ Peak } & \multirow{3}{*}{$\begin{array}{l}\text { Phase } \\
\text { Voltages (KV) }\end{array}$} & VA & 7.125 & 7.122 \\
\hline & & & VB & 7.091 & 7.095 \\
\hline & & & $\mathrm{VC}$ & 7.088 & 7.090 \\
\hline & & \multirow{3}{*}{$\begin{array}{l}\text { Phase } \\
\text { Currents(A) }\end{array}$} & IA & \multicolumn{2}{|c|}{58} \\
\hline & & & IB & \multicolumn{2}{|c|}{79} \\
\hline & & & IC & \multicolumn{2}{|c|}{52} \\
\hline & \multirow{6}{*}{ Off-Peak } & \multirow{3}{*}{$\begin{array}{l}\text { Phase } \\
\text { Voltages (KV) }\end{array}$} & $\mathrm{VA}$ & 7.108 & 7.106 \\
\hline & & & $\mathrm{VB}$ & 7.082 & 7.086 \\
\hline & & & $\mathrm{VC}$ & 7.065 & 7.068 \\
\hline & & \multirow{3}{*}{$\begin{array}{l}\text { Phase } \\
\text { Currents(A) }\end{array}$} & IA & \multicolumn{2}{|c|}{48} \\
\hline & & & IB & \multicolumn{2}{|c|}{62} \\
\hline & & & IC & \multicolumn{2}{|c|}{43} \\
\hline
\end{tabular}


VITA

Sharmila Kumari Bunga was born in Sompeta, India. She completed her Bachelor of Engineering degree in Electrical and Electronics Engineering from Andhra University, India, and she has also received her Master of Technology degree in Electrical Power Engineering from Jawaharlal Nehru Technological University, Hyderabad, India. Sharmila started the Masters in Electrical Engineering in University of Tennessee at Chattanooga in Fall 2010. Simultaneously, she worked as a graduate assistant for electrical engineering department up till December 2012. Sharmila graduated with a Master of Science degree in Electrical Engineering in May 2013. 